\title{
ASSESSING THE EFFECT OF NUTRITIONAL INTERVENTIONS ON \\ BODY COMPOSITION CHANGES DURING PREGNANCY IN MODERATELY MALNOURISHED MALAWIAN WOMEN
}

\author{
A Thesis \\ presented to \\ the Faculty of California Polytechnic State University, \\ San Luis Obispo
}

In Partial Fulfillment

of the Requirements for the Degree

Master of Science in Nutrition

by

Megan Kitagawa

September 2017 
(C) 2017

Megan Kitagawa

ALL RIGHTS RESERVED 


\section{COMMITTEE MEMBERSHIP}

TITLE: Assessing the Effect of Nutritional Interventions on Body Composition Changes

During Pregnancy in Moderately Malnourished Malawian Women

AUTHOR:

DATE SUBMITTED:

COMMITTEE CHAIR:

COMMITTEE MEMBER:

COMMITTEE MEMBER:
Megan Kitagawa

September 2017

Peggy Papathakis, Ph.D., R.D. Professor of Nutrition

Scott Reaves, Ph.D. Professor of Nutrition

Andrew Schaffner, Ph.D. Professor of Statistics 


\begin{abstract}
Assessing the Effect of Nutritional Interventions on Body Composition Changes During Pregnancy in Moderately Malnourished Malawian Women
\end{abstract}

Megan Kitagawa

Background: Malnutrition can affect the body composition changes that occur in healthy pregnancy, resulting in adverse effects to both the mother and infant. Supplementary foods with high quality protein may result in more favorable changes in lean mass and fat mass in pregnant malnourished women.

Objective: To retrospectively assess changes in body composition in moderately malnourished pregnant Malawian women in response to one of three nutritional interventions.

Methods: Height, weight, MUAC, and TSF were measured in pregnant women with MUAC $>20.6 \mathrm{~cm}$ and $<23.0 \mathrm{~cm}$ at baseline $(\mathrm{N}=1,808)$ every 2 weeks over the course of enrollment while receiving either 1) macro- and micronutrient fortified, peanut-based, ready-to-use supplementary food (RUSF), 2) corn-soy blended flour with a prenatal multiple micronutrient supplement (CSB-UNIMMAP), or 3) corn-soy blended flour with iron and folic acid (CSB-

IFA). Each provided approximately double the RDA of most micronutrients and 900 $\mathrm{kcal} / \mathrm{day}$. AMA and AFA were calculated using MUAC and TSF. MUAC, AMA, TSF, and

AFA were compared at baseline and at the end of enrollment, and the degree of change between intervention groups and age groups $(\leq 19$ years and $>19)$ were compared using ANOVA. If differences were detected, differences between groups were tested using the Tukey HSD test (continuous) or Chi-squared test (categorical). Longitudinal changes were also measured using mixed model analysis of variance.

Results: At baseline, women had small MUACs and low fat stores, but high muscle mass. Overall, women had significantly larger MUACs at the end of follow up than at baseline, except in adolescents in CSB-IFA and CSB-UNIMMAP. Women overall had significantly larger AMA at the end of enrollment than at baseline, with mature women in the RUSF group experiencing the largest increase compared to adolescents in RUSF and all women in CSB-

UNIMMAP and CSB-IFA. On average, AMA was between the $50^{\text {th }}-75^{\text {th }}$ percentiles compared to women in the western world, indicating maintenance of muscle mass despite moderate malnutrition. TSF and AFA were both low in all age groups, falling below the $5^{\text {th }}$ percentile for mature women and below the $10^{\text {th }}$ percentile in adolescents compared to women in the Western world. There was no difference in birth weight across intervention groups. Among births that occurred during the rainy season, every $\mathrm{cm}$ of MUAC at the end of enrollment resulted in a $0.29 \mathrm{~cm}$ greater birth length.

Conclusions: Overall, women improved their nutritional status but did not recover from moderate malnutrition over the course of enrollment. MUAC and BMI were the strongest predictors of birth weight, highlighting the contribution of overall nutritional status to birth outcomes. Women had high muscle mass relative to fat stores, with women in the RUSF group experiencing the largest accrual in muscle. More accurate and objective methods to measure body composition could provide greater detail about changes in body composition over the course of pregnancy in response to supplementary foods. 


\section{ACKNOWLEDGMENTS}

Thank you to my graduate advisor, Dr. Peggy Papathakis, for her guidance, encouragement, and support throughout my experience at Cal Poly. Thank you to my graduate committee chairs, Dr. Scott Reaves and Dr. Andrew Schaffner, for contributing their wisdom throughout this process and my graduate school experience. Thank you to my sister Danielle, my mom, dad, and all of my family members for endlessly supporting me throughout my endeavors and encouraging me to push my boundaries. Thank you to the support system of my graduate cohort, undergraduate peers, and the wonderful faculty members of Cal Poly; I am endlessly grateful for your friendship and motivating words. 


\section{TABLE OF CONTENTS}

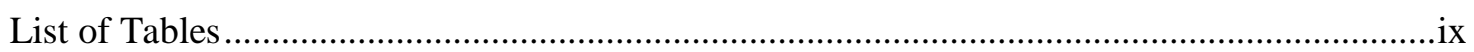

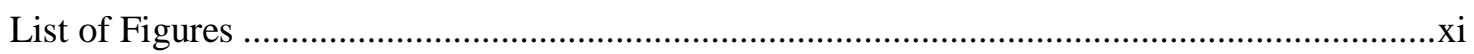

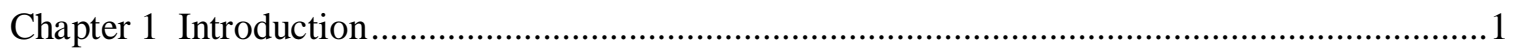

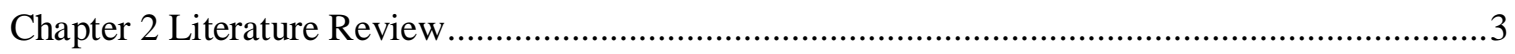

2.1 Body composition changes in normal pregnancy ........................................................

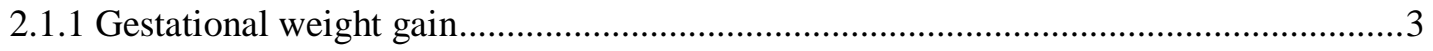

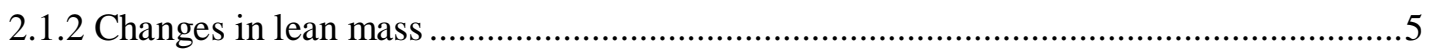

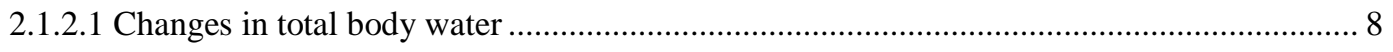

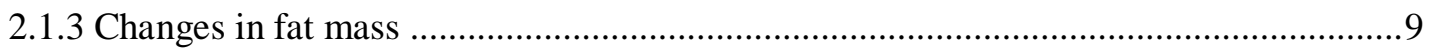

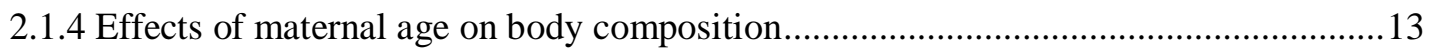

2.1.5 Methods of body composition assessment during pregnancy ...................................15

2.1.6 International trends in maternal and infant birth outcomes .......................................18

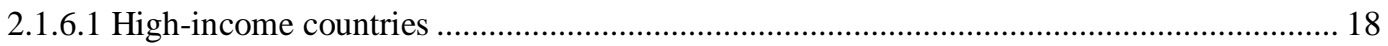

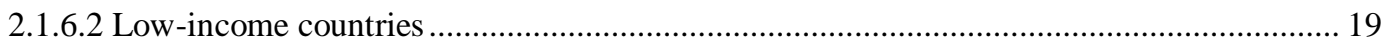

2.2 Body Composition Adaptations in Pregnant Women with Undernutrition ........................22

2.2.1 Consequences of low anthropometric measurements on birth outcomes ....................23

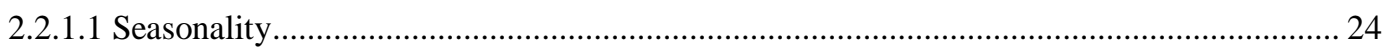

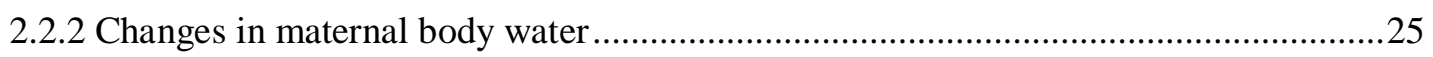

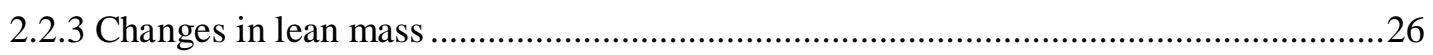

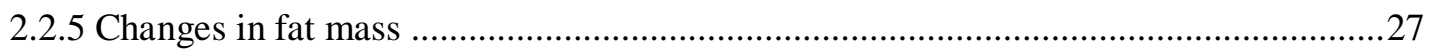

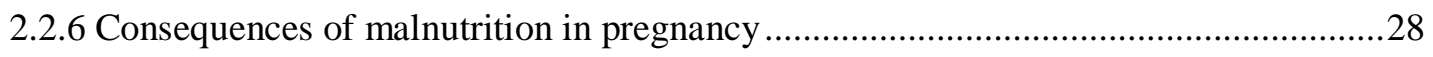

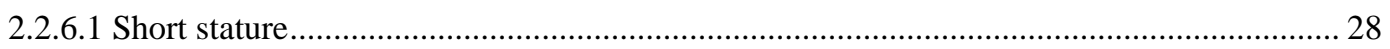

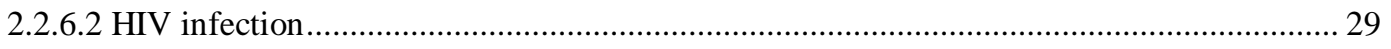

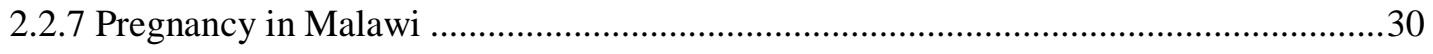

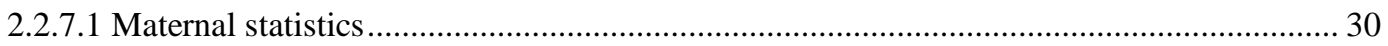




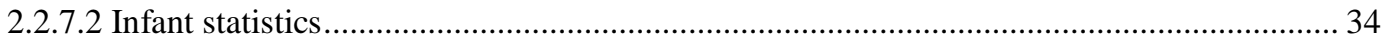

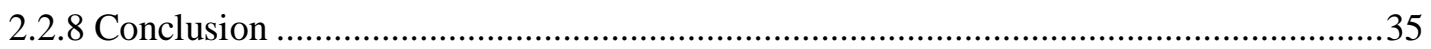

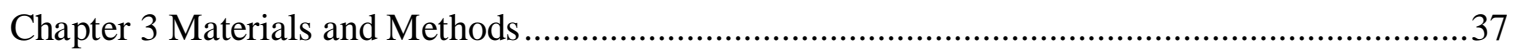

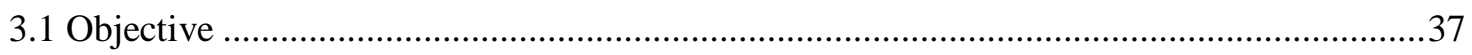

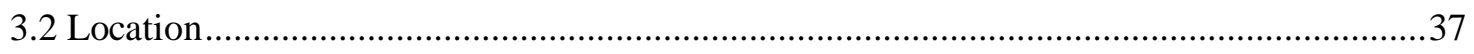

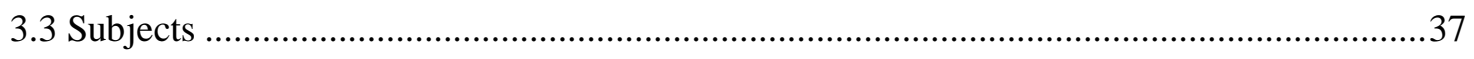

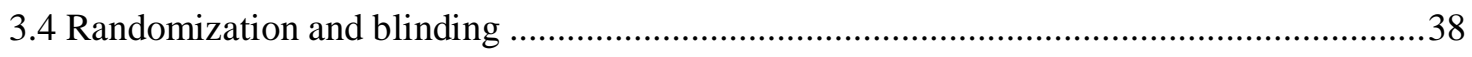

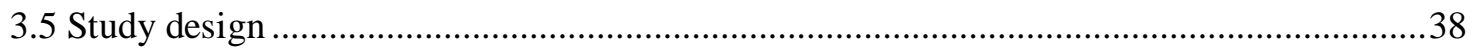

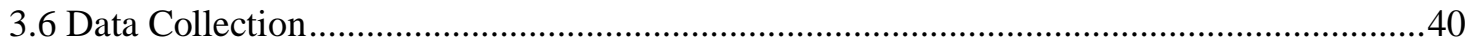

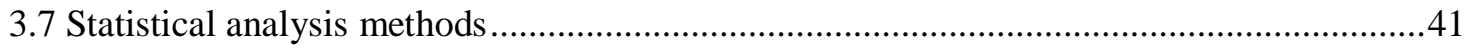

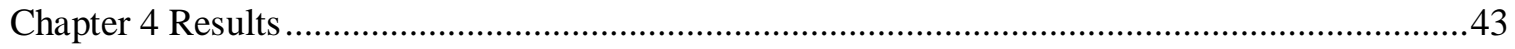

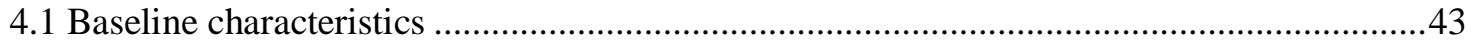

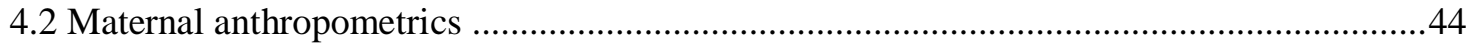

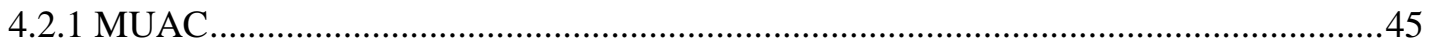

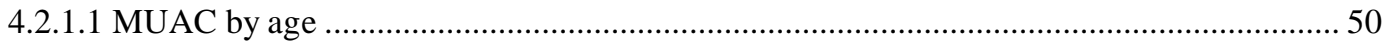

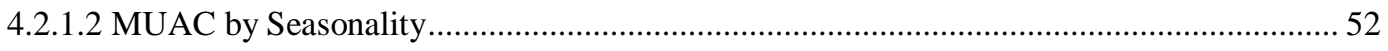

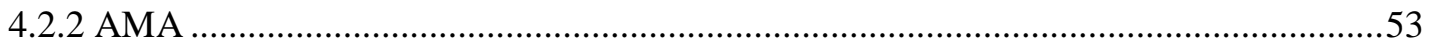

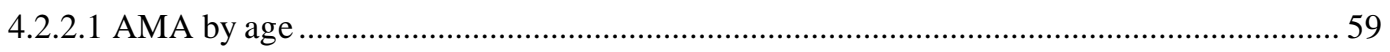

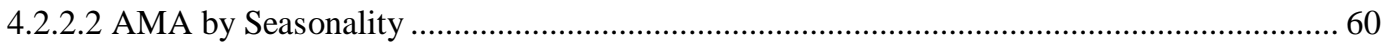

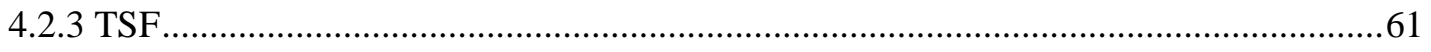

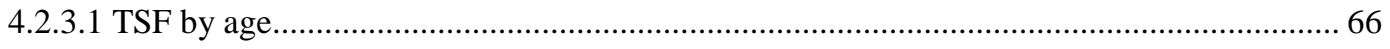

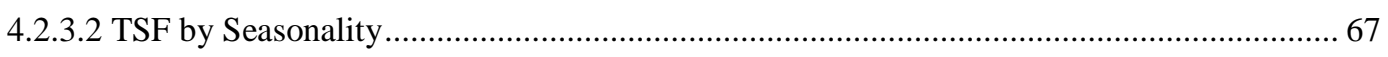

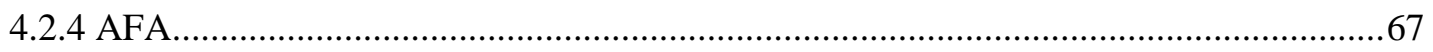

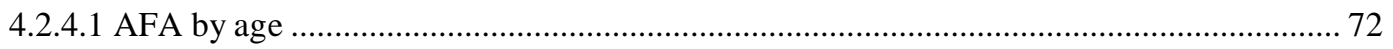

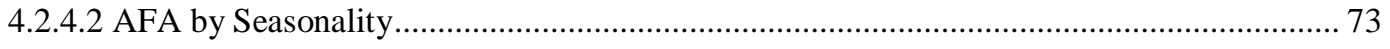

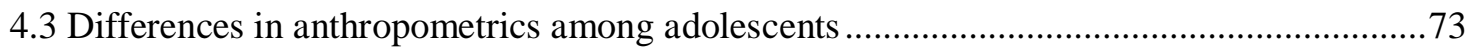




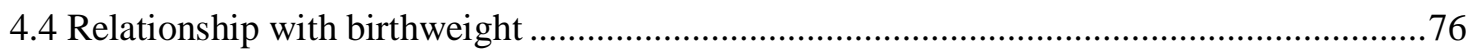

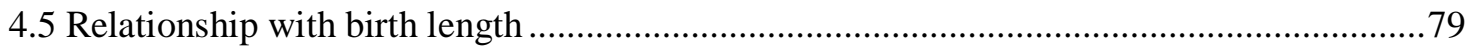

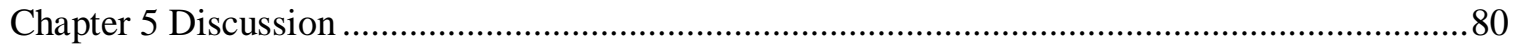

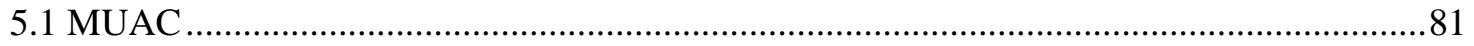

5.2 AMA

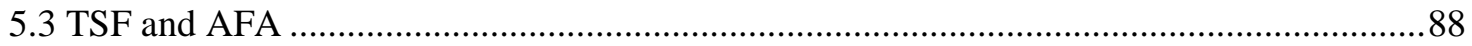

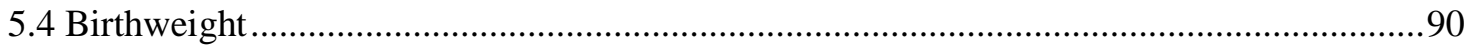

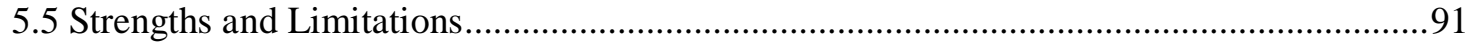

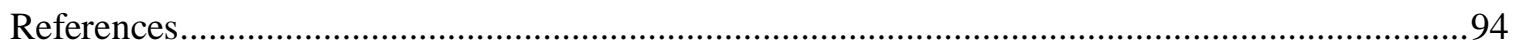




\section{LIST OF TABLES}

Table 1: 2009 I.O.M. recommendations for gestational weight gain and rate of

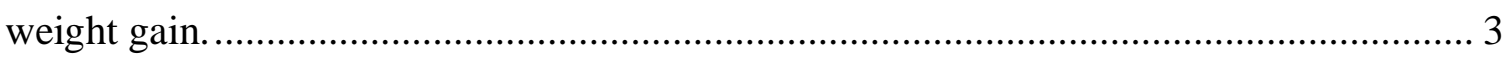

Table 2. Anthropometrics of pregnant Malawian adolescents and adults. ...................... 33

Table 3: Baseline characteristics of enrolled women across interventions. Values

expressed as mean \pm standard deviation unless otherwise stated.

Table 4. Mean gestational weight gain and mean weeks on treatment across

interventions. Values expressed as raw means \pm SD.

Table 5. Initial and terminal MUAC, and absolute and weekly change across

interventions.

Table 6: Initial and terminal MUAC and absolute and weekly change across

interventions separated by age

Table 7. Initial and terminal AMA, and absolute and weekly change across

interventions. Values are expressed as LS means \pm SE.

Table 8. Initial and terminal AMA, and absolute and weekly change across

interventions by age group. Values are expressed as LS means \pm SE.

Table 9. Initial and final TSF, and absolute and weekly change. Raw means \pm SD

are in the top row and LS means $\pm \mathrm{SE}$ are in the bottom row for each

Table 10. Mean initial and final TSF values, and absolute and weekly changes

separated by age groups. Values expressed as LS means \pm SE.

Table 11. Initial and final AFA, and absolute and weekly change.

Table 12. Mean initial and final AFA values, and absolute and weekly changes

separated by age groups

Table 13. Mean birthweight for women in each intervention group. Values 
expressed as raw mean \pm SD.

Table 14: $\beta$ and standardized $\beta$ for birthweight. 


\section{LIST OF FIGURES}

Figure 1. Components of gestational weight gain, adapted from Pitkin (1976)............... 5

Figure 2. Maternal mortality ratio in Malawi from 1990 - 2015. (Adapted from

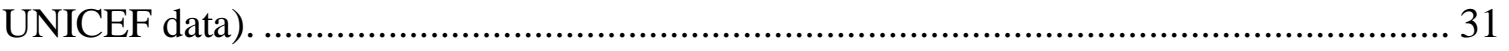

Figure 3. Prevalence of female malnutrition in Malawi by BMI. (WHO, 2015). ........... 32

Figure 4: Age distribution of enrolled women. Yellow bars represent

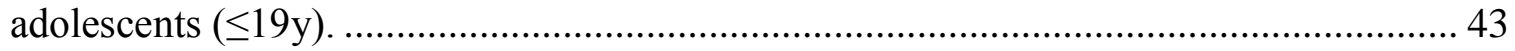

Figure 5: Initial and terminal MUAC across interventions. ....................................... 46

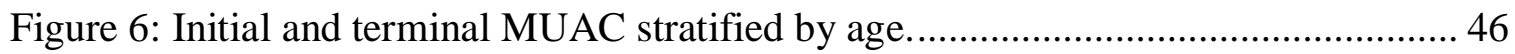

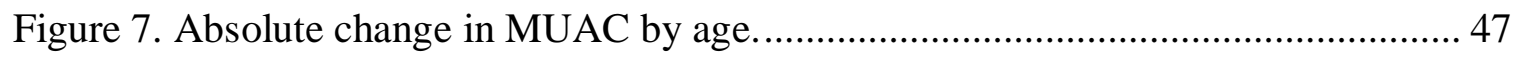

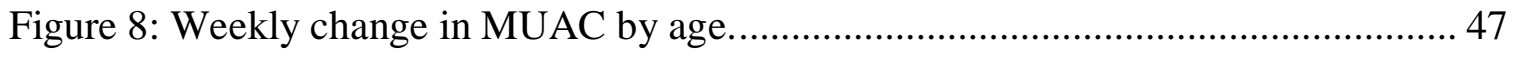

Figure 9: Initial and terminal AMA across interventions. ........................................ 55

Figure 10: Initial and terminal AMA stratified by adolescence. .................................. 55

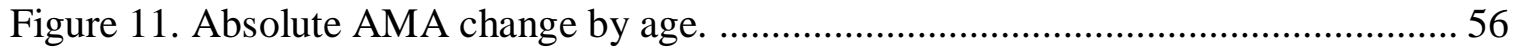

Figure 12: Weekly change in AMA by age group.................................................. 56

Figure 13. Initial and terminal values of TSF in each intervention group...................... 62

Figure 14. Initial and terminal TSF values in each intervention group separated by age. 62

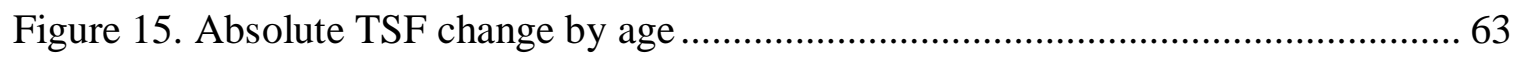

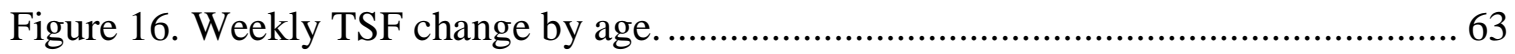

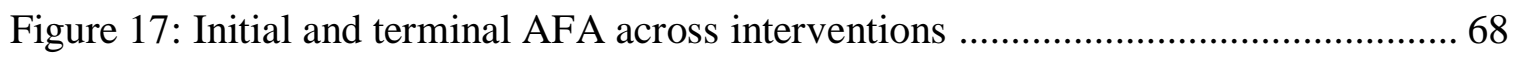

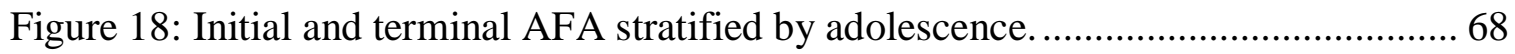

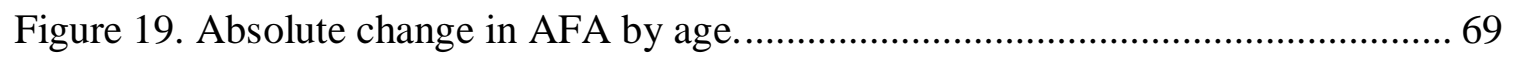

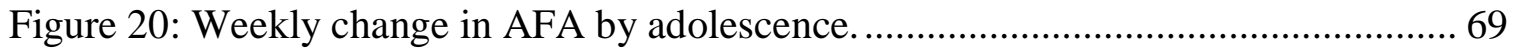

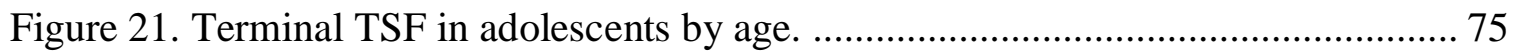


Figure 22. Terminal AFA in adolescents by age group. 


\section{CHAPTER 1 INTRODUCTION}

Malnutrition is an international problem, particularly in developing countries. Pregnant women are particularly vulnerable to becoming undernourished, due to the increased nutrient needs required for fetal growth and maternal tissue expansion (Institute of Medicine, 1990; Papathakis, Singh, \& Manary, 2016). Poverty and inadequate access to food can increase the prevalence and severity of maternal malnutrition, resulting in lifelong health consequences for the mother and child. Maternal malnutrition increases the risk for low birth weight (LBW) infants, stillbirths, preterm birth, neonatal mortality, and halted linear growth (Papathakis et al., 2016). Maternal malnutrition can also increase the prevalence of short stature and reduced immune function, negatively affecting the mother's health (Kosmiski, 2011; Özaltin, Hill, \& Subramanian, 2010).

Malawi is a low-income country in Sub-Saharan Africa with one of the highest rates of maternal mortality in the world at 634 per 100,000 live births (The World Bank, 2015). Fertility rates are high, with an average of 5.0 children per woman (The World Bank, 2015). Malawi's population is young overall, with $21.7 \%$ of individuals falling between 15 and 19 years old (National Statistical Office of Malawi, 2011). The rates of HIV infection have fallen nationwide to $9.1 \%$, but infection affects women disproportionately, with approximately 560,000 women presenting with HIV infection (UNICEF, 2012).

In a healthy pregnancy, the mother's nutrient needs increase to accommodate fat and lean tissue accrual, that is diverted toward fetal development as pregnancy progresses. Fetal development is determined by maternal nutrient intake and tissue expansion. The nutrient requirements of pregnancy and changes in body composition can be affected by 
maternal age; adolescents have increased nutrient requirements to support vertical growth and pubertal development. Pregnant adolescents therefore are at increased risk of malnutrition (Holness, 2015; Boniface F Kalanda, Verhoeff, \& Brabin, 2006).

The current standard of care for pregnant women with malnutrition in Malawi is a corn-soy blended flour ration with iron and folic acid supplementation. The literature suggests that malnourished pregnant women have smaller increases in lean tissue and fat mass compared to healthy pregnant women, resulting in smaller infants overall . Previous studies of supplementary foods in similar populations have had marginal effects on recovery from malnutrition Therefore, further investigation into the nutrient needs of malnourished pregnant women in developing countries is needed to determine the effectiveness of different supplementary foods on recovery from malnutrition. Additionally, characterizing the changes in body composition in these populations compared to those of healthy pregnant women is important to establish standards for growth during pregnancy in developing countries. 


\section{CHAPTER 2 \\ LITERATURE REVIEW}

\subsection{BODY COMPOSITION CHANGES IN NORMAL PREGNANCY}

\subsubsection{Gestational weight gain}

Pregnancy is a highly dynamic physiological state. Starting at conception, the maternal body enters an anabolic state during which the body accrues maternal fat-free and fat mass, fetal fat-free and fat mass, increased blood volume, amniotic fluid, and placental growth (Rasmussen, Yaktine, \& Institute of Medicine, 2009). Gestational weight gain (GWG) occurs with increases, and the degree of gain is highly influenced by a variety of maternal and external factors (Carlin \& Alfirevic, 2008). The Institute of Medicine (IOM) recommends a different total amount and rate of weight gain for optimal pregnancy outcomes dependent on prepregnancy BMI (Rasmussen et al., 2009). Women with high prepregnant BMI $\left(>25.0 \mathrm{~kg} / \mathrm{m}^{2}\right)$ are recommended less weight gain during pregnancy than women who are normal or underweight, as shown in Table 1 (Rasmussen et al., 2009). These recommended ranges are based on evidence of weight gain supporting optimal fetal outcomes, and to avoid the negative effects of both inadequate and excessive GWG.

Table 1: 2009 I.O.M. recommendations for gestational weight gain and rate of weight gain.

\begin{tabular}{lllll}
\hline & \multicolumn{2}{c}{ Total weight gain } & \multicolumn{2}{l}{$\begin{array}{l}\text { Rates of weight gain in 2nd and 3rd } \\
\text { trimester }\end{array}$} \\
\cline { 2 - 5 } $\begin{array}{l}\text { Prepregnancy } \\
\text { BMI }\end{array}$ & Range in kg & Range in lbs & $\begin{array}{l}\text { Mean (range) in } \\
\text { kg/week }\end{array}$ & $\begin{array}{l}\text { Mean (range) in } \\
\text { lbs/week }\end{array}$ \\
\hline $\begin{array}{l}\text { Underweight } \\
\left(<18.5 \mathrm{~kg} / \mathrm{m}^{2}\right)\end{array}$ & $12.5-18$ & $28-40$ & $0.51(0.44-0.58)$ & $1(1-1.3)$ \\
\hline $\begin{array}{l}\text { Normal weight } \\
\left(18.5-24.9 \mathrm{~kg} / \mathrm{m}^{2}\right)\end{array}$ & $11.5-16$ & $25-35$ & $0.42(0.35-0.50)$ & $1(0.8-1)$ \\
\hline $\begin{array}{l}\text { Overweight } \\
\left(25.0-29.9 \mathrm{~kg} / \mathrm{m}^{2}\right)\end{array}$ & $7-11.5$ & $15-25$ & $0.28(0.23-0.33)$ & $0.6(0.5-0.7)$ \\
\hline $\begin{array}{l}\text { Obese } \\
\left(\geq 30.0 \mathrm{~kg} / \mathrm{m}^{2}\right)\end{array}$ & $5-9$ & $11-20$ & $0.22(0.17-0.27)$ & $0.5(0.4-0.6)^{1}$ \\
\hline
\end{tabular}

1 Adapted from Rasmussen et al., 2009 
Excessive GWG is becoming increasingly prevalent in developed countries, where women are becoming pregnant later in life and are also overweight (Kominiarek \& Peaceman, 2017).

In many developing countries or areas where food availability is inadequate, insufficient GWG and limited nutrient intake are associated with reductions in birthweight and other adverse fetal outcomes from inadequate nutrient availability (S. Lederman et al., 1997; Rasmussen et al., 2009). The IOM recommends that shorter women achieve GWG at the lower end of the recommended range (Rasmussen et al., 2009). It should be noted that the IOM recommendations are based on American women, therefore their validity is questionable in countries with women of smaller stature or where malnutrition is prevalent (Kruger, 2005).

The rate of GWG differs by trimester and is associated with various stages of fetal development (Rasmussen et al., 2009). The IOM recommends that women with normal prepregnancy BMI gain an average of $0.42 \mathrm{~kg}$ per week during the $2^{\text {nd }}$ and $3^{\text {rd }}$ trimesters. Underweight women should gain more weight per week, and overweight and obese women should have the slowest rate of gain (Rasmussen et al., 2009). Few studies have been conducted comparing differences in GWG by race. A study of 52,988 mothers in the U.S. found that black women were more likely to gain less than 15 pounds over the course of their pregnancy and less likely to gain more than 34 pounds when compared to white women (Chu, Callaghan, Bish, \& D'Angelo, 2009). However, there is limited research using comprehensive national and international data assessing differences by racial group. Overall, low-income mothers of all racial groups in the U.S. tend to have excessive weight gain compared to higher-income mothers (Rasmussen et al., 2009).

In adolescents, there tends to be a higher median GWG and rate of gain compared to mature women. A study of 1,419 low-income American women found that adolescents gained $14.2-15.5 \mathrm{~kg}$, significantly greater than that of mature women, and gained weight at a faster rate (L. M. Hediger, Scholl, Ances, Isadore, Belsky, \& Salmon, 1990). However, there has been little 
research in GWG of adolescents in an international setting, as well as associated changes in body composition.

GWG is determined partly by expansions in lean mass. The quantity and quality is determined by a variety of maternal and environmental factors, and often differs by country and race.

\subsubsection{Changes in lean mass}

During pregnancy, protein is accrued in a variety of tissues. The fetus comprises the majority of lean tissue expansion (42\%). Maternal tissues accrual also includes placental formation (10\%), expanded blood volume (14\%), and uterine and breast tissue growth (17\% and 8\%, respectively) that typically occurs later in pregnancy (Pipe et al., 1979). Figure 1 displays the different components of lean mass accrual over time.

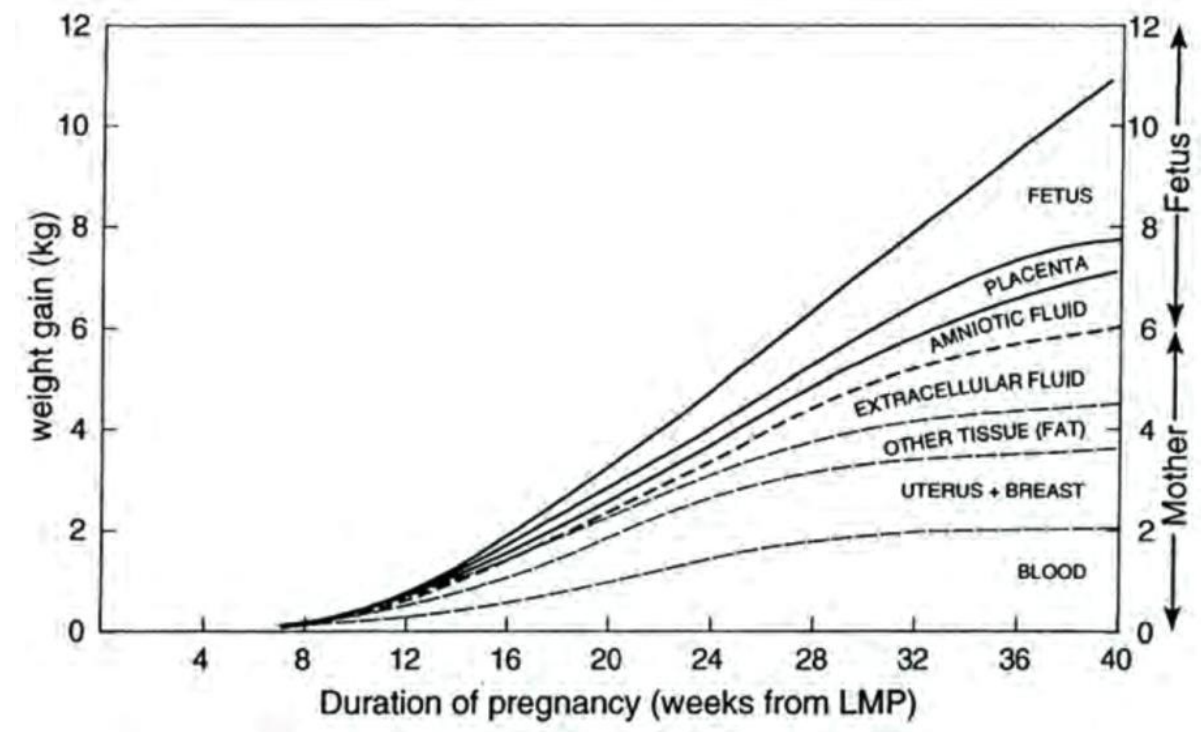

Figure 1. Components of gestational weight gain, adapted from Pitkin (1976).

The temporal changes in lean mass relative to fat and TBW are shown in Figure 2. Previous studies of body composition have found significant variation in lean mass gains. A study 
of 27 healthy English women found that women gained approximately $0.92 \mathrm{~kg}$ of lean mass from the $1^{\text {st }}$ to $3^{\text {rd }}$ trimesters (Pipe et al., 1979). Another study of 63 healthy American women found that normal weight women gained approximately $3 \mathrm{~kg}$ of lean mass over the same period, and underweight women gained $7 \mathrm{~kg}$ (Butte, Ellis, Wong, Hopkinson, \& O’Brian Smith, 2003). Multiple studies have found significant correlations between gain in maternal lean mass and infant birthweight (Butte et al., 2003; S. A. Lederman et al., 1999; Mardones-santander, Salazar, Rosso, \& Villarroel, 1998). Butte, et al. (2003) found that women with low, normal, and high BMI gained 7.2, 8.6, and $9.5 \mathrm{~kg}$ of FFM respectively, and accrued 442, 545, and 1,041 $\mathrm{g}$ of protein from 0-36 weeks gestation. FFM gain was positively correlated with birthweight $(\mathrm{r}=$ 0.39), and when FFM was separated into TBW and protein accretion, only TBW remained significant (Butte et al., 2003). A study of 224 Chilean women found a mean birthweight of 3368 $\mathrm{g}$ and $52.8 \mathrm{~kg}$ of FFM, with a significant correlation between the two. Each additional $\mathrm{kg}$ of FFM was associated with a $19.64 \mathrm{~g}$ higher birthweight. Comparing the lowest and highest quintiles for FFM, birthweight differed by approximately $400 \mathrm{~g}$ (Mardones-santander et al., 1998).

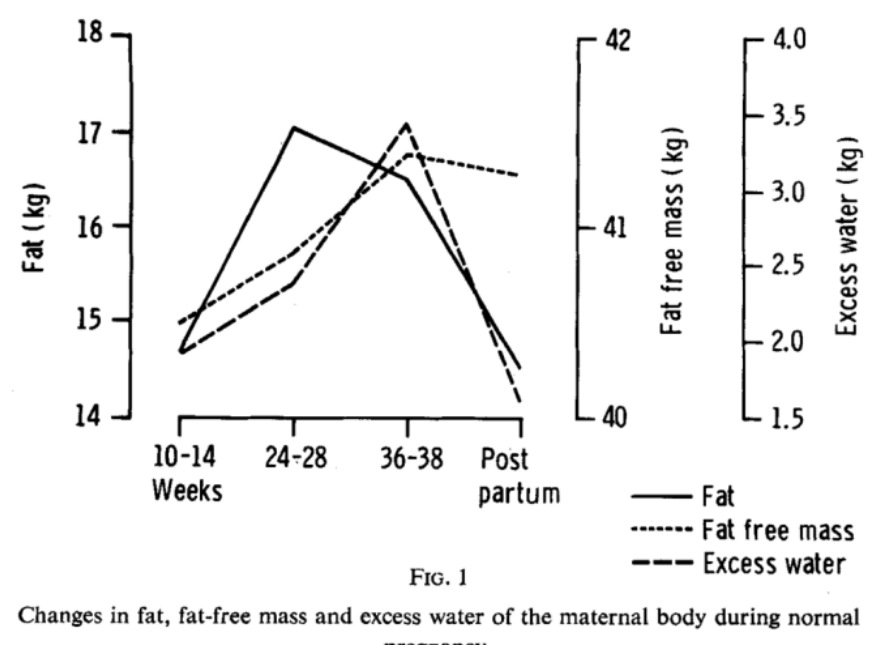

Figure 2. Adapted from Pipe, et al. (1979)

A common anthropometric measurement used to assess nutritional status is mid-upper arm circumference (MUAC). Although lean and fat mass can not be separated with this 
measurement alone, it is a useful parameter for quickly assessing changes in nutriture. Most research settings and hospitals in developed countries will have other methods for determining amounts of lean mass, however, in field settings and in resource-limited areas, MUAC is useful for estimating lean mass (Tang et al., 2013). MUAC generally increases during pregnancy; a study of 1,066 Argentinean pregnant women found that underweight women in this study gained $2.4 \mathrm{~cm}$ in MUAC over the course of pregnancy, while normal weight women gained $1.9 \mathrm{~cm}$ (López, Calvo, Poy, del Valle Balmaceda, \& Cámera, 2011). MUAC has significant positive correlations with infant birthweight and length in both healthy and undernourished populations, although few studies have been conducted in well-nourished populations due to the ability to assess other predictors. A study of 92 adequately-nourished Brazilian pregnant women found that every $1 \mathrm{~cm}$ increase in MUAC was associated with a $45.5 \mathrm{~g}$ increase in infant birthweight per week of gestation (Ricalde, Gustavo, \& Cristina d'A, 1998). Another study of 1,436 adequately nourished Vietnamese women also found significant correlations between MUAC and birthweight. The women's pre-pregnancy MUAC was $24.6 \mathrm{~cm}$, and each additional SD increase in MUAC was associated with a $166 \mathrm{~g}$ higher birthweight (Young et al., 2015).

Assessment of lean mass using higher technology to measure body composition have found similar results. Dual x-ray absorptiometry, a gold standard method discussed later, was used to measure LBM, percent fat, and FM of healthy Indian women 12-21 days following delivery. They found that LBM had the greatest positive correlation with infant birthweight compared to maternal compared to maternal BMI, FM, and percent fat (Kulkarni, Shatrugna, \& Balakrishna, 2006). One possible mechanism for this relationship is increased rate of protein turnover. A study of 27 healthy multiparous women were given an oral dose of labeled glycine to assess whole-body protein turnover, the rate at which proteins are synthesized and degraded in the body and a measure of maternal ability to accrue lean tissue. Body composition was estimated using skinfold thicknesses. Muscle and visceral tissue were calculated separately. Mothers with the highest protein turnover at 18 weeks gestation gave birth to the longest infants, with the 
greatest association with levels of visceral mass. The rate of protein turnover and birthweight and length were not associated with total dietary protein intake (Duggleby \& Jackson, 2001).

\subsubsection{Changes in total body water}

In order to estimate quantities of lean mass during pregnancy, total body water must also be measured. Although the percentage of water in lean tissue is known in non-pregnant women, the physiological changes associated with pregnancy cause significant deviation from these values (Institute of Medicine, 1990). In general, total body water and tissue hydration increase during pregnancy; however, the degree to which this occurs often varies significantly between individuals. In the $1^{\text {st }}$ trimester of pregnancy, water content of lean tissue increases from $72.5 \%$ at 10 weeks gestation and to approximately $75.0 \%$ at 40 weeks (Institute of Medicine, 1990). In relation to GWG, for a reference $12.5 \mathrm{~kg} \mathrm{GWG}$, total water gain is distributed in the fetus $(2,414$ g), placenta (540 g), amniotic fluid (792 g), blood-free uterus (800 g), mammary gland (304 g), blood (1,267 g) and ECF (1,496 g with no edema and 4,697 with edema) (Rasmussen et al., 2009). Other estimates of extracellular fluid have been found to be as large as $3 \mathrm{~kg}$ in edematous pregnant women (F. Hytten \& Chamberlain, 1991). Hytten estimated that edematous pregnant women can retain over $3 \mathrm{~kg}$ additional body water compared to pregnant women without edema (F. E. Hytten, Thomson, \& Taggart, 1966). Total TBW accretion has been estimated to be approximately 7-8 L in healthy pregnancies (Rasmussen et al., 2009). Healthy women typically increase their plasma volume by about $1250 \mathrm{~mL}$ in their fist pregnancy, typically before $32-34$ weeks of gestation. The amount of increase is partly dependent on fetal size. (Chamberlain \& Broughton-Pipkin, 1998). Gestational age and presence of edema can also affect total body water accumulation.

One study assessed the individual components of gestational weight gain and their contribution to infant birthweight. In addition to dry measurements of lean tissue, both intracellular and extracellular fluid as total body water (TBW) were measured. Total body potassium (TBK) measurements reflect total body protein. Hydration of FFM increased with 
pregnancy progression, and birthweight was positively correlated with total gain in TBW, TBK, and FFM (markers of protein accretion), but not FM (Butte et al., 2003). In a previous study of well-nourished American pregnant women, maternal body water, assessed via deuterium dilution, was a significant predictor of infant birthweight, but maternal body fat near delivery was not (S. A. Lederman et al., 1999). These findings are supported by a different study that found significant decrements in birthweight in mothers who were given diuretics to induce body water loss during pregnancy (Campbell, et al. 1975).

\subsubsection{Changes in fat mass}

GWG consists of both gains in fat and gains in fluid and lean mass. The degree of change in each compartment can vary significantly between individuals depending on gestational age and pre-pregnancy BMI. A study of 15 healthy Swedish women measured adipose tissue volume (ATV) using magnetic resonance imaging. ATV increased by $5.43 \mathrm{~L}$ during pregnancy, and $76 \%$ of it was subcutaneous (Sohlstrom \& Forsum, 1995). Of the total fat deposited, $46 \%$ is located in the lower trunk area, $32 \%$ in the upper trunk area, $16 \%$ in the thighs, $4 \%$ in the upper arms, and $1 \%$ each in the calves and forearms (Sohlstrom \& Forsum, 1995). Maternal body fat tends to peak at the end of the $2^{\text {nd }}$ trimester before decreasing in the $3^{\text {rd }}$ trimester (Pipe et al., 1979). The weight gain in the beginning of pregnancy is associated with the rapid expansion of all maternal tissues, such as fat, blood, and protein (Rasmussen et al., 2009). However as the fetus develops more rapidly in the second half of pregnancy, the demand for nutrients increases, and maternal lipolysis is increased to help meet these demands, resulting in the loss in FM (M. L. Hediger, Scholl, Schall, Healey, \& Fischer, 1994).

Lederman et al. found that fat gain during pregnancy closely correlated with GWG, with obese women gaining the least amount of fat compared to underweight and normal weight women. Additionally, fat gain increased with increased gestational weight gain within each weight category. This suggests that with sufficient GWG, fat is accrued once sufficient lean mass 
and body water has accumulated, and that if sufficient fat is present, the body does not need to accrue more fat for fetal development (S. Lederman et al., 1997). However, previous studies have found that fat mass is not necessarily a significant predictor of infant birthweight in healthy pregnancy, while total GWG and body water are (Forsum, Sadurskis, \& Wager, 1988; S. A. Lederman et al., 1999). However, a study of Brazilian pregnant women did find a significant relationship of mid-pregnancy FM and birthweight, with no significant relationship between LBM and birthweight (Toro-Ramos, Sichieri, \& Hoffman, 2016). This lack of a consistent relationship between fat gains and infant birthweight could be related to individual variability in insulin sensitivity over the course of pregnancy, reflective of a mother's ability to shunt nutrients toward the fetus (Toro-Ramos et al., 2016).

Skinfold measurement is a common method of assessing body fat in a field setting. However, they are often difficult to assess and interpret during pregnancy, as many conventional sites, such as the chest and abdomen, change in physiology as pregnancy progresses. Taggart, et al (1967) assessed the changes in skinfolds over the course of pregnancy. In this study, triceps, biceps, scapula, costal, suprailiac, mid-thigh, and knee-cap skinfolds were all measured in 84 healthy, well-nourished Scottish women at clinic visits occurring at conception, weeks 10, 20, 30, and 38 weeks gestational age. Fat was also estimated using measurements of total body water using a hydration coefficient in 48 women. At 10 weeks, skinfold measurements were all highly correlated with each other, and there was moderate correlation with body weight. There was little variation in coefficients between sites at 10 weeks. Fat estimations from TBW did not correlate well with estimations from skinfolds. Between 10 and 30 weeks, the greatest longitudinal increases were seen in the suprailiac site, more moderate changes at scapula, costal, mid-thigh, and biceps, and insignificant change at triceps and knee sites. The greatest proportional change seemed to occur in more central sites, relative to peripheral sites, up to 30 weeks gestation. There was an increase in mid-thigh skinfolds, and a decrease in costal and triceps skinfolds over 30-38 
weeks, with no observable change at other sites (Taggart, Holliday, Billewicz, Hytten, \& Thomson, 1967).

Increase in total skinfolds was greater in primiparous women than multiparous women. Overweight women who began their pregnancy with greater fat stores experienced smaller increases in skinfolds compared to thinner women. After 30 weeks, maternal body weight continued to increase significantly but dry weight and TSF experienced minimal increases and decrease, respectively. These observations could occur as a result of increasing linear fetal growth toward the end of pregnancy (Taggart et al., 1967). However, this study noted a sharp decrease in skinfold measurements immediately following delivery, suggesting that skinfolds in pregnancy may not be completely reflective of subcutaneous fat, as the rate of loss suggested by these findings is physiologically unlikely.

A study by Hediger et al. (1994) assessed changes in both central and peripheral skinfolds in low-income American women, with fewer sites but also a larger sample size $(\mathrm{N}=608)$. Changes in triceps skinfolds had much greater predictive value on birthweight than subscapular (central) skinfolds. Women who accrued the most arm fat area (AFA) from 28 weeks to birth with lower FFM increases had smaller babies. If overall GWG was high but the gains were associated only with increases in AFA, it was associated with smaller infant birthweight (M. L. Hediger et al., 1994).

The findings of Hediger et al. at first seem inconsistent with that of the previously mentioned study in that Taggart, et al. observed smaller changes in peripheral fat stores compared to central stores. However, this could be attributed to healthier pregnancies in the Taggart investigation, relative to Hediger's which found a significant decrement in birthweight with increasing peripheral fat stores (M. L. Hediger et al., 1994; Taggart et al., 1967). Therefore, a larger increase in peripheral fat relative to FFM and central fat stores could result in decreased fetal development as maternal resources are shunted towards peripheral adipose rather than transferred to the fetus. A study by Villar et al. (1992) found that change in thigh skinfold over 
the course of measurement was the only skinfold parameter with any predictive ability on birthweight (Villar et al., 1992). Therefore, maternal fat stores are possibly utilized preferentially to accommodate fetal development. Although the distribution of fat mobilization is difficult to predict, significant increases in fat mass later in pregnancy, especially in limbs, could be associated with poorer birth outcomes as maternal resources are shunted away from the fetus.

The Bacon Chow study assessed the effects of a maternal feeding program on pregnancy outcomes in marginally malnourished women in rural Taiwan (Adair \& Pollitt, 1985). Maternal weight, triceps, and subscapular skinfold measurements were taken over the course of the study. The study supplement provided $800 \mathrm{kcal}$ and 40 grams of protein per day, compared to a control beverage supplying approximately $40 \mathrm{kcal}$ and trace amounts of protein. There were no statistically significant differences between the treatment and control groups in mean maternal bodyweight and triceps and subscapular skinfolds before delivery. However, the treatment group experienced significant incremental increases in infant birthweights, despite the lack of maternal anthropometric changes. Researchers hypothesized that the fetus can sequester nutrients from the supplement more readily than the mother's fat stores, and that the increased energy from the supplement may have resulted in higher levels of physical activity from their agricultural lifestyles. Regardless, provision of supplemental energy during pregnancy may not necessarily have significant effects in moderately malnourished pregnancies in rural southeast Asia (Adair \& Pollitt, 1985; Adair, Pollitt, \& Mueller, 1984)

The triceps skinfold is the most common anthropometric measure used to assess arm fat area in a field setting as a measure of health (Taggart et al., 1967). A study assessed skinfolds over the course of pregnancy, and found that the most significant increases occurred during the $2^{\text {nd }}$ trimester, with little increase during the $3^{\text {rd }}$. However, compared to fat mass measured by deuterium dilution, greater variability was observed in the change in skinfold measurements. It was hypothesized that the skinfolds may be attributed to the accumulation of subcutaneous fluid in late pregnancy, emphasizing the difficulty in assessing fat mass during pregnancy using 
skinfold thicknesses (Pipe et al., 1979). Since then, new equations for pregnancy have been created for estimating body fat using body density, that will be further discussed later in this review (van Raaij, Peek, Vermaat-Miedema, Schonk, \& Hautvast, 1988). In a study that compared various methods of fat mass assessment in 147 pregnant Slovenian women, there were significantly and clinically different intra-woman estimates of body fat. Various equations typically used for assessment of body fat percentage all also had significantly different findings within each woman (Robič et al., 2014). Further investigation is needed to establish equations optimal for use during pregnancy.

\subsubsection{Effects of maternal age on body composition}

Adolescent pregnancy has increased risk of negative maternal and infant outcomes. Pregnant adolescents often need to gain more weight during pregnancy relative to mature mothers because of their own linear growth concurrent with maternal and fetal growth during pregnancy (Rasmussen et al., 2009). The 2009 IOM report recommended use of WHO age cut points to categorize adolescents as $<20$ years old. Prepregnancy BMI is used to guide weight gain recommendations because child growth charts are not appropriate to apply in obstetric practices in regards to weight gain (Rasmussen et al., 2009; Robič et al., 2014).

In a large-scale study of Latin American women, pregnant adolescents $<15$ years of age had significantly greater risk for maternal death, anemia, and early neonatal death compared to women 20-24 years old. Adolescents in this study also had increased risk for postpartum hemorrhage, low birth weight, preterm delivery, and small-for-gestational age (SGA) infants (Conde-Agudelo, Belizán, \& Lammers, 2005). Additionally, a Canadian study also found increased risk of spontaneous abortion and membrane rupture in adolescents (Fleming et al., 2013).

In many developing countries, pregnancy occurs earlier on average compared to developed countries, and the prevalence of adolescent pregnancies is higher (Holness, 2015). 
Adolescent pregnancy is an international problem, and negative outcomes could be attributed to a variety of biological and socioeconomic factors, such as pubertal growth requirements and inadequate access to food or healthcare (Chen et al., 2007; Fleming et al., 2013). In a study of 361 Jamaican women, adolescents had significantly lower skinfold thicknesses and MUAC measurements than mature women throughout the entire pregnancy, suggesting smaller fat stores at the beginning of pregnancy and smaller relative increases (Thame, Trotman, Osmond, Fletcher, \& Antoine, 2007). Adolescents in this study had a significantly lower pre-pregnancy BMI compared to mature women $\left(22.8\right.$ and $\left.25.7 \mathrm{~kg} / \mathrm{m}^{2}\right)$ and exhibited a significantly larger increase in lean body mass between the first antenatal visit and 35 weeks than mature women, gaining 6.2 and $5.4 \mathrm{~kg}$ of lean body mass, respectively $(\mathrm{P}<0.0001)$. Additionally, maternal weight gain was significantly greater in adolescents $(10.8$ and $9.1 \mathrm{~kg}, \mathrm{P}<0.0001)$ (Thame et al., 2007). AfricanAmerican teenagers (age > 16.5 years) who gave birth to LBW infants had significantly smaller increases in MUAC and losses in AFA compared to teenagers that experienced increases in AFA who gave birth to normal size infants (Maso, Gong, Jacobson, Bross, \& Heald, 1988).

One study assessed bone age as a function of pubertal development in American black pregnant adolescents. Although bone age was not significantly associated with negative pregnancy outcomes, decreased bone maturity was associated with faster GWG during the second trimester and a smaller increase in stature compared to skeletally mature adolescents (StevensSimon \& McAnarney, 1993). Pubertal growth appears to be prioritized over fetal development when resources are scarce, highlighting the importance of obstetric care for adolescent pregnancies in developing countries.

There are mixed findings on the influence of low maternal age on infant outcomes, particularly in countries where adolescents have greater access to healthcare (Thame et al., 2007). In a study of Peruvian mothers, adolescent mothers had smaller infants compared to mature women even when matched for nutritional status. The mean birthweight of women age 18-25 was $3240 \mathrm{~g}$, while birthweight for women 16 and younger was $3138 \mathrm{~g}$. The significant age-related 
differences in birthweight occurred between women $\geq 17$ years and $<17$ years. (Frisancho, Matos, Leonard, \& Yaroch, 1985).

In resource-poor settings, there is competition for limited nutrients and energy between maternal pubertal growth and the developing fetus. The distribution of gestational weight gain often favors maternal growth in adolescents over the fetus compared to mature women (Frisancho, 1997). A study of 594 low-income American mothers assessed changes in knee height with birthweight (T. Scholl, Hediger, Schall, Khoo, \& Fischer, 1994). Knee height was measured as a function of maternal vertical growth that is incompressible, compared to spinal length that can be compressed with progressing pregnancy. Adolescents who underwent the greatest increase in knee height (reflective of the greatest vertical growth) and accrued the largest amount of fat gave birth to significantly smaller infants than mature women and adolescents who completed their growth and lost fat over pregnancy. This suggests that teens' bodies preferentially shunt maternal energy stores toward anabolism of growth-related maternal tissue associated over fetal development. In this study, in growing mothers, increased energy intake also significantly increased birthweight compared to mature mothers, suggesting protection of maternal fat stores and greater reliance on maternal diet for fetal growth (T. Scholl et al., 1994). Adolescent pregnancy in this sample was also associated with a $282 \mathrm{~g}$ decrease in birthweight on average compared to mature mothers (T. O. Scholl, Hediger, \& Ances, 1990).

\subsubsection{Methods of body composition assessment during pregnancy}

Multiple methods exist for assessment of body composition, but few are appropriate during pregnancy in developing countries.

Dual-energy X-ray absorptiometry (DXA) is considered the gold standard method to measure body composition and proportion of lean and fat mass, its distribution, and bone structure in non-pregnant populations. DXA uses low-level radiation that may pose a risk to the fetus, and is therefore contraindicated during pregnancy. 
Air displacement plethysmography (ADP) measures the volume of air displaced by a body in the compartment and can measure body fat mass and percentage, lean mass, body volume, and density (Henriksson, Löf, \& Forsum, 2013). ADP can be affected by air trapping in body creases or hair, and may overestimate fat in pregnancy (McCarthy, Strauss, Walker, \& Permezel, 2004).

Hydrodensitometry, or underwater weighing, involves displacement of water to estimate body composition based on varying tissue densities. This method tends to overestimate adipose in pregnancy due to the relatively lower density of gestational tissues compared to lean mass. It is also expensive and invasive to the user (McCarthy et al., 2004).

Deuterium dilution involves the consumption of isotope labeled water (doubly labeled water, DLW) followed by the measurement of isotope in saliva or urine. Time must be allotted for complete dilution of the isotope in body water, and fasting is required before ingestion. Both of these factors can be affected by pregnancy, in that total body water volume generally ex pands and therefore requires more time for equilibration, and fasting during pregnancy can be difficult for the mother (S. Lederman et al., 1997). DLW is expensive, labor-intense, and requires timesensitive sample collections, making it impractical for large-scale field studies.

Bioelectrical impedance (BIA) is faster and less invasive than DXA and DLW for assessment of body composition. It involves conduction of a single-frequency electrical current to determine height ${ }^{2} /$ resistance and height ${ }^{2} /$ reactance to estimate total body water and extracellular water (Ghezzi et al., 2001; Lukaski, Siders, Nielsen, \& Hall, 1994). The electrical current poses no harm to the mother or developing fetus, and can be used to easily monitor longitudinal TBW changes. It provides less accurate measurements of body composition compared to DXA in healthy non-pregnant individuals, but is useful and acceptably accurate for assessment of body composition in lactating South African mothers (Bosy-Westphal et al., 2008; Papathakis, Rollins, Brown, Bennish, \& Van Loan, 2005). Several studies have created equations to predict body fat mass from measurements of body density and total body water that could be applied to these assessment methods (van Raaij et al., 1988). 
Anthropometric measurements include height, weight, skinfold thickness and mid-upper arm circumference (MUAC). Skinfold thickness can be measured at multiple body sites to assess location and amounts of subcutaneous fat using established equations based on assumptions of hydration of fat free mass. In normal pregnancy however, these traditional equations may not necessarily be valid due to accumulation of body water. Use of skinfold measurements may overestimate FM (Taggart et al., 1967). Previous studies have created equations for use during pregnancy, but are specific to certain periods of gestation (Huston Presley, Wong, Roman, Amini, \& Catalano, 2000; Paxton et al., 1998). Skinfolds are also easily compressible if repeated. If technicians are highly trained, skinfold measurements can provide accurate measurements of body fat in a limited resource setting and where many measurements or subjects are required. Additionally, they can be useful for observing changes in distribution of fat stores as well (Widen \& Gallagher, 2014). Skinfold thicknesses are often more useful as a measurement in itself rather than a method to estimate FM. Use of pregnancy equations to determine FM may not accurate in this setting.

Multiple methods were compared for assessment of fat mass in late gestation of 41 healthy American women. Skinfold thicknesses (triceps, biceps, subscapular, and suprailiac), BIA, ADP, and deuterium dilution were used to assess FM. In women with who experienced greater increases in FM, BIA tended to overestimate FM, while skinfold thickness showed overestimation at lower levels of FM when compared to DXA. This study also assessed the validity of the 4-compartment method, which divides body tissues into FM, body water, protein, and bone mineral content (BMC) and was measured by DXA performed postpartum. The 4compartment method consistently underestimated FM, while the SFT consistently overestimated at all levels of FM. The most accurate and precise method for measuring FM was ADP. FM between DXA measurements at delivery and skinfold thickness at 37 weeks were closely correlated however, suggesting that skinfold thickness is a useful field anthropometric measurement for large populations of pregnant women (Marshall et al., 2016). 
There are few conclusive investigations in the literature assessing ability to use anthropometric measurements, isotopic dilution, ADP, and BIA during pregnancy in resourcepoor settings. Cost, invasiveness to the subject, contraindications during pregnancy, and the physiologic processes of pregnancy reduce the ability to effectively use more accurate methods of assessment. Further studies are needed to determine a more precise yet feasible method than anthropometric measurements for use in field settings to determine amount and distribution of FM and FFM.

\subsubsection{International trends in maternal and infant birth outcomes}

\subsubsection{High-income countries}

There are numerous external variables that affect pregnancy and birth outcomes around the world. Generally, women in higher income countries are more likely to have healthier pregnancies due to access to quality obstetric care and easy food availability (Blössner \& de Onis, 2005). Compared to low-income countries like Malawi, the stillbirth rate in the United States was 5.96 per 1000 births in 2013 compared to 22 per 1000 (MacDorman \& Gregory, 2015; The World Bank, 2015).

Many of the metabolic disorders associated with excess fat mass and obesity can have negative effects on fetal development and maternal outcomes; however, these trends are no longer limited to high-income developed countries. The double burden of malnutrition, discussed later, indicates a global trend in increased overweight and obesity during pregnancy. Overall, many women in developed countries tend to have greater lean and fat mass, gestational weight gain tending toward optimal or excessive, and higher pre-pregnancy BMI compared to pregnant women in developing countries (Kramer, 2003; Streuling, Beyerlein, Rosenfeld, Schukat, \& Von Kries, 2011; Triunfo \& Lanzone, 2014). 


\subsubsection{Low-income countries}

Women in less developed, lower-income countries are more prone to negative pregnancy outcomes as a result of inadequate energy intake. This can be caused by a variety of factors, including insufficient dietary intake, high levels of physical activity from agricultural lifestyle, reduced food availability, or infectious inflammatory diseases (Subcommittee on Nutrition and Diarrheal Diseases Control, Subcommittee on Diet, Physical Activity, and Pregnancy Outcome, \& Food and Nutrition Board, 1992; Triunfo \& Lanzone, 2015). Additionally, women in developing countries tend to become pregnant earlier in life, when they may not have completed their own growth and development (Holness, 2015). Adolescent pregnancies often have less favorable outcomes, with increased rates of stunting in both the mother and infant, and increased likelihood of complications and mortality (Black et al., 2013).

A study comparing body composition of women in pastoral vs. farming communities of Kenya found that during pregnancy, women had low body fat overall $(21.7 \pm 3.8 \%$ and $22.7 \pm 4.5 \%$ respectively, $\mathrm{P}>0.05)$ and high $\mathrm{FFM}(40.5 \pm 3.9$ and $39.7 \pm 4.7 \mathrm{~kg}$ respectively, $\mathrm{P}>0.05)$. Infants also weighed $2.9 \pm 0.4$ and $2.8 \pm 0.4 \mathrm{~kg}$, respectively $(\mathrm{P}<0.05)$. Differences in birthweight between the two communities were attributed to increased dietary adequacy from cattle, and greater socioeconomic status in the pastoral group, although LBW was still highly prevalent in this community at $16.8 \%$ and $31.3 \%$ (Keverenge-Ettyang, van Marken Lichtenbelt, Esamai, \& Saris, 2006).

Another study of Tanzanian pregnant adolescents found that 54\% of the women were stunted $(<151 \mathrm{~cm})$, and average MUAC was $23.4 \pm 2.1 \mathrm{~cm}$, with severe wasting observed in $27 \%$ of women. Mean infant BW was $2600 \pm 480 \mathrm{~g}$, with $48 \% \mathrm{LBW}$. Concurrent nutritional deficiency and pubertal development can have poor consequences for the developing fetus, common in countries like Tanzania and Malawi (Shirima \& Kinabo, 2005). Another study of 854,377 women across Latin America also found that young age $(<25 \mathrm{y})$ is associated with adverse pregnancy outcomes, similar to findings in other countries (Conde-Agudelo et al., 2005). 
Many developing countries are subject to significant changes in lifestyle and food availability due to seasonality. Physical activity can significantly increase to meet demands of an agricultural lifestyle, and drought or flooding can significantly reduce food supply (Branca, Pastore, Demissie, \& Ferro-Luzzi, 1993; Hartikainen, Maleta, Kulmala, \& Ashorn, 2005; Kashiwazaki, Dejima, Orias-Rivera, \& Coward, 1995). The effects of seasonality can further worsen pregnancy outcomes in an already malnourished mother. One study assessed the effects of seasonality on fat gain in pregnant women when given a dietary supplement in the Gambia. The supplement consisted of groundnut biscuits and a vitamin-fortified tea, and was intended to provide $600-800 \mathrm{kcal} / \mathrm{d}$. The supplemented group was found to have significantly increased body fat, and was protective against the losses in fat mass during the rainy season experienced in both groups. This loss in fat mass occurs as a result of limited food supply and diminishing finances from the previous harvest season, and provides further evidence for the effects of seasonality on birth outcomes in developing countries (Lawrence, Coward, Lawrence, Cole, \& Whitehead, 1987).

Because of these downstream influences, average birthweight in a given area can be reflective of the overall health status of that population. In these settings, even if women are wellnourished prior to conception, favorable pregnancy outcomes may not always be attained. A study of 419 Ghanian pregnant women found that only $3.82 \%$ were underweight, while $57.76 \%$ were normal weight and $38.42 \%$ were overweight or obese, but only $50.36 \%$ gained sufficient or excess weight according to IOM recommendations. The mean birthweight of these infants was relatively low $(2.98 \pm 0.68 \mathrm{~kg})$, and differed significantly by adequacy of weight gain and prepregnancy BMI separately (Abubakari, Kynast-Wolf, \& Jahn, 2015). Many external factors were hypothesized to predict these changes, such as quality of obstetric care at each location and socioeconomic status, that can confound studies in many other countries as well.

Maternal stunting (defined as height $<150 \mathrm{~cm}$ ) can influence pregnancy outcomes negatively as well, and the causes of stunting are often consistent across populations. A cross- 
sectional study of pregnant and non-pregnant adolescents in Bangladesh found that $49 \%$ were stunted (height-for-age Z-score <-2) and 40\% were underweight (weight-for-age Z-score <-2). Literacy and younger age were protective against stunting in pregnant adolescents, and episodes of diarrhea or dysentery increased risk of thinness and lower AMA and AFA Z-scores. Physical activity exhibited varying effects, with light-to-moderate activity being protective against stunting, and heavy activity increasing AMA Z-scores. In this population, and possibly others as well, health status and physical activity significantly affect body composition and stature, while literacy, which is associated with greater socioeconomic status, is correlated with decreased stunting (Rah et al., 2009). Although cultural differences exist in expectations for pregnancy and types of physical activity performed by adolescent girls in various developing countries, similar findings could be observed in other settings as well.

The influences of changes in anthropometric measurements and age on pregnancy outcomes are relatively consistent and reliable across populations in developing countries. Changes in skinfolds and anthropometric measurements in Argentinean women significantly predict birthweight in both underweight and overweight mothers. The women with the smallest infants also had the smallest measurements in both skinfolds and MUAC, and the change over the course of pregnancy was smallest with increasing prepregnancy BMI (López et al., 2011). Similar positive correlations with fat mass during pregnancy and birthweight were found in a cohort of Brazilian women (Toro-Ramos et al., 2016).

Malnutrition encompasses both under- and overnutrition, and in lower-income countries. Rates of both along with their associated negative outcomes, including fetal growth restriction, stunting, maternal morbidity, have increased in recent years (Black et al., 2013). Interventions focused on these higher risk groups during pregnancy can help reduce the risk of disease and adverse health outcomes worldwide. 


\subsection{BODY COMPOSITION ADAPTATIONS IN PREGNANT WOMEN WITH UNDERNUTRITION}

Malnutrition refers to both overnutrition and undernutrition, but is most closely associated with inadequate macro- and micronutrient intake. Although there are several types of deficiencies and clinical manifestations, such as protein-energy malnutrition and specific micronutrient deficiencies, malnutrition shall be used as a collective term to encompass nutritional inadequacies most commonly observed in Malawi (Maleta, 2006).

There are several indicators commonly used to classify severity of malnutrition, which is important for determining nutritional risk. Moderate malnutrition is defined by the WHO as a weight-for-age between - 3 and -2 z-scores below the median of the WHO child growth standards, or women with a MUAC of $<23.0 \mathrm{~cm}$ in this study. MUAC has been previously found to be an appropriate and effective anthropometric indicator to identify pregnant women as acutely malnourished in many African settings (Ververs, Antierens, Sackl, Staderini, \& Captier, 2013). Previously discussed measures of anthropometric assessment can be used to further quantify malnutrition during pregnancy, such as skinfold measurements, pre-pregnancy BMI, hemoglobin concentration, and gestational weight gain.

Malnutrition is common in countries where infectious disease is prevalent and diet is poor as a result of inadequate access or availability to nutritious food. Malnutrition is therefore more prevalent in areas of poor socioeconomic status where basic needs such as adequate food, housing, and healthcare are insufficient (Blössner \& de Onis, 2005). Malnutrition in pregnancy has negative health effects on both the mother and infant. The increased energy needs of pregnancy in combination with inadequate energy intake and high levels of physical activity can result in reduced maternal energy stores and tissue accretion, as well as poor fetal development. Evidence shows that the influence of malnutrition on fetal growth and pregnancy outcomes is affected by a variety of maternal factors, including anthropometrics at the start of and during pregnancy, and composition of micro- and macronutrient intake (Papathakis et al., 2016). 


\subsubsection{Consequences of low anthropometric measurements on birth outcomes}

Previous WHO meta-analyses indicate that pre-pregnancy BMI $<20$ is associated with significantly greater risk of IUGR compared to BMI $>24 \mathrm{~kg} / \mathrm{m}^{2}$ (Blössner \& de Onis, 2005). Low birthweight (LBW, birthweight $<2500 \mathrm{~g}$ ) is strongly associated with malnutrition in pregnancy, and is associated with poor infant outcomes, such as increased risk of death and lifelong compromised immune function and growth (United Nations Children's Fund and World Health Organization, 2004). Maternal stunting is common after multiple generations of undernutrition, and has been shown to have negative outcomes for their pregnancies.

Low MUAC has been identified as an important anthropometric indicator of poor nutritional status in the humanitarian context, and is associated with smaller birthweights and increased rates of LBW (Ricalde et al., 1998; Ververs et al., 2013). Low MUAC is also associated with reduced birth length and stunting (Ricalde et al., 1998; Wilkinson et al., 2015). In a study of 92 pregnant Brazilian women, each cm smaller MUAC at enrollment was associated with a 45.5 g decrease in birthweight (Ricalde et al., 1998). Another study of 114 Tanzanian pregnant women found that women in the lowest tertile for MUAC at enrollment $(\leq 25.5 \mathrm{~cm})$ had infants with significantly smaller birth lengths than infants from mothers in the largest tertile $(46.1 \mathrm{~cm}$ vs 47.4 $\mathrm{cm}, \mathrm{P}=0.036$ ), but not birthweights (Wilkinson et al., 2015). A study of 1,436 Vietnamese pregnant women found that each $\mathrm{cm}$ smaller MUAC at enrollment resulted in a $166 \mathrm{~g}$ smaller birthweight $(\mathrm{P}<0.0001)$. MUAC is relatively reflective of protein stores in the body, and a smaller MUAC and thinner arm reflect wasting (Ververs et al., 2013). Although there is debate about the appropriate cutoff to define low MUAC, the evidence has suggested that MUAC $<23.0$ is associated with greater prevalence of LBW, and is more inclusive when screening for malnutrition than smaller cutoffs (Ververs et al., 2013).

Low GWG (GWG below IOM recommendations) is also a predictor of poor infant outcomes. An investigation of 2,760 healthy pregnant women in the Netherlands found that among women who had low pre-pregnancy BMI, $23.7 \%$ were below the IOM recommendations 
for weight gain $(12.5-18.0 \mathrm{~kg})$. These lean women had a $51 \%$ higher risk of delivering a LBW infant compared to normal weight women. Women who gained below the median weight gain $(15.9 \mathrm{~kg})$ had a 2.04-times increased risk of delivering a LBW infant (Frederick, Williams, Sales, Martin, \& Killien, 2008). The previously mentioned study of 1,436 Vietnamese pregnant women also found a significant relationship between GWG and birthweight. Women who gained $<8 \mathrm{~kg}$ during their pregnancy had 2.9 times greater odds of delivering a SGA infant and 3.1 times greater odds of delivering a LBW infant (Young et al., 2015). A study of 581 pregnant Malawian women found that each additional $100 \mathrm{~g} /$ week of GWG resulted in a $31 \mathrm{~g}$ greater birth weight $(\mathrm{P}=$ 0.007) (Kulmala et al., 2001). GWG is a reflection both of maternal energy intake and fetal growth, congruent with the evidence that suggests inadequate GWG results in smaller infants overall (Institute of Medicine, 1990).

In Malawi, adolescent pregnancies exhibit more significant malnutrition, indicated by greater prevalence of low weight-for-age, MUAC, and BMI compared to non-adolescents (Boniface F Kalanda et al., 2006). Pregnant adolescents in Bangladesh were shown to have limited linear growth, and losses in BMI, MUAC, and percent body fat compared to neverpregnant adolescents (Rah et al., 2008). Maternal stunting was also highly prevalent in similar groups (Rah et al., 2009). Competition for nutrients between the mother and fetus is common in this setting, as well as high rates of chronic infection that can inhibit placental transfer of nutrients to the fetus. Maternal body composition will often shift away from the physiological changes seen in normal pregnancy in response to inadequate nutritional intake. Anabolism of various components of maternal and fetal tissue will be limited relative to a healthy pregnancy. This increases the risk of mortality or morbidity in the mother or the fetus.

\subsubsection{Seasonality}

In many agriculture-dependent communities, season will often contribute significantly to food availability and energy intake (Lawrence et al., 1987; Thomas et al., 2013). In Africa, 
seasons are defined by a rainy season and a dry season. The rainy season is often attributed to periods of food shortages and increase in agricultural labor, as well as an increase in infectious and parasitic illnesses (Rayco-Solon, Fulford, \& Prentice AM., 2005). The increase in physical activity associated with agricultural labor can further increase the energy deficit created during food shortages, thereby worsening pregnancy outcomes (Singh et al., 1989). A retrospective study of Gambian births found that SGA incidence was highest at the end of the annual hungry season, and incidence of SGA was negatively correlated with maternal weight (Rayco-Solon et al., 2005). Season was a significant predictor of birthweight in Zimbabwe as well (Friis et al., 2004). Timing of birth during various seasons has been shown to influence the effectiveness of nutritional supplementation interventions on various maternal and fetal outcomes (Adair \& Pollitt, 1985). The effects of seasonal changes on nutritional status has been observed in non-pregnant populations in rural Ethiopia as well (Branca et al., 1993). Understanding the influence of external variables like season and food availability on nutritional status is important for creating effective interventions.

\subsubsection{Changes in maternal body water}

When mothers are already malnourished or underweight prior to the start of pregnancy, the expansions in maternal body water that occur in normal pregnancy may be reduced. This limited plasma expansion can reduce fetal growth through inhibited cardiac output and uteroplacental blood flow (Levario-Carrillo et al., 2008). A study investigating the body composition of women with SGA infants in Mexico found significant differences in body water compared to mothers of average-for-gestational-age infants. FFM, TBW, and extracellular water in the $2^{\text {nd }}$ trimester were significantly lower than the AGA mothers (Levario-Carrillo et al., 2008). In a study of Bangladesh women, women who were short $(<145 \mathrm{~cm})$ and underweight $(\mathrm{BMI}<18.5$

$\mathrm{kg} / \mathrm{m}^{2}$ ) had the lowest ECW and TBW throughout pregnancy (Gernand, Christian, Schulze, et al., 
2012). ECW and TBW are positively associated with birthweight, and reduced ECW and TBW can result in growth-restricted pregnancies.

\subsubsection{Changes in lean mass}

Inadequate GWG is closely associated with malnutrition in pregnancy. Women with inadequate GWG may not accrue lean tissue in the same proportions as women with adequate or excessive GWG, which is important for optimal birth outcomes. Pregnancy outcomes can be influenced by gains in total body water, as well as lean and muscle mass. Measurement of maternal lean mass, particularly via anthropometric measures as AMA, can be useful predictors of LBW incidence in developing countries and resourcelimited settings. This is important for humanitarian settings in which both malnutrition is prevalent and resources for assessment and treatment are limited.

A study of AMA in HIV-infected pregnant Malawian women found that AMA was significantly affected by seasonality, which affects food availability in Malawi. Women in this study who spent the entire preceding month in famine season experienced a significant decrease in MUAC $(-0.02 \mathrm{~cm})$ and loss in AMA $\left(-0.03 \mathrm{~cm}^{2}\right)$, although AMA significantly increased in women unexposed to famine (Thomas et al., 2013). A study of 350 Bangladeshi pregnant women found that although weight and TBW increased significantly over the course of gestation, mean AMA and AFA did not (Gernand, Christian, Paul, et al., 2012). Mean birthweight in this study was $2681 \pm 412 \mathrm{~g}$, with a LBW prevalence of approximately $1 / 3$. This study also measured placental weight which was positively correlated with birthweight and AMA (Gernand, Christian, Paul, et al., 2012). Gains in muscle mass could be more beneficial to fetal development and be more indicative of improvement in nutritional status than initial AMA. 
When dietary intake is insufficient, as is common in the current study's population moderately malnourished mothers, inadequate increases in lean mass can result in poor maternal and fetal outcomes (Gernand, Christian, Paul, et al., 2012; Kulkarni et al., 2006; Thomas et al., 2013).

\subsubsection{Changes in fat mass}

In resource-limited settings, malnourished pregnant women often do not accrue fat as readily as normal weight women (Friis et al., 2004; Thomas et al., 2013). If energy intake is limited, energy is most likely to be mobilized for the developing fetus and to maternal lean tissue accretion, rather than stored as adipose. Therefore, changes in fat mass in malnourished pregnant women may have different effects on fetal development relative to that of a healthy pregnancy. A study of changes in fat mass in pregnant Gambian women found that changes in fat mass had a wide range $(-4.7 \mathrm{~kg}$ to $3 \mathrm{~kg})$, compared to well-nourished European women who tend to gain $\sim 3.8 \mathrm{~kg}$ of body fat (Lawrence et al., 1987). The greatest losses in fat mass in this study occurred during the rainy season, when food availability was at its lowest and in women with the largest initial amounts of body fat. Inversely, the smallest losses and greatest gains were experienced by women with the lowest amounts of body fat. Losses were minimized in women provided a dietary supplement, compared to women who were unsupplemented (Lawrence et al., 1987). The findings of this study are suggestive of how readily adipose stores are mobilized when food availability is low and fat mass is minimal compared to well-nourished women.

The previously discussed study of Bangladeshi women found that increases in AFA between 20-32 weeks was negatively correlated with placental weight, but with no 
association with birthweight (Gernand, Christian, Paul, et al., 2012). Increases in AFA late in pregnancy were more common and greater in women with low prepregnancy BMI. Changes in AMA and AFA in early and late pregnancy in this study were not correlated, suggesting different mechanisms for changes as previously discussed (Gernand, Christian, Paul, et al., 2012). Although sufficient fat stores prior to conception are suggestive of adequate nutrition status, accrual of fat throughout pregnancy is most likely not beneficial to fetal development if lean mass and placental transfer does not occur proportionally. In malnourished mothers with inadequate energy intake, fat accrual may actually divert nutrients away from the fetus and away from the normal physiologic processes of pregnancy.

\subsubsection{Consequences of malnutrition in pregnancy}

\subsubsection{Short stature}

Maternal short stature, defined by height $\leq 150 \mathrm{~cm}$, can increase risk of adverse pregnancy outcomes, and create an intergenerational cycle of stunting and impaired development (Özaltin et al., 2010). This is one of the risks of adolescent pregnancy: in addition to competition of nutrients between maternal development and fetal development, short stature correlates with inadequate pelvic development (Brabin, Verhoeff, \& Brabin, 2002). If height and pubertal development are inadequate, pregnancy can cause pelvic distortion and significant damage to internal organs in the mother, and lead to SGA birth (Shirima \& Kinabo, 2005) and risk of maternal mortality from caesarean delivery. Short women are more likely to require caesarean delivery because inadequate pelvic development may cause obstructed birth. Together with iron deficiency anemia, maternal short stature can be attributed to at least $20 \%$ of maternal mortality (Black et al., 2013). 
A study of 181 pregnant adolescents in Tanzania found that the prevalence of stunting was high (53.9\%), and mean MUAC was $23.4 \pm 2.1 \mathrm{~cm}$ (Shirima \& Kinabo, 2005). The prevalence of wasting was high at $46.7 \%$ (MUAC $<23.0 \mathrm{~cm}$ ). $86 \%$ of subjects were anemic, with mean hemoglobin concentrations of $9.5 \pm 1.4 \mathrm{~g} / \mathrm{dL}$. The mean birthweight was $2600 \pm 480 \mathrm{~g}$, with $48 \%$ of infants categorized as LBW $(<2500 \mathrm{~g})$. There was a significant positive correlation between birthweight and weight gain. Inadequate weight gain and short stature were closely correlated as well, and the rate of caesarean delivery was higher in women of short stature (Shirima \& Kinabo, 2005). Maternal short stature has also been associated with infant stunting in Malawi (Espo et al., 2002).

\subsubsection{HIV infection}

Concurrent HIV infection and undernutrition during pregnancy can further worsen pregnancy outcomes. Chronic infection increases metabolic demands, and can exacerbate malnutrition secondary to inadequate energy intake (Kosmiski, 2011; Schaible \& Kaufmann, 2007). Malnutrition then reduces immune function, increasing the progression of HIV infection, perpetuating a cycle of worsening malnutrition and illness (Donald P Kotler, 2000; Schaible \& Kaufmann, 2007). HIV infection can cause deviations in body composition from normal. In women, HIV infection without antiretroviral treatment causes significant losses in body protein and fat, each representing approximately $10 \%$ of each individual's observed weight loss respectively. Although this is somewhat attenuated with antiretroviral treatment, losses in lean and fat tissue are still observed with the increase in energy expenditure associated with HIV(Donald P Kotler, 2000). Additionally, an expansion of extracellular water volume has been observed in HIV infection (D P Kotler, 2000).

A study compared the body composition of 620 HIV-positive, non-pregnant Rwandan women with 211 HIV-negative, non-pregnant women. HIV-positive women had less FFM (40.7 kg vs. $41.8 \mathrm{~kg}, \mathrm{P}=0.008)$, less fat measured via skinfolds $(15.6 \mathrm{~kg}$ vs $17.4 \mathrm{~kg}, \mathrm{P}<0.001)$, and a significantly higher prevalence of underweight $\left(\mathrm{BMI}<18.6 \mathrm{~kg} / \mathrm{m}^{2}\right)$ in the HIV-positive group 
(19\% vs. $26 \%, \mathrm{P}<0.05)$. (Mutimura et al., 2010). However, the HIV-positive group in this study was significantly younger $(7.0$ years, $\mathrm{P}<0.001)$ and shorter $(2.1 \mathrm{~cm}$ shorter, $\mathrm{P}<0.001)$ than the HIV-negative group. After adjustment for age and height, the differences in body composition were no longer significant. Additionally, fat mass measured with BIA was not different between the two groups. Therefore, it is difficult to attribute the changes observed to HIV infection (Mutimura et al., 2010). Few studies have been performed comparing the body composition of HIV-infected pregnant women against non-infected pregnant women in the same population.

Although only a small percentage of women in the current study were HIV-positive (10.6\%), the additive effects of chronic infection and inadequate nutrition can have adverse effects in these groups.

\subsubsection{Pregnancy in Malawi}

\subsubsection{Maternal statistics}

Malawi is a small country in southeastern Sub-Saharan Africa with a total population of approximately 16 million in 2013 . The maternal mortality ratio is approximately 634 deaths per 100,000. It has been slowly decreasing over recent decades, as seen in Figure 2, but currently stands as the $13^{\text {th }}$ highest in the world (WHO \& MCA, 2015). According to the 2010 Demographic Health Survey, the perinatal mortality rate is 40 per 1000 births, a value that remains relatively constant across income groups but increases with adolescent pregnancy. The literacy rate is $68 \%$. (National Statistical Office of Malawi, 2011). An analysis of 6,684 women found that $9 \%$ of women are underweight, and $77 \%$ of women had a normal BMI. Approximately $2 \%$ have very short stature (height $<145 \mathrm{~cm}$ ), although the rate tends to vary by region (National Statistical Office of Malawi, 2011). Rates of malnutrition have increased from previous decades, as shown in Figure 3. 


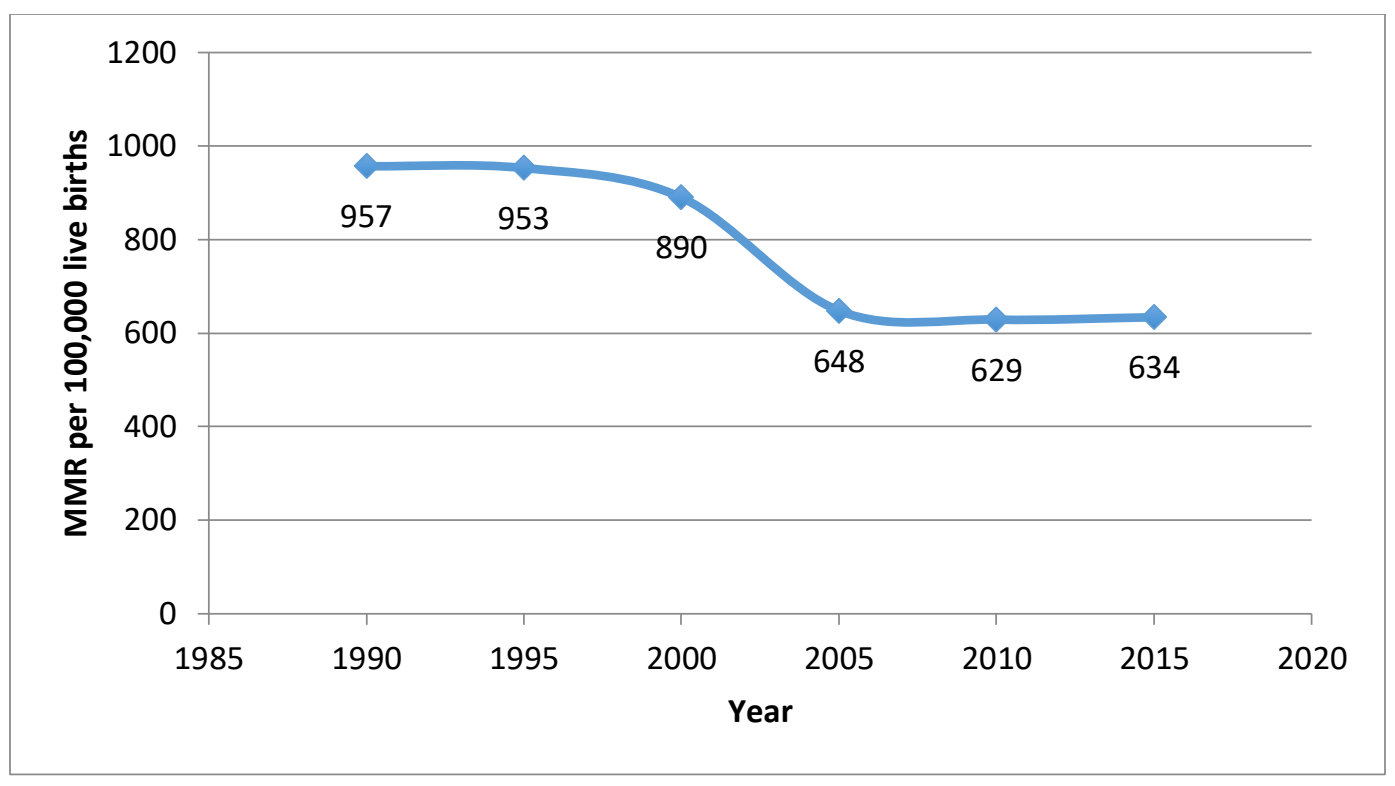

Figure 2. Maternal mortality ratio in Malawi from 1990 - 2015. (Adapted from UNICEF data).

Significant changes in maternal mortality have been estimated over the previous several decades in Malawi. The maternal mortality ratio was estimated to have been 317 per 100,000 live births in 1980 to 748 in 1990, increasing again to 971 in 1999, decreasing to 846 in 2005 and finally falling faster to 484 in 2010 . This is attributed to improvements in HIV treatment and obstetric care, although it is difficult to identify all of the causes of death in Malawi due to lack of reporting and knowledge (Colbourn et al., 2013). Other surveys of maternal mortality estimated the ratio to be as high as 1120 per 100,000 live births in 2000. This paper attributed the most common causes of death to be sepsis, complications of abortion, and obstructed labor in the 1980s, although improvements to healthcare quality and reporting have occurred since then. (Geubbels, 2006).

The three most common causes of biological maternal death in Africa overall are hemorrhage, infections, and hypertensive disorders. These causes of death can be exacerbated by the "Three Delays," which include the "delay by the patient in the decision to seek care, the delay in reaching the appropriate care once the decision has been made to seek care, and the delay in receiving adequate care after arriving at the health facility" (Colbourn et al., 2013 p. 2). 


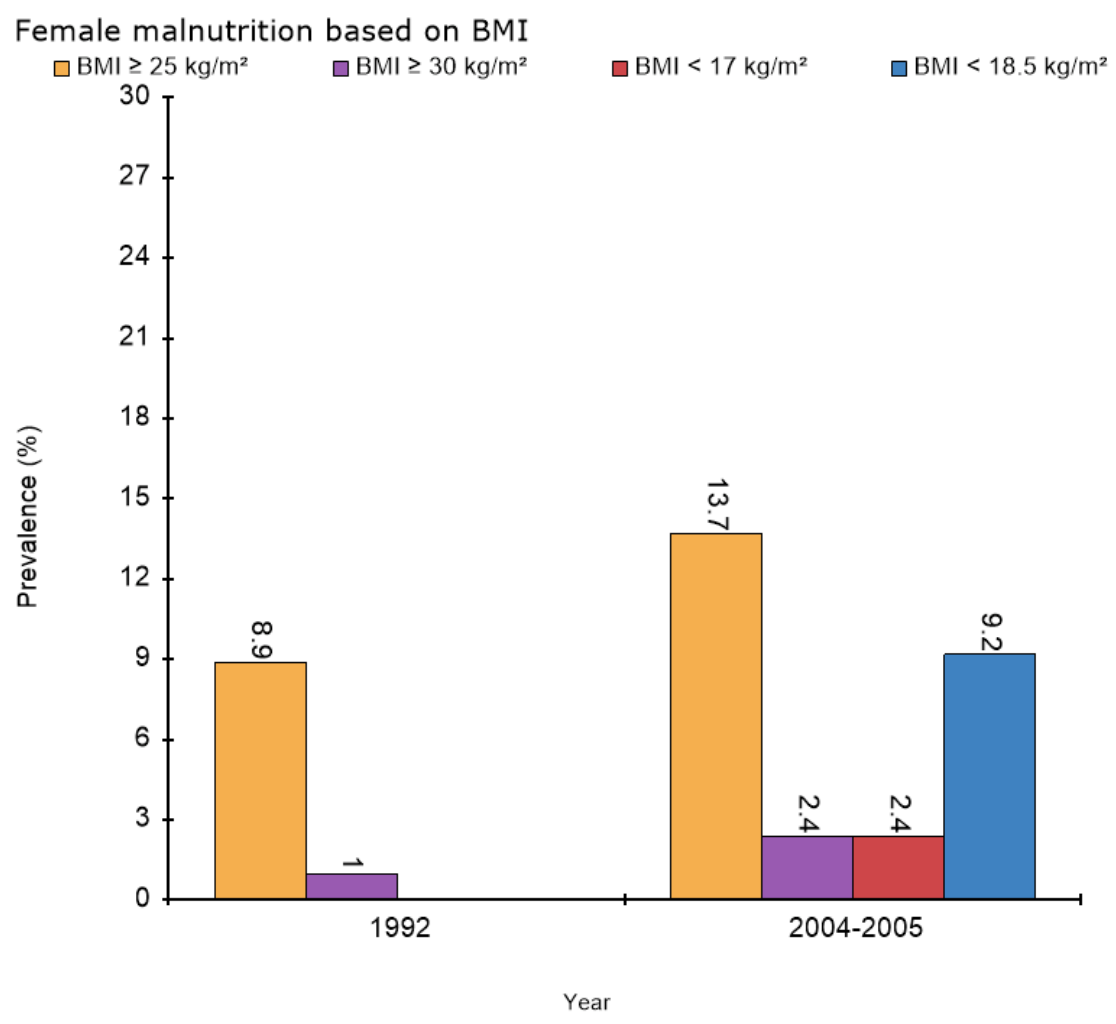

Figure 3. Prevalence of female malnutrition in Malawi by BMI. (WHO, 2015).

Rates of maternal short stature and low MUAC values vary in other assessments of Malawian women, suggesting consistency in the effects malnutrition on growth and health status but also inconsistencies in reporting. An observational study of 991 pregnant mothers in a rural area of South Malawi found that $19.3 \%$ were adolescent $(12-19 y)$, and $82.6 \%$ of all women were illiterate. Adolescents were significantly shorter, had lower BMI, and smaller MUAC on average than adults, as seen in Table 2. They also tended to be underweight more frequently in the first trimester than adults (Kalanda et al., 2006). Additionally, this study compared Malawian percentiles for growth against CDC percentiles, and found significant differences at all values. The Malawian $90^{\text {th }}$ percentile was close to the CDC $50^{\text {th }}$ percentiles for weight, height, and MUAC across ages $14-20$. The CDC curves show an increase in height during puberty that is 
not seen in Malawian growth curves. The average GWG over the course of enrollment in this study was $685 \mathrm{~g}$ across both adolescents and adults, with adolescents experiencing marginally lower GWG than adults (36g vs $1100 \mathrm{~g}, \mathrm{p}=0.09$ ). (Kalanda, 2007). A smaller study of 118 pregnant Malawian adolescents in the Chikwawa District Hospital area found that $33.9 \%$ were stunted (Fazio-Tirrozzo et al., 1998).

Table 2. Anthropometrics of pregnant Malawian adolescents and adults.

\begin{tabular}{l|lll}
\hline & Adolescents & Adults & P-value \\
\hline $\begin{array}{l}\text { Weight } \\
(\mathbf{k g})\end{array}$ & $49.5 \pm 5.0$ & $51.8 \pm 6.4$ & $<0.01$ \\
\hline $\begin{array}{l}\text { Weight }<\mathbf{5 0} \mathbf{~ k g} \\
(\%)\end{array}$ & 53.4 & 37.3 & 0.01 \\
\hline $\begin{array}{l}\text { Height } \\
(\mathbf{c m})\end{array}$ & $156 \pm 6.1$ & $157 \pm 5.6$ & 0.01 \\
\hline $\begin{array}{l}\text { Height }<\mathbf{1 5 0} \mathbf{~ c m} \\
(\%)\end{array}$ & 11.6 & 8.2 & $\mathrm{NS}$ \\
\hline $\begin{array}{l}\text { MUAC } \\
(\mathbf{c m})\end{array}$ & $24.1 \pm 2.0$ & $25.3 \pm 2.1$ & $<0.01$ \\
\hline $\begin{array}{l}\text { MUAC }<23 \mathbf{~ c m} \\
(\%)\end{array}$ & 17.9 & 12.7 & 0.01 \\
\hline $\begin{array}{l}\text { BMI } \\
(\mathbf{k g} / \mathbf{m})\end{array}$ & $20.4 \pm 1.8$ & $21.0 \pm 2.3$ & 0.001 \\
\hline $\begin{array}{l}\text { BMI }<\mathbf{1 8 ~} \mathbf{~ k g / m} \\
(\%)\end{array}$ & 17.9 & 12.7 & 0.067 \\
\hline $\begin{array}{l}\text { Illiteracy } \\
(\%)\end{array}$ & 77.9 & 75.1 & $\mathrm{NS}$ \\
\hline
\end{tabular}

From: (Kalanda et al., 2006)

A study of 1,523 Malawian pregnant women from Shire Valley assessed the prevalence of cephalo pelvic disproportion (CPD), previously mentioned as a result of short stature that can increase risk for negative pregnancy outcomes if the infant is too large relative to the pelvis. In this sample, 270 were $<20$ years old, and 20 were $<16$ years old, with $2.3 \%$ of women overall exhibiting CPD. Birthweight increased significantly with increasing height, and the greatest proportion of women with CPD was higher with infant birthweight $>3500 \mathrm{~g}$ and maternal height $<154 \mathrm{~cm}$. What is unique about the Malawian sample is that CPD was more common in older women than adolescents. Malawian adolescents are therefore at little risk of developing 
complications of CPD from nutritional supplementation, particularly if inadequate fetal growth is already occurring (Brabin et al., 2002).

MUAC, AFA, and AMA have been correlated with dietary patterns in HIV-positive Malawian pregnant women. Dietary patterns were stratified into animal-based, plant-based, and grain-based diets. Those consuming the animal-based diets were most often wealthier and consumed the most protein, fat, and overall energy compared to the other dietary patterns. However, AMA was higher in the women consuming the grain-based diet than the animal-based diet (Ramlal et al., 2015). The women consuming the grain-based diet were the least wealthy of the group, which could possibly be related to the lifestyles associated with socioeconomic status in Malawi. Engaging in more agricultural physical activity to support their livelihood could have contributed to higher levels of AMA than more sedentary, wealthier women.

\subsubsection{Infant statistics}

A study from 2000 in Malawi found that the infant mortality rate was 136 per 1000 live births, with the strongest predictors being inadequate weight gain, LBW, maternal HIV infection, young maternal age, and premature birth (Vaahtera et al., 2000). In comparison, the infant mortality rate in the United States in 2015 is approximately 6 per 1000 live births (CDC, 2014). According to UNICEF, Malawi's infant mortality rate in 2012 was 46 per 1000 live births, a noticeable decrease from that observed in this study, but much higher than most developed countries. Maternal malnutrition can further exacerbate predictors of infant mortality,

Some of the most significant predictors of birthweight in 581 women attending rural Malawi clinics included initial weight, length of pregnancy, and GWG (Kulmala et al., 2001). Low BMI, MUAC, and bodyweight are positively associated with IUGR in Malawi, indicating the importance of monitoring these anthropometric measures to optimize pregnancy outcomes (Pelletier et al., 1995). MUAC is a useful measurement of nutritional status in Malawi, where access to antenatal clinics and care is limited, and additional measurement methods are inaccessible or impractical for the setting. In HIV-infected Malawian mothers, MUAC has been 
found to be a significant predictor of infant birthweight (Thomas et al., 2012). The Breastfeeding, Antiretrovirals, and Nutrition (BAN) study measured maternal anthropometry as one of its variables, and its relationship with fetal growth and birthweight in 1005 HIV-infected women in Malawi. The mean baseline MUAC was $26.5 \mathrm{~cm}$, mean AMA was $36.8 \mathrm{~cm}^{2}$, and mean AFA was $19.7 \mathrm{~cm}^{2}$. The average infant birthweight was $2998 \mathrm{~g}$. For each $1 \mathrm{~cm}$ increase in baseline MUAC there was a $31.8 \mathrm{~g}$ increase in birthweight, and each $1 \mathrm{~cm}^{2}$ increase in baseline AMA and AFA was associated with a $6.88 \mathrm{~g}$ and $6.97 \mathrm{~g}$ increase in birthweight respectively (Thomas et al., 2012). Although HIV-infection does not make up a majority of pregnant women in Malawi, it is still highly prevalent $(9.1 \%)$, and is useful for comparison with the current study population containing both HIV-infected and uninfected women.

\subsubsection{Conclusion}

Overall, pregnant women experience increases in fat mass at the beginning of pregnancy and increases in lean mass toward the end of pregnancy from the products of conception and expansion of their own tissues. The degree to which these changes occur can be highly variable even in healthy pregnancies. There is inconsistent evidence regarding the effects of malnutrition on changes in body composition during pregnancy, particularly in developing countries. Additionally, the relationship of altered body composition during pregnancy with infant outcomes is not fully investigated.

Malnutrition during pregnancy has widespread and long-term consequences for both the mother and the infant. These effects range from alterations in physiologic development, such as increased placental weight and IUGR, to long term effects following birth and development, such as stunting and altered hormonal and metabolic profiles (Triunfo \& Lanzone, 2015). Increasing energy and micronutrient intake relative to the increased needs of pregnancy is an ideal approach to reducing rates of malnutrition. However, more research is needed to establish a successful intervention for malnourished pregnancies on a global scale (Papathakis et al., 2016). 
Although there have been several investigations into the role of body composition on pregnancy outcomes, the contributions are not yet fully known. GWG appropriate for the mother's pre-pregnancy BMI is vital for a healthy pregnancy, but can be difficult to predict the adverse physiological effects of undernutrition during pregnancy. Sufficient baseline amounts and gains in both lean mass and fat mass at certain stages of pregnancy are critical for healthy pregnancy and minimizing risk of disease and adverse events. The current study seeks to assess the effects of dietary interventions on accrual of lean and fat tissue during moderately malnourished pregnancy, and its relationship with birthweight. 


\section{CHAPTER 3 \\ MATERIALS AND METHODS}

\subsection{OBJECTIVE}

The objective of this research was to assess changes in MUAC, arm muscle area, TSF, and arm fat area in a sample of moderately malnourished pregnant Malawian women before and after receiving one of three supplemental interventions to determine if one intervention is more effective at restoring lean mass or fat mass than others. We also differences in maternal anthropometry and birth outcomes between mature women and adolescents over the course of intervention.

\subsection{LOCATION}

Pregnant women were enrolled at study sites in the health districts of Blantyre, Chikhwawa, Mulanje, and Zomba.

\subsection{SUBJECTS}

This was a secondary analysis of 1,808 women enrolled in the randomized controlled clinical trial Mamachiponde.

Inclusion criteria for Mamachiponde included:

- Pregnant with MUAC $\geq 20.6 \mathrm{~cm}$ and $\leq 23.0 \mathrm{~cm}$.

- Willingness/ability to attend antenatal clinic visits every two weeks during pregnancy.

- $\geq 16$ years old

- Willingness to remain in area for delivery and until 3 months postpartum.

- Provision of written and verbal consent. 
- Consent to undergo HIV testing if not previously completed.

Exclusion criteria for Mamachiponde included:

- Severe malnutrition (MUAC $<20.6 \mathrm{~cm}$ ).

- Pregnancy complications, i.e. gestational diabetes, preeclampsia, or hypertension.

- Severe anemia (hemoglobin $<7.0 \mathrm{~g} / \mathrm{dL}$ ).

- Concurrent participation in any other nutrition study or supplemental feeding program.

- $<16$ years old

The study was registered in ClinicalTrials.gov NCT02120599 and was approved by the Institutional Review Boards of Washington University (St. Louis), California Polytechnic State University (San Luis Obispo), and the College of Medicine at University of Malawi (Blantyre).

\subsection{RANDOMIZATION AND BLINDING}

Subjects were block randomized (block of size 60) to receive one of three nutritional interventions. They were then individually randomized at enrollment.

\subsection{STUDY DESIGN}

Mamachiponde was a researcher-blinded, randomized controlled trial designed to determine whether a micronutrient-fortified, ready-to-use supplementary food (RUSF), or a corn-soy blended flour (CSB+) with a multiple micronutrient supplement provided to moderately malnourished pregnant women would result in improved recovery from malnutrition and improved maternal and infant outcomes, when compared to the 
international standard of care. This standard of care is fortified CSB flour with daily iron and folic acid supplements. All treatment and control foods and supplements were given in a 14 day supply.

1. RUSF: This treatment provided $900 \mathrm{kcal} / \mathrm{day}, 38 \mathrm{~g}$ protein/day, and $200 \%$ of the RDA during pregnancy for most micronutrients, with the exception of vitamin A, vitamin $\mathrm{B}_{3}$, folic acid, iodine, magnesium, and calcium that were supplemented near $100 \%$. The energy content was strategically designed to provide an additional 360-450 kcal required during the second and third trimesters of pregnancy, with an additional $450-550 \mathrm{kcal}$ to encourage recovery from malnutrition. No additional supplements were provided with this food.

2. CSB + UNNIMAP: This treatment included provision every two weeks of $5 \mathrm{~kg}$ of corn-soy blended (CSB+) flour with a standard antenatal micronutrient tablet called UNNIMAP containing 15 micronutrients. This treatment provided similar amounts of energy, protein, and micronutrients as the RUSF.

3. CSB-IFA: The control group is the current Malawian standard of care treatment for moderate and severe malnutrition during pregnancy. This treatment included 5 $\mathrm{kg}$ CSB every two weeks with daily iron $(60 \mathrm{mg})$ and folic acid $(400 \mu \mathrm{g})$.

Subjects visited clinic every two weeks for anthropometric measurements, health status checkups, and provision of their treatment food. Women achieving a MUAC $>23.1$ cm at any point during the intervention were considered "graduated." Women whose MUAC remained $>23.1 \mathrm{~cm}$ (remained graduated) for two or more consecutive visits no longer received the food supplement, but still received standard daily iron and folic acid supplements. Upon graduating, women visited monthly to monitor for any relapse into 
malnutrition. If relapse (MUAC <23.1) did occur, mothers were again provided their previously assigned treatment food. All mothers were included in the analysis, whether graduation or relapse occurred.

\subsection{DATA COLLECTION}

Women eligible and willing to consent in the study had anthropometric measurements taken by a study team member at antenatal clinic visits occurring every two weeks after enrollment. These measurements included height, weight, MUAC, triceps skinfold (TSF), and blood pressure. Weight was expressed in kilograms using a Detecto Slimpro scale and height was measured in centimeters with a Seca stadiometer. MUAC was measured twice with a TALC measuring tape; if the measurements had a difference $>1 \mathrm{~mm}$, a third measurement was taken and the two closest measurements were used. TSF was also measured twice with Lange skinfold calipers, and followed similar protocol for error as MUAC. The average of the two MUAC and TSF measurements were then used in calculations and analysis.

Arm muscle area (AMA) was calculated from MUAC and TSF values using the equation:

$\operatorname{AMA}\left(\mathrm{cm}^{2}\right)=(\text { MUAC }-\pi \times \mathrm{TSF})^{2} \div 4 \pi$

In order to calculate arm fat area (AFA), upper arm area (AA) must be first calculated using:

$$
\mathrm{AA}=(4 \pi) \times \mathrm{D}^{2}
$$

Upper arm area can then be incorporated into the following equation:

$$
\mathrm{AFA}\left(\mathrm{cm}^{2}\right)=\mathrm{AA}-\mathrm{AMA}
$$


Changes in MUAC, AMA, TSF, and AFA were defined as the average difference between the measurements at enrollment and terminal measurements for each woman before delivery.

Women enrolled at differing stages of pregnancy, and therefore had varying numbers of antenatal visits between enrollment and delivery. The number of antenatal visits attended ranged from 3 to 17 . Adolescence was defined using WHO criteria as age $\leq 19$ years old

A separate analysis was performed to assess the effects of seasonality on anthropometric changes and birth outcomes. Seasonality was defined by birth occurring either during the rainy season (December to April) or during the dry season (May to November).

A separate subgroup analysis was performed in adolescents comparing very young adolescents (16-17 years old) to older adolescents (18-19 years old) to test for any effects of pubescence and maternal linear growth on maternal body composition during enrollment.

\subsection{STATISTICAL ANALYSIS METHODS}

Baseline characteristics and differences were tested using the chi-squared test for categorical variables and one-way analysis of variance followed by Tukey's honestly significant difference (HSD) test for continuous variables. Dunnett's test was also used to test whether the means for subjects in CSB-UNIMMAP and RUSF were different from that of CSB-IFA. Analysis of variance (ANOVA) was used to test for differences in means between intervention groups and age groups and for interactions between treatment group and time as well as treatment group and age. 
The original data set encoded weeks on treatment, which we converted to weeks from delivery so that that values would be comparable across subjects (e.g. two women may have 5 weeks on treatment, but at very different stages in pregnancy. Gestational age is difficult to measure in this setting. This time variable (weeks from delivery) was then used in longitudinal models using mixed effects analysis of variance with pregnancy ID as a random effect.

Additionally, absolute changes in MUAC, AMA, and AFA (defined as absolute change $=$ terminal - initial value) were analyzed with weeks on treatment in the model to account for the effect of treatment lengths on absolute changes. Testing for sensitivity of points representing women who were enrolled for a very short time ( $<3$ antenatal visits) and long enrollment periods (>15 antenatal visits) and showed that these women did not have significant influence on the average trajectory of MUAC, AMA, TSF, and AFA. Exclusion of these women at ends of the range had no significant effect on the model, therefore women with all treatment lengths were included in analysis.

Least squares (LS) means are reported with standard error (SE) in addition to raw means and standard deviations (SD) to assess the effect of treatments after adjusting for other covariates in the model, such as treatment length and age, and also report variability in the raw data, unless stated otherwise. 


\section{CHAPTER 4}

RESULTS

\subsection{BASELINE CHARACTERISTICS}

The age range of the 1808 subjects was 16 to 45 years and the median age was 20 years. As seen in Figure 4, age in this sample was not normally distributed. The most frequently reported age was 18 years $(\mathrm{N}=337)$. Eight hundred seventy one women were 19 years or younger $(48.1 \%)$. Within the adolescents, $18.6 \%$ were underweight $(\mathrm{BMI} \leq$ $18.5 \mathrm{~kg} / \mathrm{m}^{2}$ ) and $24.6 \%$ were of short stature (height $\leq 150 \mathrm{~cm}$ ).

Additional baseline characteristics of women enrolled are listed in Table 3.

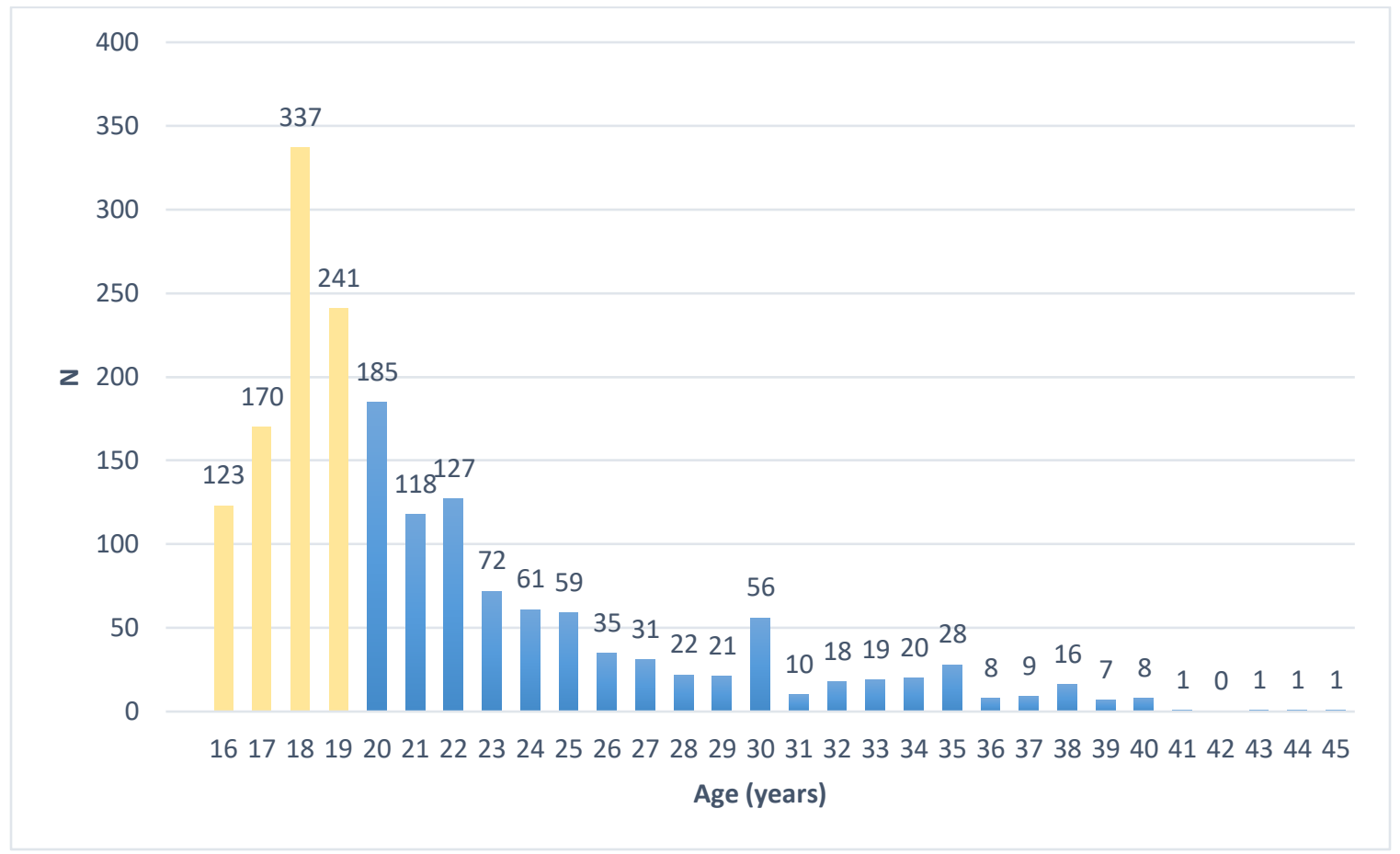

Figure 4: Age distribution of enrolled women. Yellow bars represent adolescents ( $\leq 19 \mathrm{y})$. 
Table 3: Baseline characteristics of enrolled women across interventions. Values expressed as mean \pm standard deviation unless otherwise stated.

\begin{tabular}{cccccc}
\hline & $\begin{array}{c}\text { CSB-IFA } \\
\mathbf{( N = 6 0 2 )}\end{array}$ & $\begin{array}{c}\text { CSB- } \\
\text { UNIMMAP } \\
(\mathbf{N = 6 0 1})\end{array}$ & $\begin{array}{c}\text { RUSF } \\
(\mathbf{N = 6 0 5})\end{array}$ & $\begin{array}{c}\text { Overall } \\
(\mathbf{N = 1 8 0 8})\end{array}$ & P-value \\
\hline Age, years & $21.84 \pm 5.50$ & $21.32 \pm 5.03$ & $21.48 \pm 5.40$ & $21.55 \pm 5.31$ & 0.2247 \\
\hline $\begin{array}{c}\text { Adolescents, } \\
\mathbf{N}(\%)\end{array}$ & $281(46.7)$ & $294(48.9)$ & $296(48.9)$ & $871(48.1)$ & 0.8425 \\
\hline Weight, kg & $46.87 \pm 3.94$ & $46.85 \pm 4.24$ & $46.74 \pm 3.99$ & $46.82 \pm 4.06$ & 0.8201 \\
\hline Height, cm & $154.31 \pm 5.59$ & $153.97 \pm 5.95$ & $154.34 \pm 5.50$ & $154.21 \pm 5.68$ & 0.4442 \\
\hline $\begin{array}{c}\text { Short stature, } \\
\mathbf{N}(\%)\end{array}$ & $136(22.6)$ & $153(25.5)$ & $134(22.1)$ & $423(23.4)$ & 0.3635 \\
\hline BMI, kg/m & $19.68 \pm 1.31$ & $19.76 \pm 1.34$ & $19.62 \pm 1.41$ & $19.69 \pm 1.36$ & 0.2297 \\
\hline $\begin{array}{c}\text { Underweight, } \\
\mathbf{N}(\%)\end{array}$ & $115(19.1)$ & $110(18.3)$ & $105(17.4)$ & $330(18.3)$ & 0.7412 \\
\hline $\begin{array}{c}\text { HIV-infected } \\
\mathbf{N}(\%)\end{array}$ & $69(11.5)$ & $60(10.0)$ & $63(10.4)$ & $192(10.6)$ & 0.67 \\
\hline
\end{tabular}

Adolescence is defined as age $\leq 19$ years old. Short stature is defined as height $<150 \mathrm{~cm}$. Underweight is defined as $\mathrm{BMI}<18.5 \mathrm{~kg} / \mathrm{m}^{2}$.

\subsection{MATERNAL ANTHROPOMETRICS}

BMI at enrollment ranged from 15.24 to $24.05 \mathrm{~kg} / \mathrm{m}^{2}$. Weight gain before delivery ranged from $0 \mathrm{~kg}$ to $13.6 \mathrm{~kg}$. The median weight gain before delivery was 2.5 $\mathrm{kg}$. Weight gain before delivery was defined as the change in weight from enrollment to delivery. Table 4 depicts weight gain before delivery, mean length of treatment, and the average weekly weight gain of women across groups. Weight gain before delivery was highest in the RUSF group, and lowest in the CSB-UNIMMAP group $(\mathrm{P}=0.0479)$. Weeks on treatment and average weekly weight gain did not differ significantly between groups $(\mathrm{P}=0.8952$, and 0.3103 , respectively). Using simple linear regression, weight gain before delivery was a significant predictor of absolute change in MUAC, AMA, TSF, and AFA. Every kg of weight gain before delivery, after adjustment for weeks on treatment, resulted in a $0.14 \mathrm{~cm}$ greater increase in MUAC, $0.32 \mathrm{~cm}^{2}$ greater increase in 
AMA, $0.13 \mathrm{~mm}$ greater increase in TSF, $0.19 \mathrm{~cm}^{2}$ greater increase in AFA $(\mathrm{P}<0.0001$ for all, 95\% CIs [0.13, 0.16], [0.28, 0.37], [0.09, 0.17], [0.16, 0.24], respectively).

Table 4. Mean gestational weight gain and mean weeks on treatment across interventions. Values expressed as raw means $\pm \mathrm{SD}$.

\begin{tabular}{llllll}
\hline & CSB-IFA & $\begin{array}{l}\text { CSB- } \\
\text { UNIMMAP }\end{array}$ & RUSF & Overall & P-value \\
\hline $\begin{array}{l}\text { Weight gain } \\
\text { before } \\
\text { delivery (kg) }\end{array}$ & $2.95 \pm 2.43$ & $2.75 \pm 2.29$ & $3.11 \pm 2.61$ & $2.94 \pm 2.45$ & 0.0479 \\
\hline $\begin{array}{l}\text { Weeks on } \\
\text { treatment }\end{array}$ & $9.17 \pm 5.73$ & $9.06 \pm 5.68$ & $8.99 \pm 5.75$ & $9.08 \pm 5.71$ & 0.8592 \\
\hline $\begin{array}{l}\text { Average } \\
\text { weekly weight } \\
\text { gain }(\mathbf{k g})\end{array}$ & $0.32 \pm 0.21$ & $0.31 \pm 0.19$ & $0.33 \pm 0.19$ & $0.32 \pm 0.20$ & 0.3103 \\
\hline
\end{tabular}

\subsubsection{MUAC}

Mean MUAC for all mothers at enrollment was $22.28 \pm 0.59 \mathrm{~cm}$, with no difference between groups $(\mathrm{P}=0.9264)$ (Table 5). Mean terminal MUAC for all mothers was $22.41 \pm 0.92 \mathrm{~cm}$, with no difference across groups $(\mathrm{P}=0.1098)$. On average, terminal MUAC was significantly greater than initial MUAC in all groups (Figure 5). Terminal MUAC did not differ by intervention group, but weeks on treatment had a significant effect on terminal MUAC. Compared to the overall mean, for every week on treatment, terminal MUAC decreased by $0.03 \mathrm{~cm}, 95 \% \mathrm{CI}[-0.04,-0.02](\mathrm{P}<0.0001)$. 


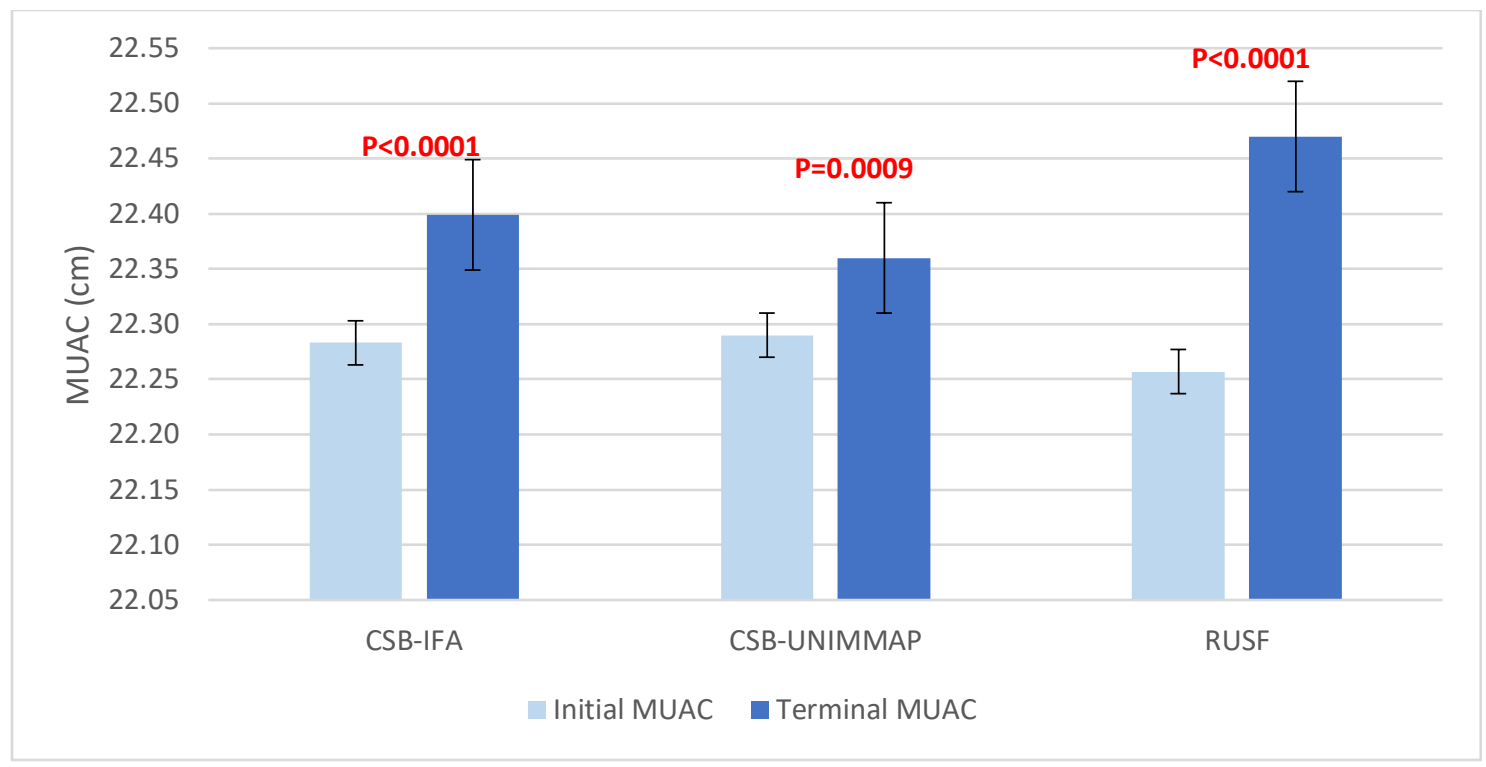

Figure 5: Initial and terminal MUAC across interventions.

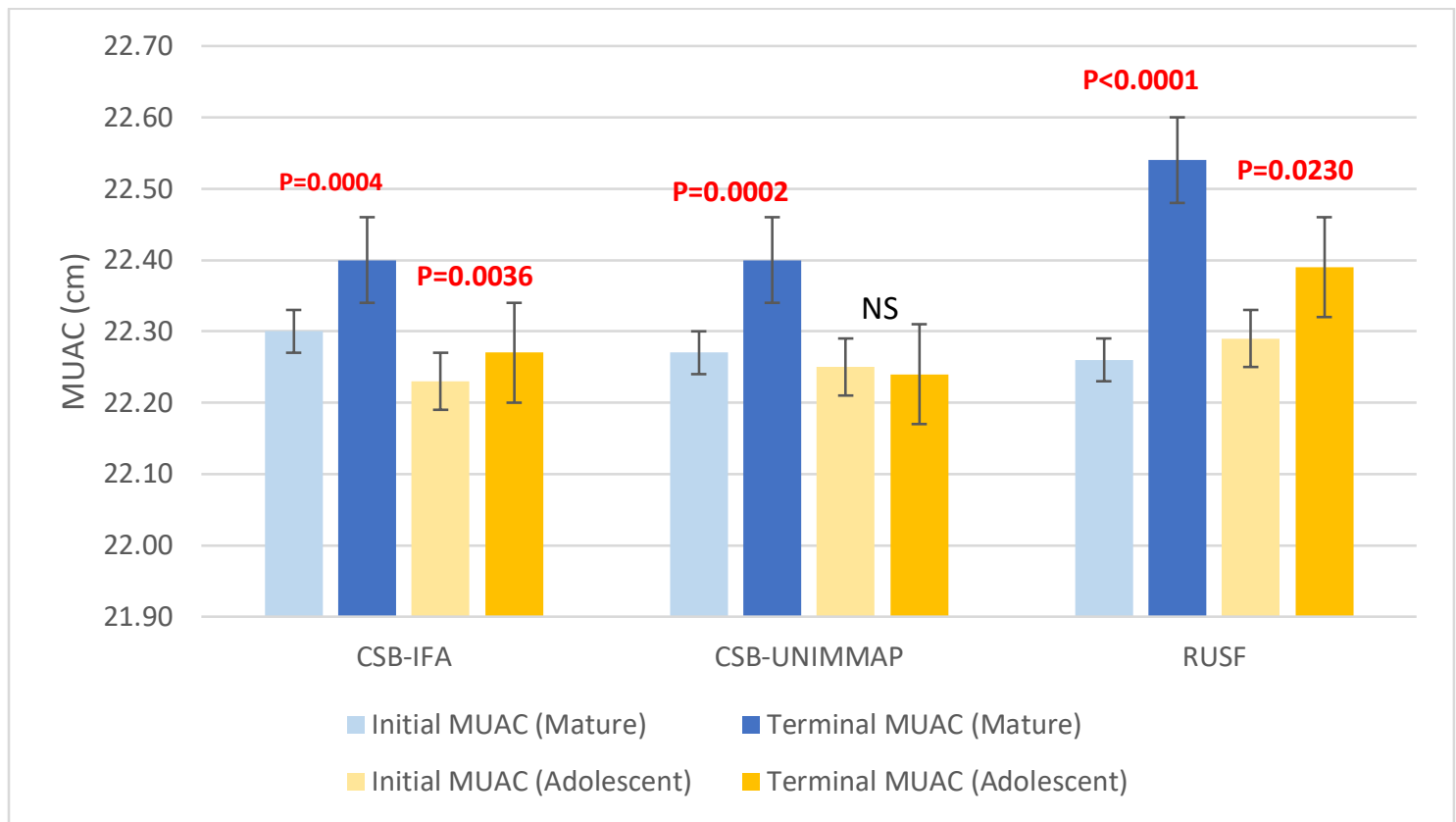

Figure 6: Initial and terminal MUAC stratified by age. 


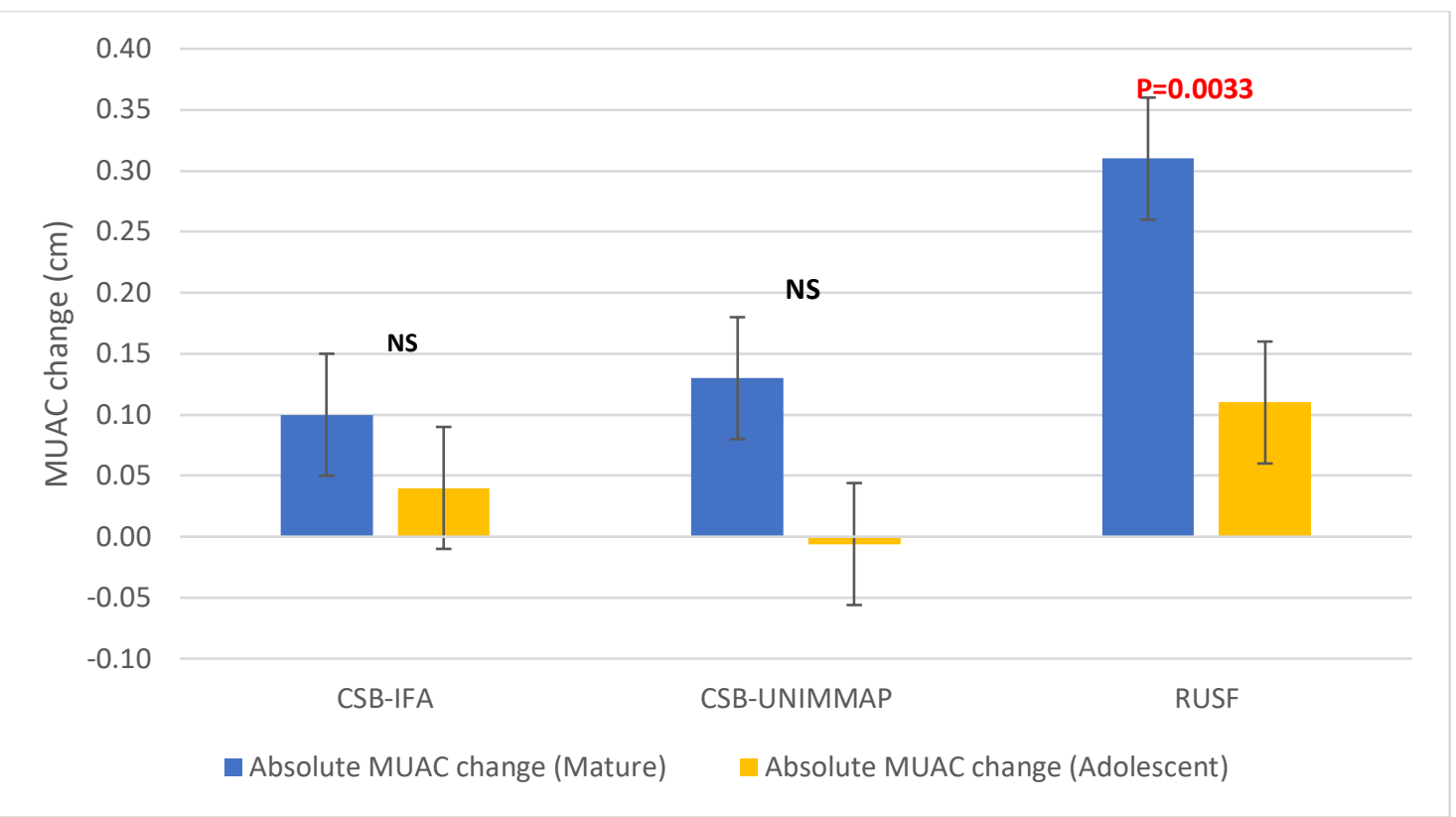

Figure 7. Absolute change in MUAC by age.

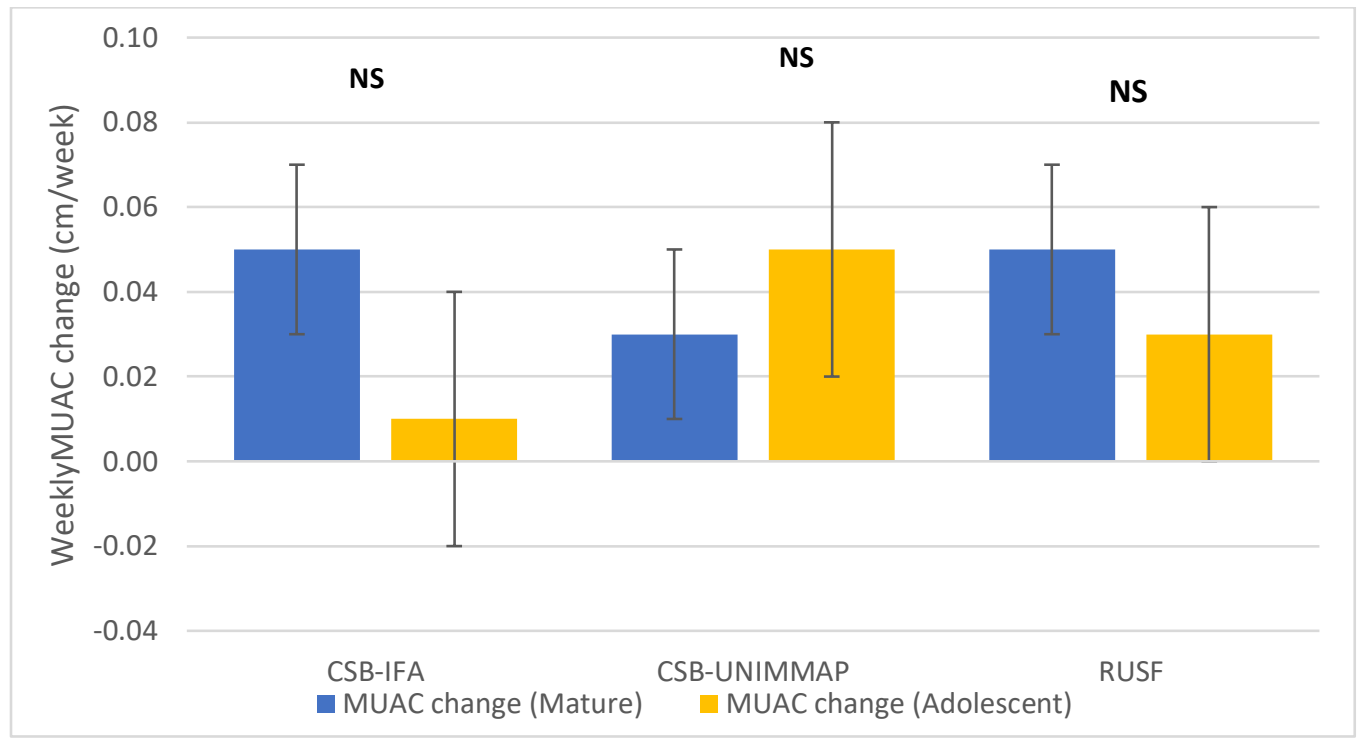

Figure 8: Weekly change in MUAC by age. 
Table 5. Initial and terminal MUAC, and absolute and weekly change across interventions.

\begin{tabular}{|c|c|c|c|c|c|c|c|c|}
\hline & & CSB-IFA & $\begin{array}{l}\text { CSB- } \\
\text { UNIMMAP }\end{array}$ & RUSF & Overall & $\begin{array}{l}\text { Intervention } \\
\text { effect } P \text {-value }\end{array}$ & $\begin{array}{l}\text { Time } \\
\text { effect } P \text { - } \\
\text { value }\end{array}$ & $\begin{array}{l}\text { Time*Intervention } \\
\text { effect P-value }\end{array}$ \\
\hline \multirow{2}{*}{$\begin{array}{l}\text { Initial } \\
\text { MUAC, } \\
\text { cm }\end{array}$} & Raw mean \pm SD & $22.27 \pm 0.61$ & $22.26 \pm 0.61$ & $22.27 \pm 0.60$ & \multirow[b]{2}{*}{$22.27 \pm 0.61$} & \multirow[b]{2}{*}{0.9264} & \multirow[b]{2}{*}{ N/A } & \multirow[b]{2}{*}{ N/A } \\
\hline & $\mathrm{LS}$ mean $\pm \mathrm{SE}$ & $22.27 \pm 0.02$ & $22.26 \pm 0.02$ & $22.27 \pm 0.02$ & & & & \\
\hline \multirow{2}{*}{$\begin{array}{l}\text { Terminal } \\
\text { MUAC, } \\
\text { cm }\end{array}$} & Raw mean $\pm \mathrm{SD}$ & $22.40 \pm 0.89$ & $22.36 \pm 0.89$ & $22.47 \pm 0.96$ & \multirow[b]{2}{*}{$22.41 \pm 0.92$} & \multirow[b]{2}{*}{0.1098} & \multirow[b]{2}{*}{$<0.0001$} & \multirow[b]{2}{*}{0.1953} \\
\hline & $\mathrm{LS}$ mean $\pm \mathrm{SE}$ & $22.39 \pm 0.05$ & $22.36 \pm 0.05$ & $22.44 \pm 0.05$ & & & & \\
\hline \multirow{2}{*}{$\begin{array}{l}\text { Absolute } \\
\text { MUAC } \\
\text { change, cm }\end{array}$} & Raw mean $\pm \mathrm{SD}$ & $0.13 \pm 0.67$ & $0.10 \pm 0.70$ & $0.20 \pm 0.78$ & \multirow[b]{2}{*}{$0.14 \pm 0.72$} & \multirow[b]{2}{*}{0.0181} & \multirow[b]{2}{*}{$<0.0001$} & \multirow[b]{2}{*}{0.1568} \\
\hline & $\mathrm{LS}$ mean $\pm \mathrm{SE}$ & $0.07 \pm 0.04^{a}$ & $0.07 \pm 0.04^{a}$ & $0.21 \pm 0.04^{b}$ & & & & \\
\hline \multirow{2}{*}{$\begin{array}{l}\text { Weekly } \\
\text { MUAC } \\
\text { change, } \\
\text { cm/week }\end{array}$} & Raw mean $\pm \mathrm{SD}$ & $0.028 \pm 0.34$ & $0.041 \pm 0.46$ & $0.040 \pm 0.26$ & \multirow[b]{2}{*}{$0.036 \pm 0.36$} & \multirow[b]{2}{*}{0.8135} & \multirow[b]{2}{*}{ N/A } & \multirow[b]{2}{*}{ N/A } \\
\hline & $\mathrm{LS}$ mean $\pm \mathrm{SE}$ & $0.028 \pm 0.02$ & $0.041 \pm 0.02$ & $0.040 \pm 0.02$ & & & & \\
\hline
\end{tabular}


Table 6: Initial and terminal MUAC and absolute and weekly change across interventions separated by age

\begin{tabular}{|c|c|c|c|c|c|c|c|c|c|c|c|c|}
\hline & & \multicolumn{2}{|l|}{ CSB-IFA } & \multicolumn{2}{|c|}{ CSB-UNIMMAP } & \multicolumn{2}{|l|}{ RUSF } & \multicolumn{2}{|l|}{ Overall } & \multirow{2}{*}{$\begin{array}{l}\text { Intervention } \\
\text { effect } P \text { - } \\
\text { value }\end{array}$} & \multirow{2}{*}{$\begin{array}{l}\text { Time } \\
\text { effect } \\
\text { P-value }\end{array}$} & \multirow{2}{*}{$\begin{array}{l}\text { Time*Intervention } \\
\text { effect P-value }\end{array}$} \\
\hline & & Mature & Adolescent & Mature & Adolescent & Mature & Adolescent & Mature & Adolescent & & & \\
\hline \multirow{2}{*}{$\begin{array}{l}\text { Initial } \\
\text { MUAC } \\
(\mathbf{c m})\end{array}$} & $\begin{array}{l}\text { Raw } \\
\text { mean } \\
\pm \mathrm{SD}\end{array}$ & $22.30 \pm 0.60$ & $22.23 \pm 0.62$ & $22.27 \pm 0.61$ & $22.25 \pm 0.61$ & $22.26 \pm 0.61$ & $22.29 \pm 0.59$ & $22.28 \pm 0.61$ & $22.26 \pm 0.60$ & \multirow[b]{2}{*}{0.9291} & \multirow[b]{2}{*}{ N/A } & \multirow[b]{2}{*}{ N/A } \\
\hline & $\begin{array}{l}\text { LS } \\
\text { mean } \\
\pm \mathrm{SE}\end{array}$ & $22.30 \pm 0.03$ & $22.23 \pm 0.04$ & $22.27 \pm 0.03$ & $22.25 \pm 0.04$ & $22.26 \pm 0.03$ & $22.29 \pm 0.04$ & $22.28 \pm 0.02$ & $22.26 \pm 0.02$ & & & \\
\hline \multirow{2}{*}{$\begin{array}{l}\text { Terminal } \\
\text { MUAC } \\
\text { (cm) }\end{array}$} & $\begin{array}{l}\text { Raw } \\
\text { mean } \\
\pm \text { SD }\end{array}$ & $22.44 \pm 0.88$ & $22.36 \pm 0.91$ & $22.42 \pm 0.86$ & $22.30 \pm 0.93$ & $22.54 \pm 1.0$ & $22.39 \pm 0.91$ & $22.47 \pm 0.91$ & $22.35 \pm 0.92$ & \multirow{2}{*}{0.0909} & \multirow{2}{*}{$<0.0001$} & \multirow{2}{*}{0.2177} \\
\hline & $\begin{array}{l}\mathrm{LS} \\
\text { mean } \\
\pm \mathrm{SE}\end{array}$ & $22.40 \pm 0.06^{a}$ & $22.27 \pm 0.07^{a}$ & $22.40 \pm 0.06^{a}$ & $22.24 \pm 0.07^{a}$ & $22.54 \pm 0.07^{a}$ & $22.39 \pm 0.07^{a}$ & $22.45 \pm 0.04^{a}$ & $22.30 \pm 0.04^{b}$ & & & \\
\hline \multirow{2}{*}{$\begin{array}{l}\text { Absolute } \\
\text { MUAC } \\
\text { change } \\
(\mathrm{cm})\end{array}$} & $\begin{array}{l}\text { Raw } \\
\text { mean } \\
\pm \mathrm{SD}\end{array}$ & $0.14 \pm 0.67$ & $0.12 \pm 0.68$ & $0.15 \pm 0.67$ & $0.04 \pm 0.72$ & $0.30 \pm 0.77$ & $0.11 \pm 0.77$ & $0.20 \pm 0.71$ & $0.09 \pm 0.73$ & \multirow[b]{2}{*}{0.2666} & \multirow[b]{2}{*}{0.1491} & \multirow[b]{2}{*}{0.5893} \\
\hline & $\begin{array}{l}\mathrm{LS} \\
\text { mean } \\
\pm \mathrm{SE}\end{array}$ & $0.10 \pm 0.05^{\mathrm{a}}$ & $0.04 \pm 0.05^{\mathrm{a}}$ & $0.13 \pm 0.05^{\mathrm{a}}$ & $0.00 \pm 0.05^{\mathrm{a}}$ & $0.31 \pm 0.05^{b}$ & $0.11 \pm 0.05^{a}$ & $0.18 \pm 0.03^{a}$ & $0.05 \pm 0.033^{b}$ & & & \\
\hline \multirow{2}{*}{$\begin{array}{l}\text { Weekly } \\
\text { MUAC } \\
\text { change } \\
\text { (cm/week) }\end{array}$} & $\begin{array}{l}\text { Raw } \\
\text { mean } \\
\pm \text { SD }\end{array}$ & $0.05 \pm 0.42$ & $0.01 \pm 0.20$ & $0.03 \pm 0.20$ & $0.05 \pm 0.62$ & $0.05 \pm 0.19$ & $0.03 \pm 0.31$ & $0.04 \pm 0.29$ & $0.03 \pm 0.42$ & \multirow{2}{*}{0.7902} & \multirow{2}{*}{ N/A } & \multirow{2}{*}{ N/A } \\
\hline & $\begin{array}{l}\text { LS } \\
\text { mean } \\
\pm \mathrm{SE}\end{array}$ & $0.05 \pm 0.02^{\mathrm{a}}$ & $0.01 \pm 0.02^{\mathrm{a}}$ & $0.03 \pm 0.02^{\mathrm{a}}$ & $0.05 \pm 0.02^{\mathrm{a}}$ & $0.05 \pm 0.02^{\mathrm{a}}$ & $0.03 \pm 0.03^{a}$ & $0.04 \pm 0.01^{\mathrm{a}}$ & $0.03 \pm 0.01^{\mathrm{a}}$ & & & \\
\hline
\end{tabular}


Absolute change in MUAC was positive in all intervention groups, with the greatest increase in the RUSF group, significantly different across groups $(\mathrm{P}=0.0181)$. Compared to the overall mean, women in the RUSF group had a $0.09 \mathrm{~cm}$ larger increase in MUAC, 95\% CI [0.03, 0.16] $(\mathrm{P}=0.0047)$. In a pairwise comparison, absolute MUAC change was also significantly greater in the RUSF group compared to women in CSBIFA and CSB-UNIMMAP 95\% CIs [-0.27, 0.00], $[-0.27,-0.01] \mathrm{P}=0.0480$ and 0.0287 , respectively). Every week on treatment was associated with a $0.03 \mathrm{~cm}$ smaller absolute MUAC change in all groups, 95\% CI [-0.04, -0.02] $(\mathrm{P}<0.0001)$.

\subsubsection{MUAC by age}

Initial MUAC was nearly identical in mature women and adolescent women (22.28 \pm 0.61 and 22.26 \pm 0.60 , respectively). Terminal MUAC was slightly higher in mature women than adolescents $(22.47 \pm 0.91$ and $22.35 \pm 0.92$, respectively). When accounting for age in the whole model, terminal MUAC did not differ by intervention group, as seen in Table 6 ( $\mathrm{P}=0.9291)$. However, the intervention effect differed by age group. Compared to the overall mean, adolescents in CSB-IFA had a $0.08 \mathrm{~cm}$ smaller terminal MUAC, while adolescents in CSB-UNIMMAP had a $0.09 \mathrm{~cm}$ larger terminal MUAC, 95\% CIs [-0.05, 0.07], [-0.07, 0.06] $(\mathrm{P}=0.0080$ and 0.0034 , respectively). There was no significant effect of age alone or a time*age interaction $(\mathrm{P}=0.2716)$. As seen in Figure 6, terminal MUAC was significantly greater than initial MUAC for mature women in CSB-IFA, CSB-UNIMMAP and RUSF $(\mathrm{P}=0.0004,0.0002$ and $<0.0001$, respectively), and for adolescents in CSB-IFA and RUSF $(\mathrm{P}=0.0036$ and 0.0230 , respectively). 
When stratified by age, intervention has varying effects on terminal MUAC within each age group. In mature women, terminal MUAC is significantly different between interventions $(\mathrm{P}=0.0053)$. Compared to the overall mean in mature women, mature women in CSB-UNIMMAP had a 0.14 smaller terminal MUAC, 95\% CI [-0.22, 0.06] $(\mathrm{P}=0.0012)$. In pairwise comparison, mature women in CSB-UNIMMAP had significantly lower terminal MUAC than mature women in CSB-IFA and RUSF, 95\% CI $[0.04,0.39](\mathrm{P}=0.0129$ and 0.0155 , respectively). Among adolescents, terminal MUAC did not differ by intervention group $(\mathrm{P}=0.01297)$.

When accounting for age, intervention has different effects on absolute change in MUAC by age group $(\mathrm{P}=0.0114)$. As seen in Figure 7 , absolute MUAC change was significantly lower in adolescents than mature women in RUSF $(\mathrm{P}=0.0033)$. All groups had an increase in MUAC, except for CSB-UNIMMAP adolescents who had a negligible loss in MUAC over the course of intervention as seen in Table 6. Compared to the overall mean, adolescents in CSB-IFA had $0.07 \mathrm{~cm}$ smaller change in MUAC, while adolescents in CSB-UNIMMAP had $0.06 \mathrm{~cm}$ larger increase in MUAC $(\mathrm{P}=0.0059$ and 0.0170 , respectively). There was no significant interaction with age and RUSF assignment when analyzed as a whole group model.

However, when stratified by age, intervention had varying effects on absolute MUAC change within each age group. Within mature women, absolute MUAC change significantly differed across interventions $(\mathrm{P}=0.0105)$. Compared to the mean for mature women, mature women in CSB-UNIMMAP had a $0.11 \mathrm{~cm}$ smaller increase in MUAC (P $=0.0025)$, and was significantly lower than the mean for mature women in CSB-IFA and RUSF in pairwise comparison ( $\mathrm{P}=0.0250$ and 0.0239 , respectively). Within adolescents, 
intervention also had a significant effect on absolute MUAC change $(\mathrm{P}=0.0418)$.

Compared to the overall mean for adolescents, adolescents in CSB-IFA had a $0.08 \mathrm{~cm}$ smaller change in MUAC $(\mathrm{P}=0.0176)$. In a pairwise comparison, adolescents in CSBIFA had a significantly smaller change compared to adolescents in RUSF, but not CSBUNIMMAP $(\mathrm{P}=0.0356)$.

Weekly change in MUAC did not differ significantly by intervention or between age groups, as seen in Figure 8. ( $\mathrm{P}=0.792$ and 0.3860 , respectively). When analyzed as a whole group, there is no intervention or age effect on weekly MUAC change. When stratified by age, there was no difference in weekly MUAC change $(\mathrm{P}=0.7801$ and 0.5707 for mature women and adolescents, respectively.

\subsubsection{MUAC by Seasonality}

When seasonality is included in the model, there is a significant effect on terminal MUAC $(\mathrm{P}<0.0001)$. Compared to the overall mean, birth during the rainy season (December - April) resulted in a $0.13 \mathrm{~cm}$ smaller terminal MUAC, 95\% CI [-0.17, -0.08$]$. In a pairwise comparison, women whose birth occurred during the rainy season had a $0.25 \mathrm{~cm}$ smaller terminal MUAC compared to the dry season $(22.23 \mathrm{~cm}$ vs. $22.48 \mathrm{~cm}$, respectively), 95\% CI [0.16, 0.34] $(\mathrm{P}<0.0001)$.

Seasonality also had a significant effect on the absolute increase in MUAC. Compared to the overall mean, women whose birth occurred during the rainy season had a $0.14 \mathrm{~cm}$ smaller increase in MUAC, 95\% CI [-0.17, -0.10] $(\mathrm{P}<0.0001)$. In a pairwise comparison, women whose birth occurred during the rainy season had a $0.27 \mathrm{~cm}$ smaller change in MUAC compared to the dry season $(-0.05 \mathrm{~cm}$ vs. $0.23 \mathrm{~cm}), 95 \% \mathrm{CI}[0.20$, $0.34](\mathrm{P}<0.0001)$. There was no interaction of seasonality with age or intervention on terminal $(\mathrm{P}=0.3401$ and 0.2789 , respectively $)$ or absolute change in MUAC $(\mathrm{P}=0.2575$ 
and 0.6113 , respectively). There was also no effect of seasonality on weekly change in $\operatorname{MUAC}(\mathrm{P}=0.3229)$.

When analyzed as a longitudinal mixed model, there was no evidence for a linear or quadratic relationship of MUAC change over time. There was no effect of time on the trajectory of MUAC change over the course of the intervention. Weeks on treatment had no significant effect on trajectory of MUAC when analyzed in a simpler linear regression.

\subsubsection{AMA}

Initial AMA across all groups was $29.9 \pm 2.6 \mathrm{~cm}^{2}$ on average across all groups, and did not differ by intervention $(\mathrm{P}=0.2090)$. Terminal AMA was higher than initial AMA on average across all groups at $30.73 \pm 2.9 \mathrm{~cm}^{2}$, with no difference across groups (P $=0.9306$ ). Table 7 lists initial, terminal, and absolute and weekly changes in AMA within each intervention group.

Terminal AMA did not significantly differ across intervention groups. However, weeks on treatment significantly affected terminal AMA; every week of treatment resulted in $0.09 \mathrm{~cm}^{2}$ smaller terminal AMA compared to the overall mean, 95\% CI [-0.12, -0.06] $(\mathrm{P}<0.0001)$. Terminal AMA was significantly greater than initial AMA in all groups, as seen in Figure 9.

Maternal height at enrollment significantly predicted terminal AMA. Every $\mathrm{cm}$ of height resulted in a $0.03 \mathrm{~cm}^{2}$ larger terminal AMA $(\mathrm{P}=0.0300)$. There was a marginally significant association of maternal height at enrollment and initial AMA, not different between groups. Every $\mathrm{cm}$ of maternal height was associated with a $0.02 \mathrm{~cm}^{2}$ larger initial AMA $(\mathrm{P}=0.0505)$. When height is assessed as a categorical variable, short stature 
(height $<150 \mathrm{~cm}$ ) resulted in a $0.25 \mathrm{~cm}^{2}$ smaller terminal AMA when compared to the overall mean $(\mathrm{P}=0.0025)$.

Intervention significantly affected the absolute change in AMA over the course of enrollment. On average, women in RUSF had the largest increase in AMA over the course of enrollment when compared to CSB-IFA and CSB-UNIMMAP (P=0.0363). Compared to the overall mean, women in the RUSF group had $0.26 \mathrm{~cm}^{2}(27.5 \%)$ larger increase in AMA over the course of intervention, 95\% CI [0.06, 0.47] $(\mathrm{P}=0.0115)$.

Weekly change in AMA was not significantly different across interventions when analyzed as a whole group $(\mathrm{P}=0.8787)$. 


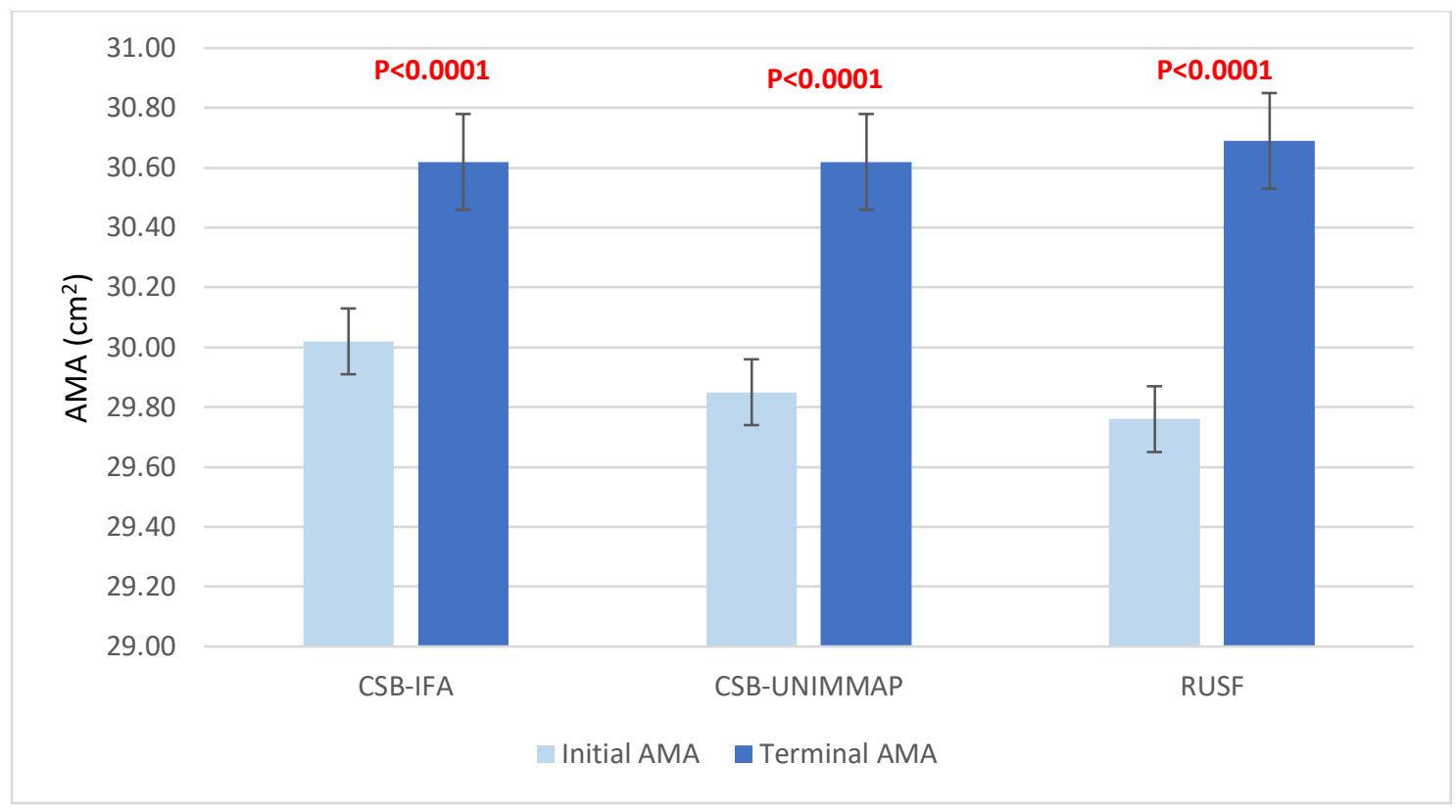

Figure 9: Initial and terminal AMA across interventions.

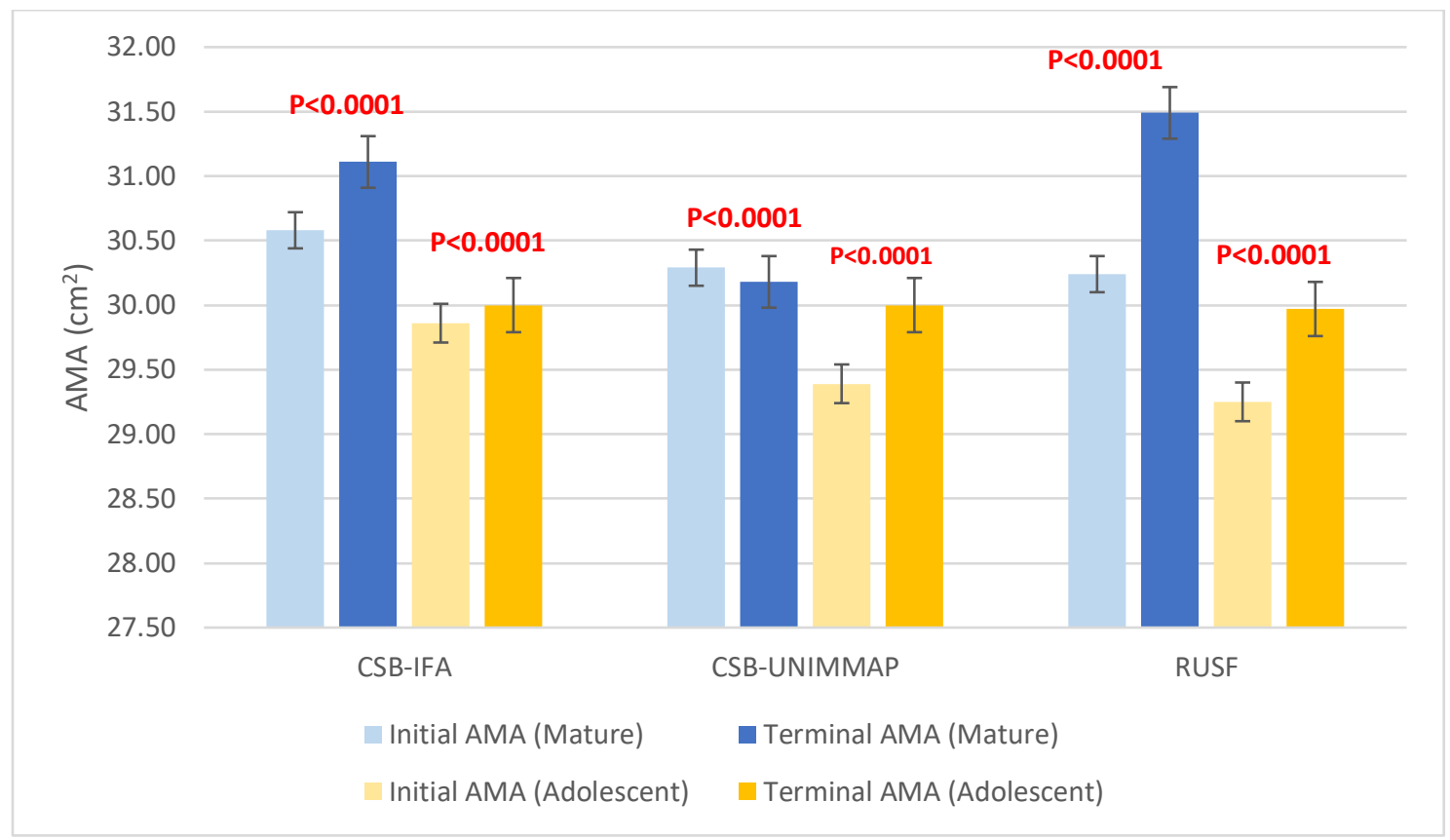

Figure 10: Initial and terminal AMA stratified by adolescence. 


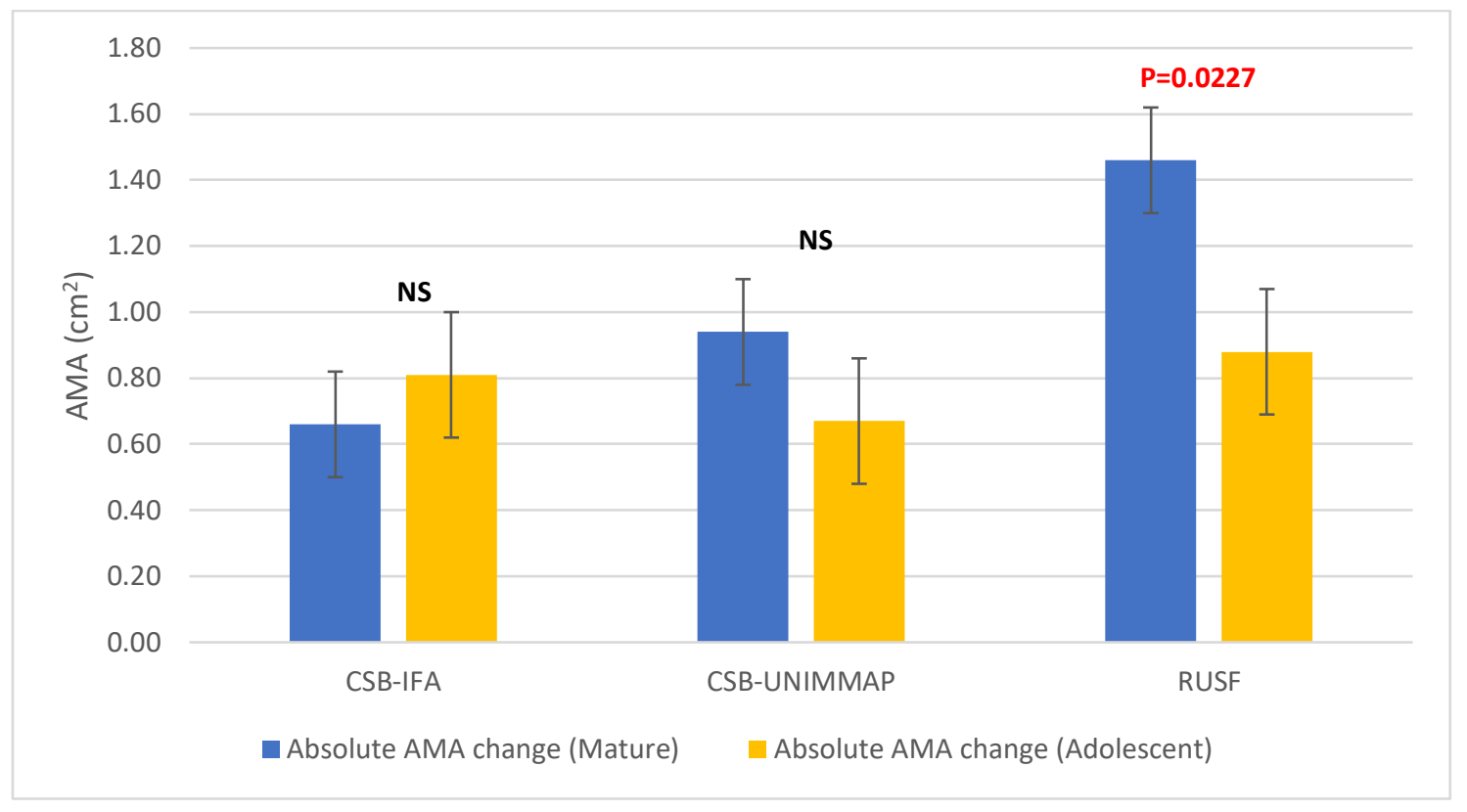

Figure 11. Absolute AMA change by age.

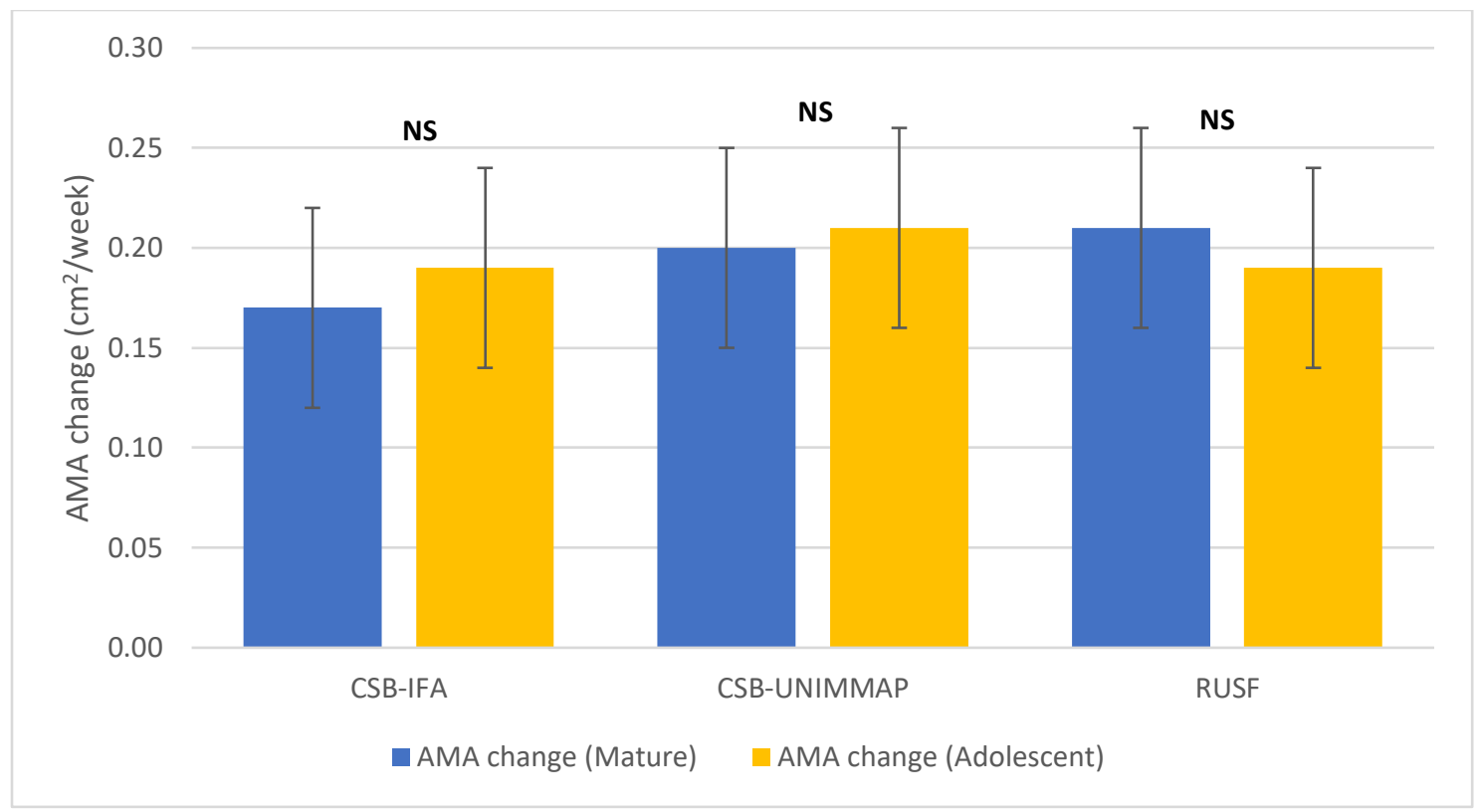

Figure 12: Weekly change in AMA by age group. 
Table 7. Initial and terminal AMA, and absolute and weekly change across interventions. Values are expressed as LS means \pm SE.

\begin{tabular}{|c|c|c|c|c|c|c|c|c|}
\hline & & CSB-IFA & $\begin{array}{l}\text { CSB- } \\
\text { UNIMMAP }\end{array}$ & RUSF & Overall & $\begin{array}{l}\text { Intervention } \\
\text { effect } P \text { - } \\
\text { value }\end{array}$ & $\begin{array}{l}\text { Time } \\
\text { effect P- } \\
\text { value }\end{array}$ & $\begin{array}{l}\text { Time*Intervention } \\
\text { effect P-value }\end{array}$ \\
\hline \multirow{2}{*}{$\begin{array}{l}\text { Initial } \\
\text { AMA, } \mathbf{c m}^{2}\end{array}$} & Raw mean $\pm \mathrm{SD}$ & $30.02 \pm 2.62$ & $29.85 \pm 2.60$ & $29.76 \pm 2.59$ & \multirow[b]{2}{*}{$29.87 \pm 2.60$} & \multirow[b]{2}{*}{0.2090} & \multirow[b]{2}{*}{ N/A } & \multirow[b]{2}{*}{ N/A } \\
\hline & $\mathrm{LS}$ mean $\pm \mathrm{SE}$ & $30.02 \pm 0.11$ & $29.85 \pm 0.11$ & $29.76 \pm 0.11$ & & & & \\
\hline \multirow{2}{*}{$\begin{array}{l}\text { Terminal } \\
\text { AMA, } \mathbf{c m}^{2}\end{array}$} & Raw mean \pm SD & $30.84 \pm 2.69$ & $30.60 \pm 2.83$ & $30.76 \pm 3.02$ & \multirow[b]{2}{*}{$30.73 \pm 2.85$} & \multirow[b]{2}{*}{0.9306} & \multirow[b]{2}{*}{$<0.0001$} & \multirow[b]{2}{*}{0.7996} \\
\hline & $\mathrm{LS}$ mean $\pm \mathrm{SE}$ & $30.62 \pm 0.16$ & $30.62 \pm 0.16$ & $30.69 \pm 0.16$ & & & & \\
\hline \multirow{2}{*}{$\begin{array}{l}\text { Absolute } \\
\text { AMA } \\
\text { change, } \text { cm }^{2}\end{array}$} & Raw mean \pm SD & $0.83 \pm 2.16$ & $0.81 \pm 2.22$ & $0.89 \pm 2.24$ & \multirow[b]{2}{*}{$0.89 \pm 2.24$} & \multirow[b]{2}{*}{0.0391} & \multirow[b]{2}{*}{0.7027} & \multirow[b]{2}{*}{0.1904} \\
\hline & $\mathrm{LS}$ mean $\pm \mathrm{SE}$ & $0.72 \pm 0.13^{\mathrm{a}}$ & $0.82 \pm 0.13^{a}$ & $1.16 \pm 0.13^{b}$ & & & & \\
\hline $\begin{array}{l}\text { Weekly } \\
\text { AMA } \\
\text { change, } \\
\text { cm²/week }^{2}\end{array}$ & Raw mean $\pm \mathrm{SD}$ & $0.18 \pm 0.77$ & $0.21 \pm 1.02$ & $0.21 \pm 0.76$ & $0.20 \pm 0.86$ & 0.8787 & N/A & N/A \\
\hline
\end{tabular}


Table 8. Initial and terminal AMA, and absolute and weekly change across interventions by age group. Values are expressed as LS means \pm SE.

\begin{tabular}{|c|c|c|c|c|c|c|c|c|c|c|c|c|}
\hline & & \multicolumn{2}{|l|}{ CSB-IFA } & \multicolumn{2}{|c|}{ CSB-UNIMMAP } & \multicolumn{2}{|l|}{ RUSF } & \multicolumn{2}{|l|}{ Overall } & \multirow{2}{*}{$\begin{array}{l}\text { Intervention } \\
\text { effect } P \text { - } \\
\text { value }\end{array}$} & \multirow{2}{*}{$\begin{array}{l}\text { Time } \\
\text { effect } \\
\text { P-value }\end{array}$} & \multirow{2}{*}{$\begin{array}{l}\text { Time*Intervention } \\
\text { effect P-value }\end{array}$} \\
\hline & & Mature & Adolescent & Mature & Adolescent & Mature & Adolescent & Mature & Adolescent & & & \\
\hline \multirow[t]{2}{*}{$\begin{array}{l}\text { Initial } \\
\text { AMA, } \mathbf{c m}^{2}\end{array}$} & $\begin{array}{l}\text { Raw } \\
\text { mean } \\
\pm \text { SD }\end{array}$ & $30.58 \pm 2.49$ & $29.36 \pm 2.61$ & $30.29 \pm 2.62$ & $29.39 \pm 2.49$ & $30.24 \pm 2.57$ & $29.25 \pm 2.52$ & $30.37 \pm 2.56$ & $29.33 \pm 2.53$ & \multirow{2}{*}{0.3304} & \multirow{2}{*}{ N/A } & \multirow{2}{*}{ N/A } \\
\hline & $\begin{array}{l}\text { LS } \\
\text { mean } \\
\pm \mathrm{SE}\end{array}$ & $30.58 \pm 0.14^{a}$ & $29.86 \pm 0.15^{b}$ & $30.29 \pm 0.15^{a}$ & $29.39 \pm 0.15^{b}$ & $30.24 \pm 0.15^{a}$ & $29.25 \pm 0.18^{b}$ & $30.37 \pm 0.08^{a}$ & $29.33 \pm 0.09^{b}$ & & & \\
\hline \multirow[t]{2}{*}{$\begin{array}{l}\text { Terminal } \\
\text { AMA, } \mathbf{c m}^{2}\end{array}$} & $\begin{array}{l}\text { Raw } \\
\text { mean } \\
\pm \text { SD }\end{array}$ & $31.29 \pm 2.69$ & $30.32 \pm 2.59$ & $31.13 \pm 2.72$ & $30.04 \pm 2.83$ & $31.48 \pm 2.98$ & $30.03 \pm 2.88$ & $31.29 \pm 2.80$ & $30.13 \pm 2.77$ & \multirow{2}{*}{0.7203} & \multirow{2}{*}{$<0.0001$} & \multirow{2}{*}{0.5839} \\
\hline & $\begin{array}{l}\text { LS } \\
\text { mean } \\
\pm \mathrm{SE}\end{array}$ & $31.11 \pm 0.20^{\mathrm{a}}$ & $30.00 \pm 0.21^{b}$ & $30.18 \pm 0.20^{a}$ & $30.00 \pm 0.21^{b}$ & $31.49 \pm 0.21^{\mathrm{a}}$ & $29.97 \pm 0.21^{b}$ & $31.25 \pm 0.12^{\mathrm{a}}$ & $29.99 \pm 0.13^{a}$ & & & \\
\hline \multirow{2}{*}{$\begin{array}{l}\text { Absolute } \\
\text { AMA } \\
\text { change, } \\
\text { cm }^{2}\end{array}$} & $\begin{array}{l}\text { Raw } \\
\text { mean } \\
\pm \text { SD }\end{array}$ & $0.72 \pm 2.13$ & $0.95 \pm 2.19$ & $0.91 \pm 2.30$ & $0.69 \pm 2.11$ & $1.25 \pm 2.27$ & $0.80 \pm 2.40$ & $0.96 \pm 2.25$ & $0.81 \pm 2.24$ & \multirow{2}{*}{0.0345} & \multirow{2}{*}{0.8903} & \multirow{2}{*}{0.1200} \\
\hline & $\begin{array}{l}\text { LS } \\
\text { mean } \\
\pm \text { SE }\end{array}$ & $0.66 \pm 0.16^{a}$ & $0.81 \pm 0.19^{a}$ & $0.94 \pm 0.16^{a}$ & $0.67 \pm 0.17^{a}$ & $1.46 \pm 0.17^{b}$ & $0.88 \pm 0.17^{a}$ & $1.02 \pm 0.10^{\mathrm{a}}$ & $0.79 \pm 0.11^{a}$ & & & \\
\hline \multirow{2}{*}{$\begin{array}{l}\text { Weekly } \\
\text { AMA } \\
\text { change, } \\
\text { cm²/week }^{2}\end{array}$} & $\begin{array}{l}\text { Raw } \\
\text { mean } \\
\pm \text { SD }\end{array}$ & $0.17 \pm 0.81$ & $0.19 \pm 0.72$ & $0.20 \pm 0.76$ & $0.21 \pm 1.24$ & $0.22 \pm 0.69$ & $0.19 \pm 0.83$ & $0.20 \pm 0.76$ & $0.20 \pm 0.96$ & \multirow{2}{*}{0.8914} & \multirow{2}{*}{ N/A } & \multirow{2}{*}{ N/A } \\
\hline & $\begin{array}{l}\mathrm{LS} \\
\text { mean } \\
\pm \mathrm{SE}\end{array}$ & $0.17 \pm 0.05^{\mathrm{a}}$ & $0.19 \pm 0.06^{\mathrm{a}}$ & $0.20 \pm 0.05^{\mathrm{a}}$ & $0.21 \pm 0.05^{\mathrm{a}}$ & $0.21 \pm 0.05^{\mathrm{a}}$ & $0.19 \pm 0.05^{\mathrm{a}}$ & $0.20 \pm 0.03^{a}$ & $0.20 \pm 0.03^{a}$ & & & \\
\hline
\end{tabular}




\subsubsection{AMA by age}

When separated by age, average initial AMA in mature women was $30.37 \pm 2.56$ $\mathrm{cm}^{2}$ and $29.33 \pm 2.54 \mathrm{~cm}^{2}$ for adolescents, not different across interventions $(\mathrm{P}=0.3304)$, as seen in Table 8. Compared to the overall mean, adolescents had a $0.52 \mathrm{~cm}^{2}$ smaller initial AMA, 95\% CI [-0.64, -0.4] (P < 0.0001).

When accounting for age as a whole group, terminal AMA differed by age and time, with no difference across interventions. Every week on treatment resulted in a 0.08 $\mathrm{cm}^{2}$ smaller terminal AMA, 95\% CI $[-0.11,-0.06](\mathrm{P}<0.0001)$. Compared to the overall mean, adolescents had a $0.64 \mathrm{~cm}^{2}$ smaller terminal AMA, 95\% CI $[0.46,0.81](\mathrm{P}<$ 0.0001). There was no difference in intervention effect when stratified by age $(\mathrm{P}=0.3379$ and 0.3828 for mature women and adolescents, respectively). Terminal AMA was larger than initial AMA in all groups, as seen in as seen in Figure 10.

When accounting for age as a whole group, intervention has a significant effect on absolute AMA change $(\mathrm{P}=0.0345)$. Compared to the overall mean, women in the RUSF group had a $0.27 \mathrm{~cm}^{2}$ larger AMA increase, 95\% CI [0.06, 0.47] $(\mathrm{P}=0.0101)$. The effect of intervention also differs by age group $(\mathrm{P}=0.0219)$. Compared to the overall mean, adolescents in CSB-IFA had a $0.20 \mathrm{~cm}^{2}$ larger increase in AMA while adolescents in RUSF had a $0.17 \mathrm{~cm}^{2}$ larger AMA increase, $95 \%$ CI [0.044, 0.35], [-0.33, -0.02] $(\mathrm{P}=$ 0.0117 and 0.0246 , respectively). When grouped by interventions, mature women in RUSF had a significantly larger AMA increase compared to adolescents as seen in Figure $11(P=0.0227)$. There was no difference between mean AMA change in mature women and adolescents in CSB-IFA and CSB-UNIMMAP. When stratified by age group, there was no intervention effect in adolescents $(\mathrm{P}=0.3903)$. However, in mature women, absolute change in AMA differed by intervention $(P=0.0167)$. Compared to the 
mean for mature women, mature women in CSB-IFA had a $0.24 \mathrm{~cm}^{2}$ smaller AMA change and mature women in RUSF had a $0.29 \mathrm{~cm}^{2}$ larger AMA increase, $95 \%$ CI [-0.45, -0.03], $[0.08,0.50](\mathrm{P}=0.0242$ and 0.0080 , respectively). In a pairwise comparison, the mean absolute AMA change in mature women in CSB-IFA was significantly different from mature women in RUSF, 95\% CI [-0.97, -0.09] $(\mathrm{P}=0.0128)$.

There was no effect of intervention or age on weekly AMA change $(\mathrm{P}=0.8914$ and 9693, respectively). There was no difference between mature and adolescent women in any of the intervention groups, as seen in Figure $12(\mathrm{P}=0.7567,0.9050$, and 0.6918 for CSB-IFA, CSB-UNIMMAP, and RUSF, respectively).

\subsubsection{AMA by Seasonality}

When seasonality is included in the model, there was a significant effect on terminal AMA. Compared to the overall mean, women whose births occurred during the rainy season had a $0.44 \mathrm{~cm}^{2}$ smaller terminal AMA, 95\% CI $[-0.57,-0.30](\mathrm{P}<0.0001)$. In a pairwise comparison, women whose birth occurred during the rainy season had a $0.87 \mathrm{~cm}^{2}(2.8 \%)$ smaller terminal AMA than those in the dry season $\left(30.11 \mathrm{~cm}^{2} \mathrm{vs}\right.$. $\left.30.99 \mathrm{~cm}^{2}\right), 95 \%$ CI $[0.59,1.15](\mathrm{P}<0.0001)$. There were no interactions of seasonality and intervention or age on terminal AMA $(\mathrm{P}=0.9892$ and 0.3547 , respectively).

Seasonality also had a significant effect on the absolute increase in AMA ( $\mathrm{P}=$ 0.0099). Compared to the overall mean, women whose births occurred during the rainy season had a $0.15 \mathrm{~cm}^{2}$ smaller increase in AMA, 95\% CI [-0.26, -0.04]. In a pairwise comparison, women whose births occurred during the rainy season had a $0.30 \mathrm{~cm}^{2}$ smaller increase in AMA compared to during the dry season $\left(0.77 \mathrm{~cm}^{2}\right.$ vs. $1.07 \mathrm{~cm}^{2}$, respectively), 95\% CI $[0.07,0.53](\mathrm{P}=0.0095)$. There were no interactions of seasonality 
and intervention or age on absolute change in AMA $(\mathrm{P}=0.2096$ and 0.8371 ,

respectively) and no effect on weekly AMA change $(\mathrm{P}=0.3229)$.

When analyzed as a longitudinal mixed model, there was strong evidence for a linear change over time. Each week closer to delivery is associated with $0.095 \mathrm{~cm}^{2}$ increase in AMA, 95\% CI [ 0.08, 0.11] (P < 0.0001). Change in AMA also differed by intervention $(\mathrm{P}=0.0008)$. Compared to the overall mean, women in CSB-IFA had 0.15 $\mathrm{cm}^{2}$ larger AMA, while women in CSB-UNIMMAP had $0.22 \mathrm{~cm}^{2}$ smaller measurements, 95\% CI $[0.03,0.27],[-0.34,-0.11](\mathrm{P}=0.0109$ and 0.0002 , respectively). In a pairwise comparison, Women in CSB-UNIMMAP had signficantly smaller changes in AMA over time compared to women in CSB-IFA and RUSF $(\mathrm{P}=0.0009$ and 0.0132 , respectively.

\subsubsection{TSF}

Terminal TSF for all women was $8.88 \pm 2.19 \mathrm{~mm}$, as shown in Table 9. Initial and terminal TSF were not different across intervention groups $(\mathrm{P}=0.2505$ and 0.3412 , respectively). However, terminal TSF was significantly lower than initial TSF in all intervention groups, as seen in Figure 13.

The absolute change in TSF over the course of enrollment was negative across all groups, with no difference between groups $(P=0.6410)$. Absolute change was significantly affected by time, with significant evidence for both a linear and curved quadratic pattern $(\mathrm{P}<0.0001$ and 0.0135 , respectively). Each week of treatment was associated with a $0.09 \mathrm{~mm}$ smaller change in TSF, 95\% CI [-0.11, -0.07] (P < 0.0001). This pattern did not differ by intervention group $(\mathrm{P}=0.2363)$.

Weekly change in TSF did not differ by intervention group $(\mathrm{P}=0.9165)$. 


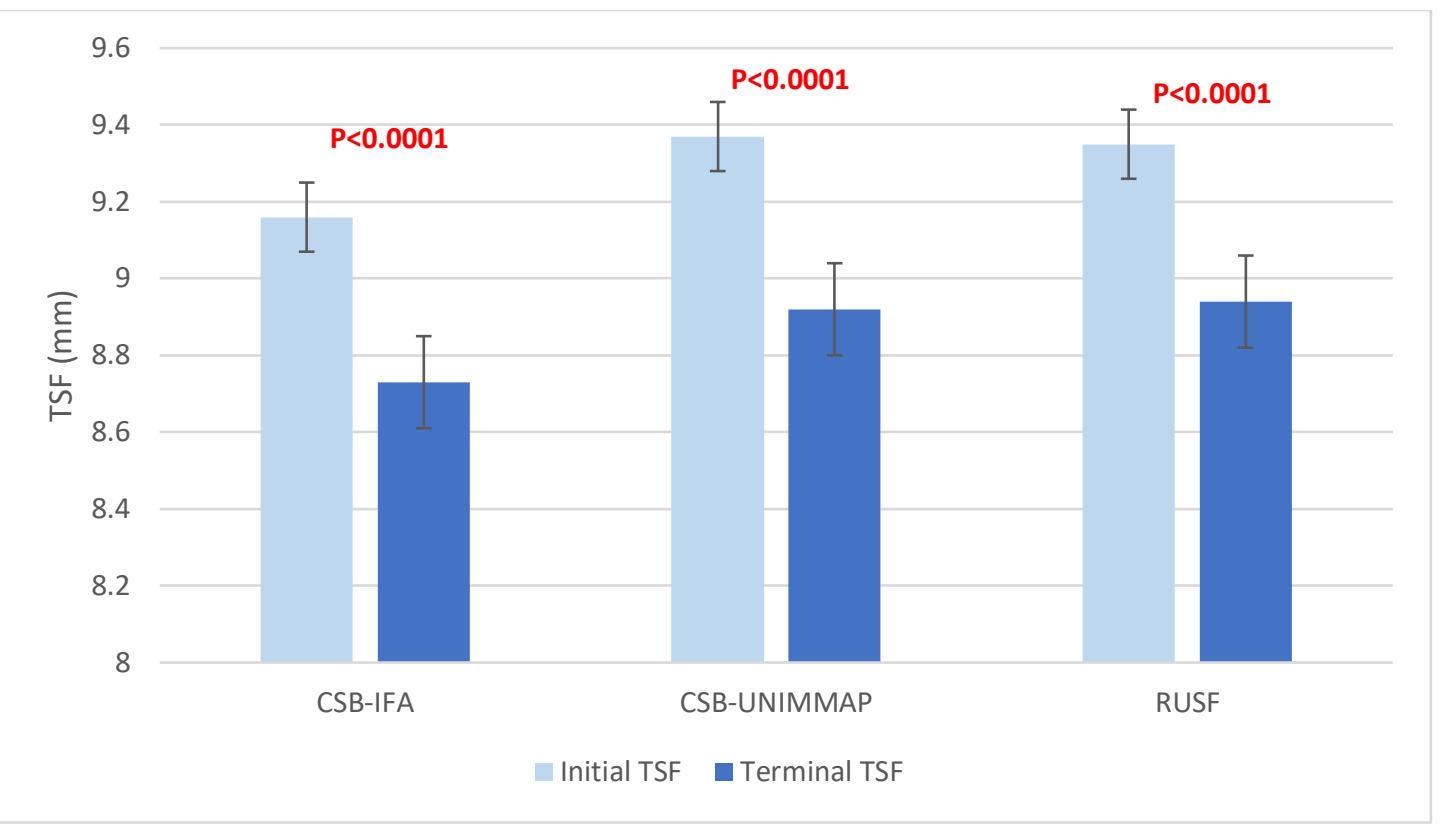

Figure 13. Initial and terminal values of TSF in each intervention group.

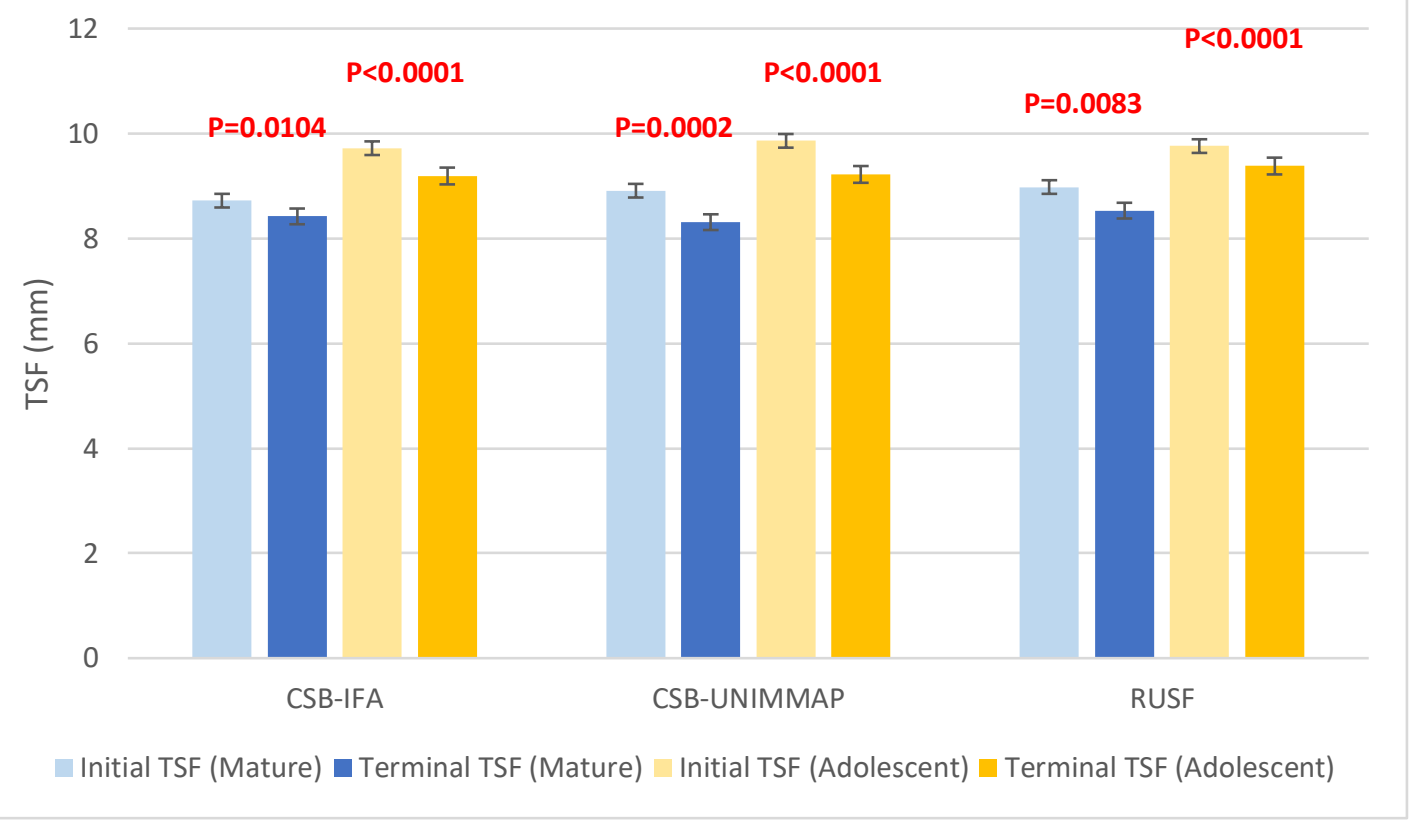

Figure 14. Initial and terminal TSF values in each intervention group separated by age. 


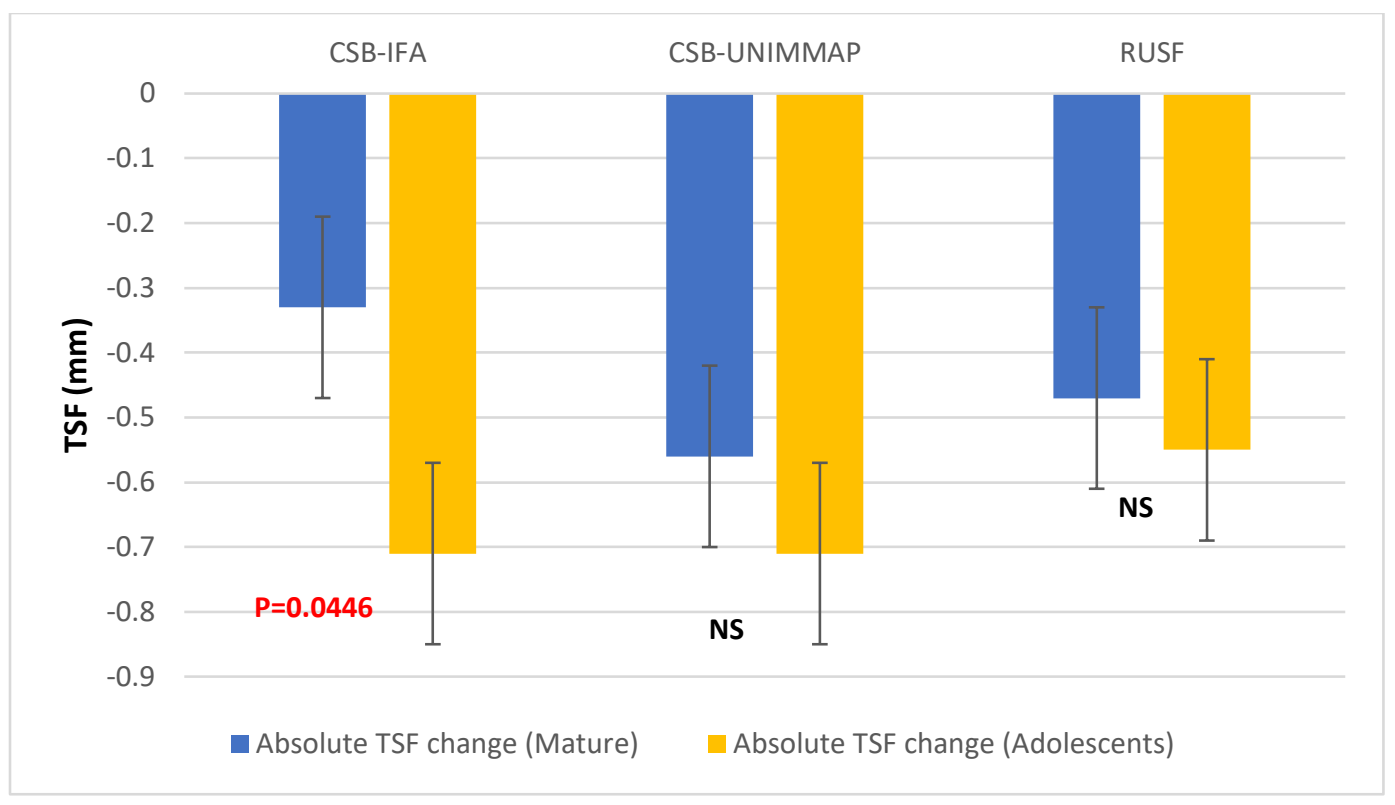

Figure 15. Absolute TSF change by age

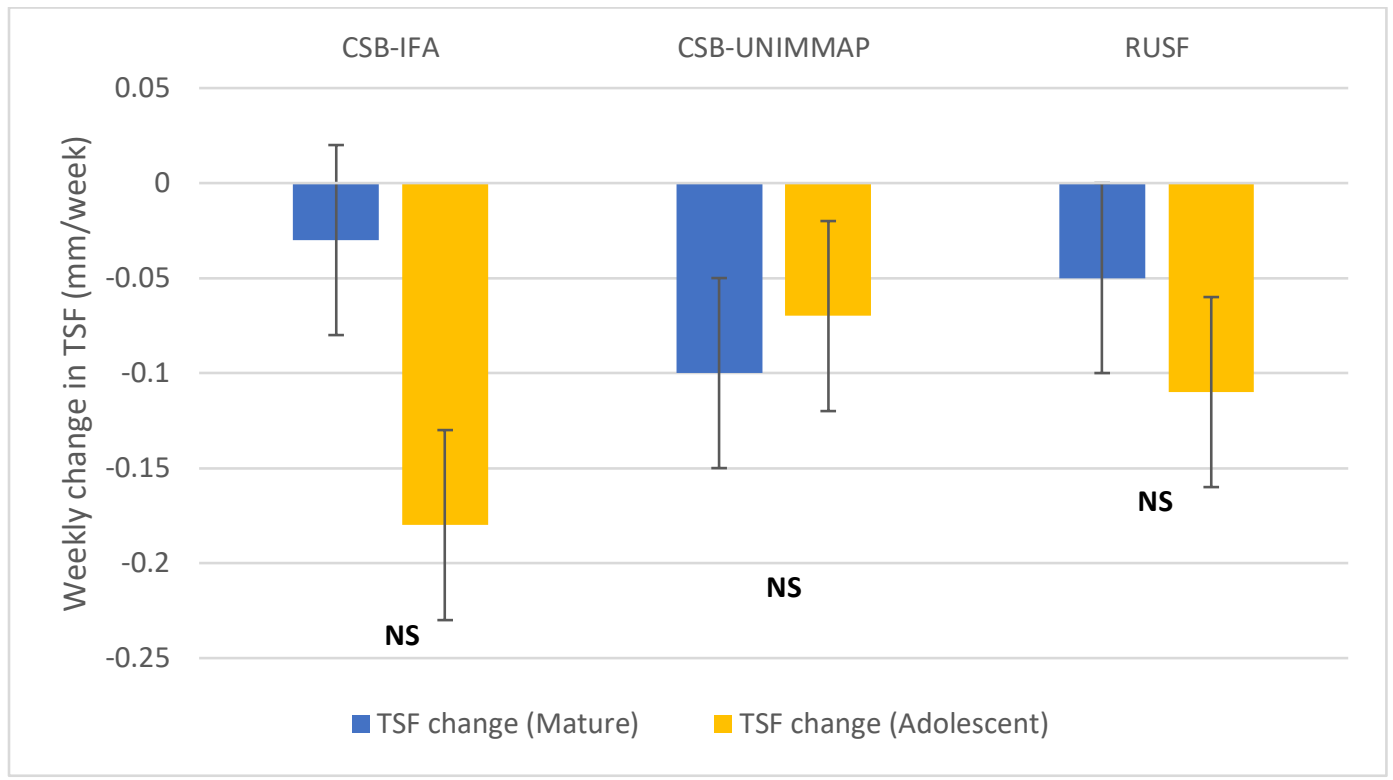

Figure 16 . Weekly TSF change by age. 
Table 9. Initial and final TSF, and absolute and weekly change. Raw means \pm SD are in the top row and LS means \pm SE are in the bottom row for each

\begin{tabular}{|c|c|c|c|c|c|c|c|c|}
\hline & & CSB-IFA & $\begin{array}{l}\text { CSB- } \\
\text { UNIMMAP }\end{array}$ & RUSF & Overall & $\begin{array}{l}\text { Intervention } \\
\text { effect } P \text { - } \\
\text { value }\end{array}$ & $\begin{array}{l}\text { Time } \\
\text { effect P- } \\
\text { value }\end{array}$ & $\begin{array}{l}\text { Time*Intervention } \\
\text { effect } P \text {-value }\end{array}$ \\
\hline $\begin{array}{l}\text { Initial TSF, } \\
\text { mm }\end{array}$ & $\begin{array}{l}\text { Raw mean } \pm \mathrm{SD} \\
\mathrm{LS} \text { mean } \pm \mathrm{SE}\end{array}$ & $\begin{array}{l}9.18 \pm 2.28 \\
\mathbf{9 . 1 8} \pm \mathbf{0 . 0 9}\end{array}$ & $\begin{array}{l}9.38 \pm 2.30 \\
\mathbf{9 . 3 8} \pm \mathbf{0 . 0 9}\end{array}$ & $\begin{array}{l}9.36 \pm 2.28 \\
\mathbf{9 . 3 6} \pm \mathbf{0 . 0 9}\end{array}$ & $9.31 \pm 2.28$ & 0.2505 & N/A & N/A \\
\hline $\begin{array}{l}\text { Terminal } \\
\text { TSF, mm }\end{array}$ & $\begin{array}{l}\text { Raw mean } \pm \mathrm{SD} \\
\mathrm{LS} \text { mean } \pm \mathrm{SE}\end{array}$ & $\begin{array}{l}8.75 \pm 2.12 \\
8.76 \pm 0.12\end{array}$ & $\begin{array}{l}8.92 \pm 2.15 \\
8.75 \pm 0.12\end{array}$ & $\begin{array}{l}8.96 \pm 2.27 \\
8.97 \pm 0.12\end{array}$ & $8.88 \pm 2.19$ & 0.3412 & $<0.0001$ & 0.3997 \\
\hline $\begin{array}{l}\text { Absolute } \\
\text { TSF } \\
\text { change, mm }\end{array}$ & $\begin{array}{l}\text { Raw mean } \pm \mathrm{SD} \\
\mathrm{LS} \text { mean } \pm \mathrm{SE}\end{array}$ & $\begin{array}{l}-0.42 \pm 1.91 \\
\mathbf{- 0 . 5} \pm \mathbf{0 . 1 1}\end{array}$ & $\begin{array}{l}-0.50 \pm 2.02 \\
\mathbf{- 0 . 6 3} \pm \mathbf{0 . 1 1}\end{array}$ & $\begin{array}{l}-0.40 \pm 1.93 \\
\mathbf{- 0 . 5 2} \pm \mathbf{0 . 1 1}\end{array}$ & $-0.44 \pm 1.95$ & 0.6410 & $<0.0001$ & 0.4426 \\
\hline $\begin{array}{l}\text { Weekly TSF } \\
\text { change } \\
(\mathrm{mm} / \text { week })\end{array}$ & $\begin{array}{l}\text { Raw mean } \pm \mathrm{SD} \\
\mathrm{LS} \text { mean } \pm \mathrm{SE}\end{array}$ & $\begin{array}{l}-0.10 \pm 0.10 \\
\mathbf{- 0 . 1 0} \pm \mathbf{0 . 0 3}\end{array}$ & $\begin{array}{l}-0.08 \pm 0.78 \\
\mathbf{- 0 . 0 8} \pm \mathbf{0 . 0 3}\end{array}$ & $\begin{array}{l}-0.08 \pm 0.52 \\
\mathbf{- 0 . 0 8} \pm \mathbf{0 . 0 3}\end{array}$ & $-0.09 \pm 0.79$ & 0.9165 & N/A & N/A \\
\hline
\end{tabular}


Table 10. Mean initial and final TSF values, and absolute and weekly changes separated by age groups. Values expressed as LS means \pm SE.

\begin{tabular}{|c|c|c|c|c|c|c|c|c|c|c|c|c|}
\hline & & CSB-IFA & & CSB-UNIN & MAP & RUSF & & Overall & & $\begin{array}{l}\text { Intervention } \\
\text { effect } P \text { - } \\
\text { value }\end{array}$ & $\begin{array}{l}\text { Time } \\
\text { effect } \\
\text { P-value }\end{array}$ & $\begin{array}{l}\text { Time*Intervention } \\
\text { effect } P \text {-value }\end{array}$ \\
\hline & & Mature & Adolescent & Mature & Adolescent & Mature & Adolescent & Mature & Adolescent & & & \\
\hline \multirow[t]{2}{*}{$\begin{array}{l}\text { Initial TSF } \\
(\mathrm{mm})\end{array}$} & $\begin{array}{l}\text { Raw mean } \\
\pm \mathrm{SD}\end{array}$ & $8.72 \pm 2.25$ & $9.71 \pm 2.19$ & $8.91 \pm 2.34$ & $9.86 \pm 2.16$ & $8.98 \pm 2.32$ & $9.76 \pm 2.17$ & $8.87 \pm 2.30$ & $9.78 \pm 2.17$ & \multirow{2}{*}{0.3692} & \multirow{2}{*}{ N/A } & \multirow{2}{*}{ N/A } \\
\hline & $\begin{array}{l}\text { LS mean } \pm \\
\text { SE }\end{array}$ & $8.72 \pm 0.13$ & $9.72 \pm 0.13$ & $8.91 \pm 0.13$ & $9.86 \pm 0.13$ & $8.98 \pm 0.13$ & $9.76 \pm 0.13$ & $8.87 \pm 0.07^{a}$ & $9.78 \pm 0.07^{b}$ & & & \\
\hline \multirow[t]{2}{*}{$\begin{array}{l}\text { Terminal } \\
\text { TSF (mm) }\end{array}$} & $\begin{array}{l}\text { Raw mean } \\
\pm \mathrm{SD}\end{array}$ & $8.43 \pm 2.24$ & $9.13 \pm 1.93$ & $8.53 \pm 2.15$ & $9.34 \pm 2.08$ & $8.65 \pm 2.31$ & $9.27 \pm 2.18$ & $8.53 \pm 2.23$ & $9.25 \pm 2.07$ & \multirow{2}{*}{0.5092} & \multirow{2}{*}{$<0.0001$} & \multirow{2}{*}{0.2157} \\
\hline & $\begin{array}{l}\text { LS mean } \pm \\
\text { SE }\end{array}$ & $8.42 \pm 0.15^{\mathrm{a}}$ & $9.19 \pm 0.16^{b}$ & $8.31 \pm 0.15^{a}$ & $9.22 \pm 0.16^{b}$ & $8.53 \pm 0.16^{a}$ & $9.38 \pm 0.18^{b}$ & $8.42 \pm 0.09^{a}$ & $9.26 \pm 0.10^{b}$ & & & \\
\hline \multirow{2}{*}{$\begin{array}{l}\text { Absolute } \\
\text { TSF } \\
\text { change } \\
(\mathrm{mm})\end{array}$} & $\begin{array}{l}\text { Raw mean } \\
\pm \mathrm{SD}\end{array}$ & $-0.27 \pm 1.80$ & $-0.60 \pm 2.04$ & $-0.45 \pm 2.00$ & $-0.57 \pm 2.05$ & $-0.31 \pm 1.98$ & $-0.48 \pm 1.90$ & $-0.34 \pm 1.93$ & $-0.54 \pm 1.99$ & \multirow{2}{*}{0.6069} & \multirow{2}{*}{$<0.0001$} & \multirow{2}{*}{0.3714} \\
\hline & $\begin{array}{l}\text { LS mean } \pm \\
\text { SE }\end{array}$ & $-0.33 \pm 0.14^{a}$ & $-0.71 \pm 0.15^{b}$ & $-0.56 \pm 0.14^{a}$ & $-0.71 \pm 0.14^{a}$ & $-0.47 \pm 0.14^{a}$ & $-0.55 \pm 0.14^{a}$ & $-0.45 \pm 0.09^{a}$ & $-0.66 \pm 0.09^{a}$ & & & \\
\hline \multirow{2}{*}{$\begin{array}{l}\text { Weekly } \\
\text { TSF } \\
\text { change } \\
\text { (mm/week) }\end{array}$} & $\begin{array}{l}\text { Raw mean } \\
\pm \text { SD }\end{array}$ & $-0.03 \pm 0.91$ & $-0.18 \pm 1.09$ & $-0.10 \pm 0.55$ & $-0.07 \pm 0.98$ & $-0.05 \pm 0.45$ & $-0.11 \pm 0.59$ & $-0.06 \pm 0.67$ & $-0.12 \pm 0.91$ & \multirow{2}{*}{0.8744} & \multirow{2}{*}{ N/A } & \multirow[b]{2}{*}{ N/A } \\
\hline & $\begin{array}{l}\text { LS mean } \pm \\
\text { SE }\end{array}$ & $-0.03 \pm 0.05^{a}$ & $-0.18 \pm 0.05^{a}$ & $-0.10 \pm 0.05^{\mathrm{a}}$ & $-0.07 \pm 0.05^{a}$ & $-0.05 \pm 0.05^{a}$ & $-0.11 \pm 0.05^{a}$ & $-0.06 \pm 0.03^{a}$ & $-0.12 \pm 0.03^{a}$ & & & \\
\hline
\end{tabular}




\subsubsection{TSF by age}

Initial TSF was $8.87 \pm 0.07 \mathrm{~mm}$ and $9.78 \pm 0.07 \mathrm{~mm}$ for mature women and adolescents, respectively, significantly greater in adolescents $(\mathrm{P}<0.0001)$. This did not differ by intervention, as seen in Table $10(\mathrm{P}=0.3692)$. After adjustment for age, terminal TSF was not significantly different across interventions, as seen in Table $\mathbf{1 0}(\mathrm{P}$ $=0.5092)$. Weeks on treatment significantly predicted terminal TSF; each week of treatment resulted in a $0.10 \mathrm{~mm}$ lower terminal TSF, 95\% CI $[-0.12,-0.07](\mathrm{P}<0.0001)$. Terminal TSF also significantly differed by age group ( $\mathrm{P}<0.0001)$. Compared to the overall mean, adolescents overall had $0.42 \mathrm{~mm}$ smaller terminal TSF, 95\% CI [0.28, 0.56]. Terminal TSF was lower than initial TSF in all age groups and interventions, shown in Figure 14. There was no difference in intervention effect on terminal TSF when stratified into age groups and analyzed separately $(\mathrm{P}=0.5129$ and 0.4594 for mature women and adolescents, respectively).

Age had no effect on the overall absolute change in TSF when analyzed as a whole group $(\mathrm{P}=0.1064)$. There was evidence for a quadratic curve in absolute TSF change with increasing number of weeks on treatment, consistent across all intervention groups $(\mathrm{P}=0.0097)$. There was no difference across intervention groups in absolute change in TSF when stratified by adolescence $(\mathrm{P}=0.5075$ and 0.7792 for mature women and adolescents, respectively). TSF loss was significantly greater in adolescents when compared to mature women in CSB-IFA, as seen in Figure $15(\mathrm{P}=0.0446)$.

Weekly change in TSF was negative in all groups $(\mathrm{P}=0.8744)$. Weekly change was also not significantly different between mature and adolescent women when analyzed within interventions, shown in Figure $16(P=0.0734,0.5904$, and 0.2527 for 
CSB-IFA, CSB-UNIMMAP, and RUSF, respectively). When stratified into age groups, there is no significant difference in weekly change across interventions.

\subsubsection{TSF by Seasonality}

When seasonality is included in the model, there is no effect of seasonality on terminal TSF $(\mathrm{P}=0.4708)$. However, there is a significant effect of seasonality on loss in TSF ( $\mathrm{P}<0.0001)$. Compared to the overall mean, women whose births occurred during the rainy season had a $0.28 \mathrm{~mm}$ larger loss in TSF, 95\% CI $[-0.38,-0.18](\mathrm{P}<0.0001)$. In a pairwise comparison, women whose births occurred during the rainy season had a 0.57 $\mathrm{mm}$ larger loss in TSF compared to during the dry season $(-0.94 \mathrm{~mm}$ vs. $-0.37 \mathrm{~mm}$, respectively), $95 \% \mathrm{CI}[0.37,0.76](\mathrm{P}<0.0001)$. There was no interaction of seasonality with intervention or age on loss in TSF ( $\mathrm{P}=0.5919$ and 0.6367 , respectively), and no effect on weekly change $(\mathrm{P}=0.1234)$.

When analyzed as a longitudinal mixed model, TSF significantly changed over time, with strong evidence for both a linear and curved quadratic relationship $(\mathrm{P}<0.0001$ and 0.0003, respectively). For every week approaching delivery, women experienced a 0.07 $\mathrm{mm}$ decrease in TSF, 95\% CI [-0.08, -0.06] $(\mathrm{P}<0.0001)$.

\subsubsection{AFA}

Terminal AFA was lower than initial AFA on average $\left(9.34 \pm 2.31 \mathrm{~cm}^{2}\right.$ vs $9.66 \pm 2.66 \mathrm{~cm}^{2}$, respectively) as seen in Table 11. Initial AFA and terminal AFA did not differ across groups $(\mathrm{P}=0.2724$ and 0.2633 , respectively), but terminal AFA was significantly lower than initial AFA in all groups, as seen in Figure 17. There was a significant linear effect of time; every week on treatment was associated with a $0.11 \mathrm{~cm}^{2}$ 
smaller terminal AFA than the overall average both when analyzed as a whole group, 95\% CI [-0.14, -0.09] $(\mathrm{P}<0.0001)$.

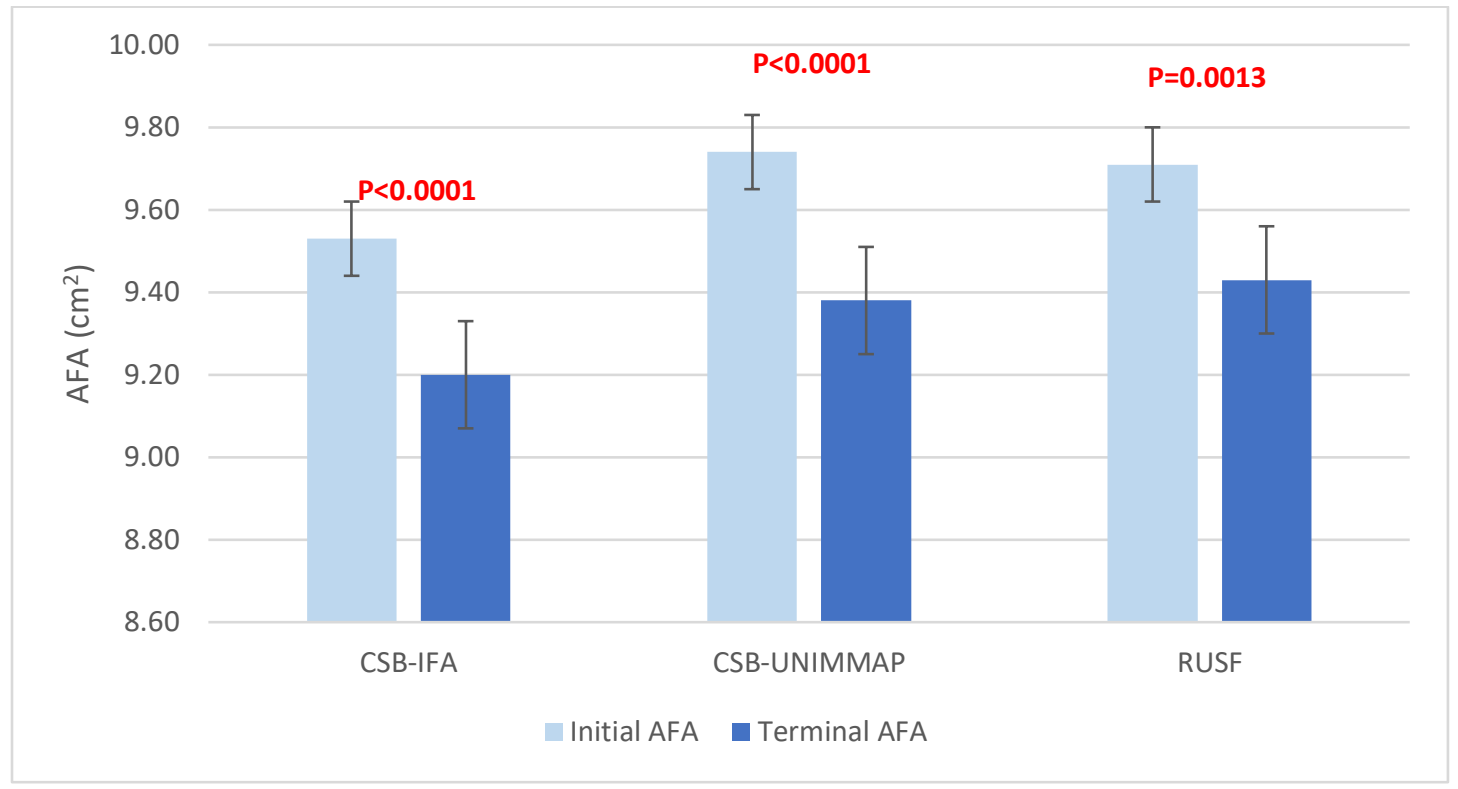

Figure 17: Initial and terminal AFA across interventions

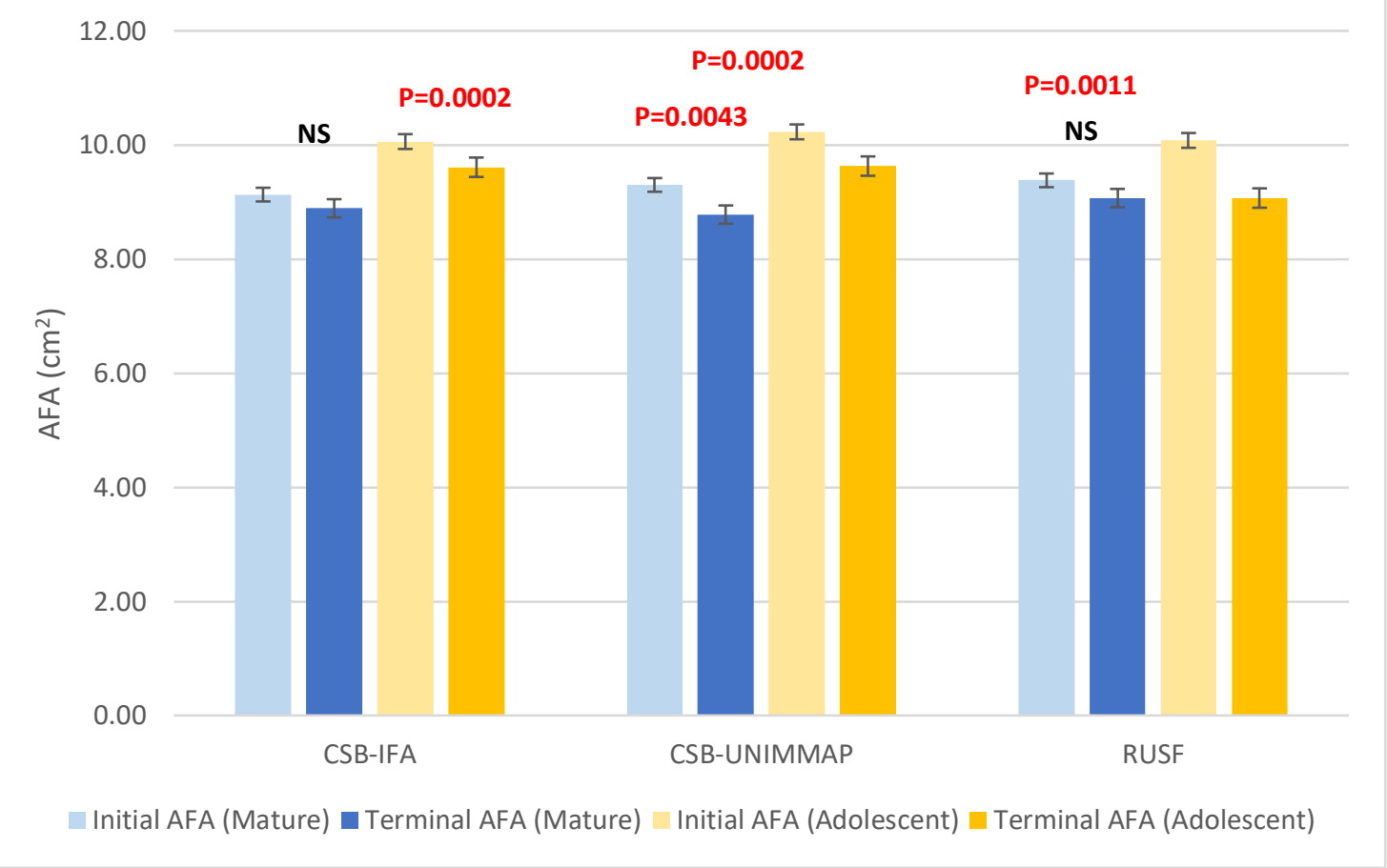

Figure 18: Initial and terminal AFA stratified by adolescence. 


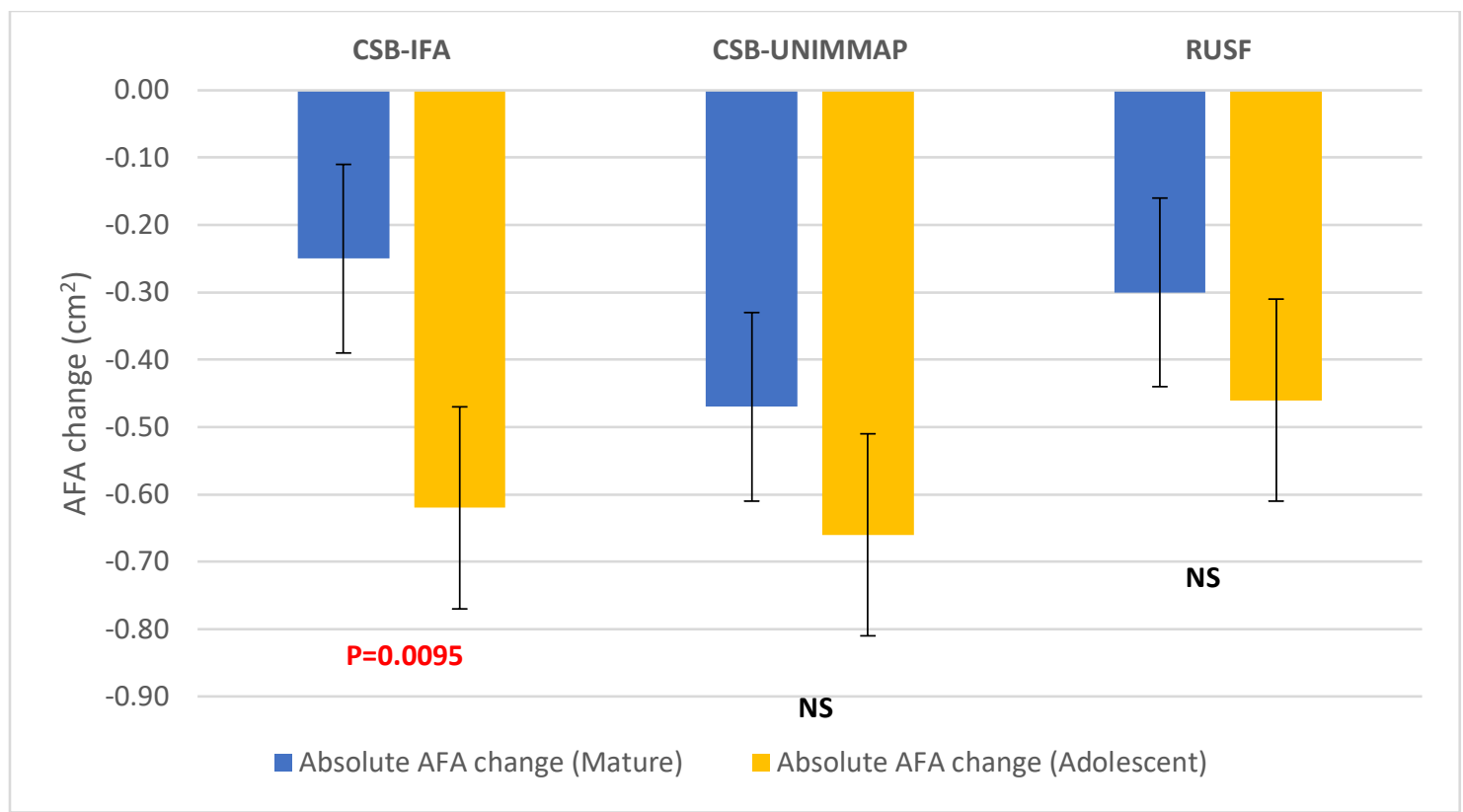

Figure 19. Absolute change in AFA by age.

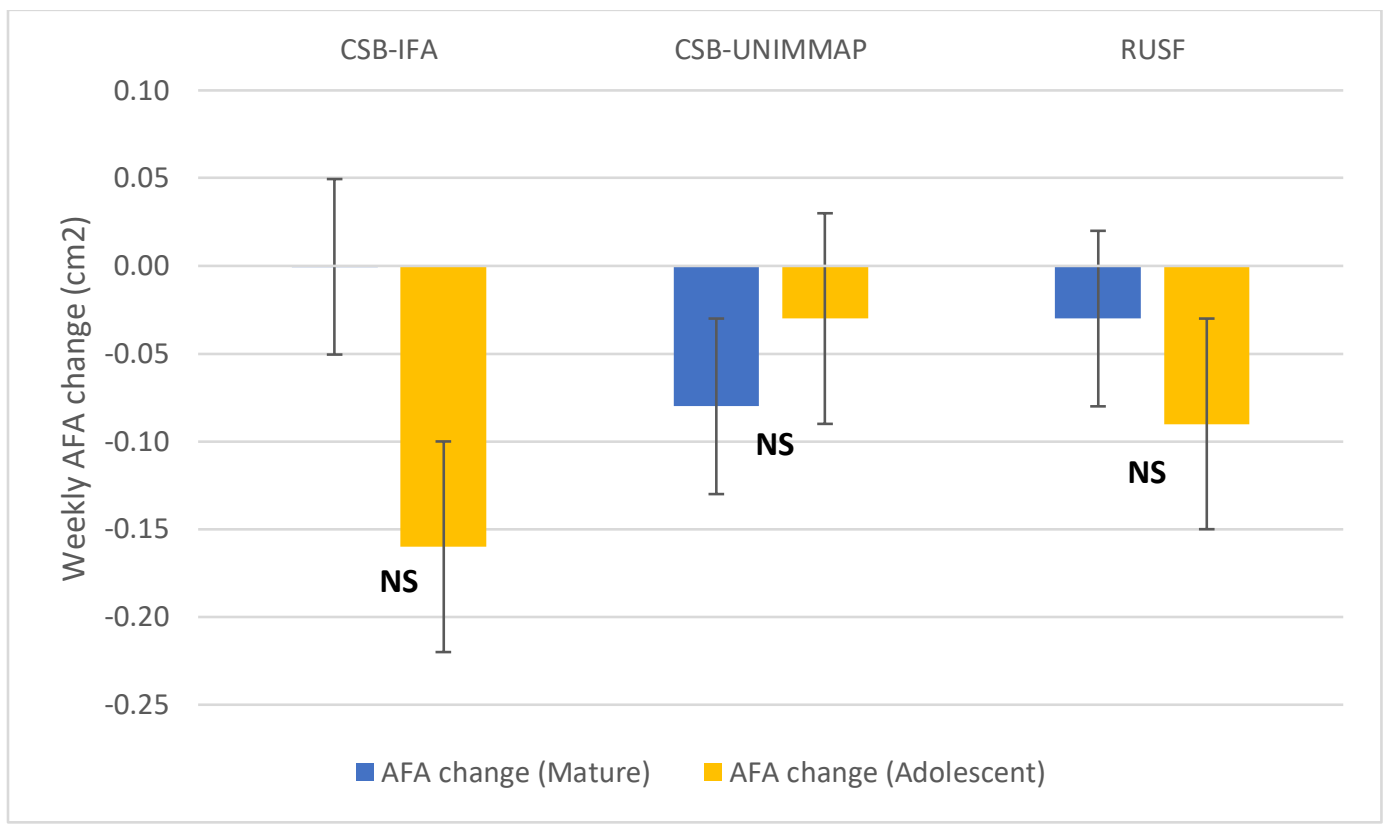

Figure 20: Weekly change in AFA by adolescence. 
Table 11. Initial and final AFA, and absolute and weekly change.

\begin{tabular}{|c|c|c|c|c|c|c|c|c|}
\hline & & CSB-IFA & $\begin{array}{l}\text { CSB- } \\
\text { UNIMMAP }\end{array}$ & RUSF & Overall & $\begin{array}{l}\text { Intervention } \\
\text { effect } P \text { - } \\
\text { value }\end{array}$ & $\begin{array}{l}\text { Time } \\
\text { effect P- } \\
\text { value }\end{array}$ & $\begin{array}{l}\text { Time*Intervention } \\
\text { effect P-value }\end{array}$ \\
\hline \multirow{2}{*}{$\begin{array}{l}\text { Initial AFA, } \\
\mathrm{cm}^{2}\end{array}$} & Raw mean $\pm \mathrm{SD}$ & $9.53 \pm 2.24$ & $9.74 \pm 2.27$ & $9.71 \pm 2.25$ & \multirow[b]{2}{*}{$9.66 \pm 2.26$} & \multirow[b]{2}{*}{0.2724} & \multirow[b]{2}{*}{ N/A } & \multirow[b]{2}{*}{ N/A } \\
\hline & $\mathrm{LS}$ mean $\pm \mathrm{SE}$ & $9.55 \pm-0.09$ & $9.75 \pm 0.09$ & $9.72 \pm 0.09$ & & & & \\
\hline \multirow[b]{2}{*}{$\begin{array}{l}\text { Terminal } \\
\text { AFA, } \mathbf{c m}^{2}\end{array}$} & Raw mean $\pm \mathrm{SD}$ & $9.20 \pm 2.26$ & $9.38 \pm 2.27$ & $9.43 \pm 2.4$ & \multirow[b]{2}{*}{$9.34 \pm 2.31$} & \multirow[b]{2}{*}{0.2633} & \multirow[b]{2}{*}{$<0.0001$} & \multirow[b]{2}{*}{0.3885} \\
\hline & $\mathrm{LS}$ mean $\pm \mathrm{SE}$ & $9.20 \pm 0.13$ & $9.19 \pm 0.12$ & $9.45 \pm 0.13$ & & & & \\
\hline \multirow[b]{2}{*}{$\begin{array}{l}\text { Absolute AFA } \\
\text { change, } \mathbf{c m}^{2}\end{array}$} & Raw mean $\pm \mathrm{SD}$ & $-0.33 \pm 1.96$ & $-0.41 \pm 2.11$ & $-0.27 \pm 2.04$ & \multirow[b]{2}{*}{$-0.38 \pm 2.04$} & \multirow[b]{2}{*}{0.4801} & \multirow[b]{2}{*}{$<0.0001$} & \multirow[b]{2}{*}{0.4383} \\
\hline & $\mathrm{LS}$ mean $\pm \mathrm{SE}$ & $-0.42 \pm 0.11$ & $-0.56 \pm 0.11$ & $-0.38 \pm 0.11$ & & & & \\
\hline $\begin{array}{l}\text { Weekly AFA } \\
\text { change, } \\
\mathrm{cm}^{2} / \text { week }\end{array}$ & Raw mean $\pm S D$ & $-0.08 \pm 0.04$ & $-0.06 \pm 0.04$ & $-0.06 \pm 0.04$ & $-0.06 \pm 0.90$ & 0.1228 & N/A & $\mathrm{N} / \mathrm{A}$ \\
\hline
\end{tabular}


Table 12. Mean initial and final AFA values, and absolute and weekly changes separated by age groups

\begin{tabular}{|c|c|c|c|c|c|c|c|c|c|c|c|c|}
\hline & & \multicolumn{2}{|l|}{ CSB-IFA } & \multicolumn{2}{|c|}{ CSB-UNIMMAP } & \multicolumn{2}{|l|}{ RUSF } & \multicolumn{2}{|l|}{ Overall } & \multirow{2}{*}{$\begin{array}{l}\text { Intervention } \\
\text { effect P-value }\end{array}$} & \multirow{2}{*}{$\begin{array}{l}\text { Time } \\
\text { effect P- } \\
\text { value }\end{array}$} & \multirow{2}{*}{$\begin{array}{l}\text { Time*Intervention } \\
\text { effect P-value }\end{array}$} \\
\hline & & Mature & Adolescent & Mature & Adolescent & Mature & Adolescent & Mature & Adolescent & & & \\
\hline \multirow{2}{*}{$\begin{array}{l}\text { Initial AFA, } \\
\mathrm{cm}^{2}\end{array}$} & Raw mean \pm SD & $9.14 \pm 2.25$ & $10.06 \pm 2.12$ & $9.30 \pm 2.37$ & $10.23 \pm 2.11$ & $9.38 \pm 2.31$ & $10.08 \pm 2.13$ & $9.27 \pm 2.30$ & $10.12 \pm 2.12$ & \multirow{2}{*}{0.3852} & \multirow{2}{*}{ N/A } & \multirow{2}{*}{ N/A } \\
\hline & $\mathrm{LS}$ mean $\pm \mathrm{SE}$ & $9.13 \pm 0.12^{\mathrm{a}}$ & $10.06 \pm 0.13^{b}$ & $9.30 \pm 0.13^{\mathrm{a}}$ & $10.23 \pm 0.13^{b}$ & $9.38 \pm 0.13^{\mathrm{a}}$ & $10.08 \pm 0.13^{b}$ & $9.27 \pm 0.07^{a}$ & $10.12 \pm 0.09^{b}$ & & & \\
\hline \multirow{2}{*}{$\begin{array}{l}\text { Terminal } \\
\text { AFA, } \text { cm }^{2}\end{array}$} & Raw mean \pm SD & $8.92 \pm 2.36$ & $9.58 \pm 2.09$ & $9.01 \pm 2.26$ & $9.78 \pm 2.22$ & $9.19 \pm 2.47$ & $9.70 \pm 2.29$ & $9.04 \pm 2.36$ & $9.69 \pm 2.20$ & \multirow{2}{*}{0.3918} & \multirow[b]{2}{*}{$<0.0001$} & \multirow[b]{2}{*}{0.2367} \\
\hline & $\mathrm{LS}$ mean $\pm \mathrm{SE}$ & $8.89 \pm 0.16^{a}$ & $9.61 \pm 0.17^{b}$ & $8.78 \pm 0.16^{a}$ & $9.63 \pm 0.17^{b}$ & $9.07 \pm 0.17^{\mathrm{a}}$ & $9.80 \pm 0.16^{b}$ & $8.91 \pm 0.10^{a}$ & $9.68 \pm 0.11^{b}$ & & & \\
\hline \multirow{2}{*}{$\begin{array}{l}\text { Absolute } \\
\text { AFA } \\
\text { change, } \text { cm }^{2}\end{array}$} & Raw mean \pm SD & $-0.18 \pm 1.89$ & $-0.48 \pm 2.09$ & $-0.35 \pm 2.07$ & $-0.49 \pm 2.16$ & $-0.15 \pm 2.12$ & $-0.39 \pm 1.97$ & $-0.23 \pm 2.03$ & $-0.45 \pm 2.07$ & \multirow[b]{2}{*}{0.4645} & \multirow[b]{2}{*}{$<0.0001$} & \multirow[b]{2}{*}{0.4351} \\
\hline & $\mathrm{LS}$ mean $\pm \mathrm{SE}$ & $-0.25 \pm 0.14^{a}$ & $-0.62 \pm 0.15^{\mathrm{a}}$ & $-0.47 \pm 0.14^{a}$ & $-0.66 \pm 0.15^{a}$ & $-0.30 \pm 0.15^{a}$ & $-0.46 \pm 0.15^{a}$ & $-0.34 \pm 0.09^{a}$ & $-0.57 \pm 0.10^{b}$ & & & \\
\hline \multirow{2}{*}{$\begin{array}{l}\text { Weekly } \\
\text { AFA } \\
\text { change, } \\
\mathrm{cm}^{2} / \text { week }\end{array}$} & Raw mean \pm SD & $0.00 \pm 1.06$ & $-0.16 \pm 1.11$ & $-0.08 \pm 0.54$ & $-0.03 \pm 1.26$ & $-0.03 \pm 0.47$ & $-0.09 \pm 0.68$ & $-0.04 \pm 0.74$ & $-0.09 \pm 1.04$ & \multirow{2}{*}{0.8532} & \multirow{2}{*}{ N/A } & \multirow[b]{2}{*}{ N/A } \\
\hline & $\mathrm{LS}$ mean $\pm \mathrm{SE}$ & $0.00 \pm 0.05^{\mathrm{a}}$ & $-0.16 \pm 0.06^{\mathrm{a}}$ & $-0.08 \pm 0.05^{a}$ & $-0.03 \pm 0.05^{a}$ & $-0.03 \pm 0.05^{\mathrm{a}}$ & $-0.09 \pm 0.06^{a}$ & $-0.04 \pm 0.03^{a}$ & $-0.09 \pm 0.04^{a}$ & & & \\
\hline
\end{tabular}




\subsubsection{AFA by age}

Mean initial AFA was significantly higher in adolescents than mature women as seen in Table $12(\mathrm{P}<0.0001)$. Compared to the overall mean, adolescents had a $0.42 \mathrm{~cm}^{2}$ larger initial AFA, 95\% CI [0.32, 0.52], with no difference across the intervention groups $(\mathrm{P}=0.3852)$.

Terminal AFA for mature women overall was $8.91 \pm 0.10 \mathrm{~cm}^{2}$ and $9.68 \pm 0.11 \mathrm{~cm}^{2}$ for adolescents, as seen in Table 10. Adolescents overall had a significantly greater terminal AFA compared to mature women, and a $0.38 \mathrm{~cm}^{2}$ larger terminal AFA when compared to the overall mean, 95\% CI [0.24, 0.53] (P $<0.0001$ for both). Within each intervention group, terminal AFA in adolescents was higher than the mean for mature women in their respective groups $(\mathrm{P}=0.0005,<0.0001$, and 0.0124 for CSB-IFA, CSBUNIMMAP, and RUSF, respectively). Terminal AFA was lower than initial AFA for adolescents in all groups, and mature women in CSB-UNIMMAP, as seen in Figure 18. Terminal AFA was still significantly affected by time, with every week of treatment resulting in a $0.12 \mathrm{~cm}^{2}$ smaller terminal AFA, consistent across all intervention groups, 95\% CI $[-0.14,-0.10](\mathrm{P}<0.0001)$.

On average, all intervention groups lost AFA over the course of the study. The mean absolute loss did not differ across intervention groups $(\mathrm{P}=0.4645)$. When analyzed as a whole group, there was significant evidence for both a linear and quadratic relationship with time $(\mathrm{P}<0.0001$ and 0.0079 , respectively). Every week of treatment resulted in a $0.10 \mathrm{~cm}^{2}$ decrease in absolute change in AFA, 95\% CI [-0.12, -0.08]. This linear relationship remained significant when separated into age groups $(\mathrm{P}<0.0001$ for both mature women and adolescents) Each week on treatment in mature women resulted in a $0.08 \mathrm{~cm}^{2}$ smaller change in AFA, and $0.11 \mathrm{~cm}^{2}$ per week in adolescents, $95 \% \mathrm{CI}$ [- 
$0.11,-0.05],[-0.14,-0.09]$. Absolute change in AFA was significantly larger in adolescents in CSB-IFA compared to mature women, as seen in Figure 19.

Weekly change in AFA was also negative, but did not differ across intervention groups as a whole group $(\mathrm{P}=0.8532)$ and when separated into age groups $(\mathrm{P}=0.4353$ and 0.3342 for mature women and adolescents respectively). There was no difference in weekly change in AFA between mature and adolescent women across all interventions, as seen in Figure $20(\mathrm{P}=0.0774,0.5494,0.2341$ for CSB-IFA, CSB-UNIMMAP, and RUSF, respectively). When stratified into age groups, there are no significant withingroup differences in intervention effect on weekly AFA change.

\subsubsection{AFA by Seasonality}

When seasonality is included in the model, there is no effect on terminal AFA (P $=0.7784)$. However, seasonality significantly affected losses in AFA $(\mathrm{P}<0.0001)$.

Compared to the overall mean, women whose births occurred during the rainy season had a $0.33 \mathrm{~cm}^{2}$ smaller terminal AFA, 95\% CI [-0.43, -0.22]. In a pairwise comparison, women whose births occurred during the rainy season had a $0.66 \mathrm{~cm}^{2}$ larger loss in AFA than during the dry season $\left(-0.89 \mathrm{~cm}^{2}\right.$ vs. $-0.23 \mathrm{~cm}^{2}$, respectively), $95 \% \mathrm{CI}[0.46,0.86]$ (P $<0.0001)$. There were no interactions of seasonality with intervention or age on AFA loss $(\mathrm{P}=0.5353$ and 0.6474 , respectively) and no significant effect on weekly loss in AFA (P $=0.1277)$.

\subsection{DIFFERENCES IN ANTHROPOMETRICS AMONG ADOLESCENTS}

In the subgroup analysis comparing younger and older adolescents, there was no difference between intervention groups and between age groups for terminal MUAC $(\mathrm{P}=$ 0.4461 and 0.5474 , respectively) and AMA $(\mathrm{P}=0.4534$ and 0.5676 , respectively $)$ 
However, there was a significant interaction of intervention and age status for terminal TSF and terminal AFA $(\mathrm{P}=0.0251$ and 0.0154 , respectively). Compared to the overall mean, very young adolescents in the CSB-IFA group had a $0.26 \mathrm{~mm}$ smaller terminal TSF, while very young adolescents in CSB-UNIMMAP had a $0.24 \mathrm{~mm}$ larger terminal TSF, 95\% CI [-0.48, -0.05], [0.03, 0.46] $(\mathrm{P}=0.0147$ and 0.0234). Compared to the overall mean for terminal AFA, very young adolescents in CSB-IFA had $0.30 \mathrm{~cm}^{2}$ smaller AFA, while very young adolescents in CSB-UNIMMAP had $0.28 \mathrm{~cm}^{2}$ larger terminal AFA, 95\% CI [-0.52, -0.07], [0.05, 0.51] $(\mathrm{P}=0.0098$ and 0.0150, respectively).

When separated into age groups and analyzed separately, there was no effect of intervention on terminal TSF and terminal AFA in older adolescents $(\mathrm{P}=0.8471$ and 0.7160, respectively). Among younger adolescents, there was a significant intervention effect on terminal TSF and terminal AFA $(\mathrm{P}=0.0101$ and 0.0095$)$. Compared to the mean for younger adolescents, those in CSB-IFA had a $0.47 \mathrm{~mm}$ smaller terminal TSF, while those in CSB-UNIMMAP had a $0.42 \mathrm{~mm}$ larger terminal TSF, 95\% CI [-0.80, 0.14], $[0.09,0.75](\mathrm{P}=0.0055$ and 0.0135 , respectively). In pairwise comparison, young adolescents in CSB-IFA had a significantly lower terminal TSF compared to those in CSB-UNIMMAP, but not RUSF (P = 0.0073), as seen in Figure 21. 


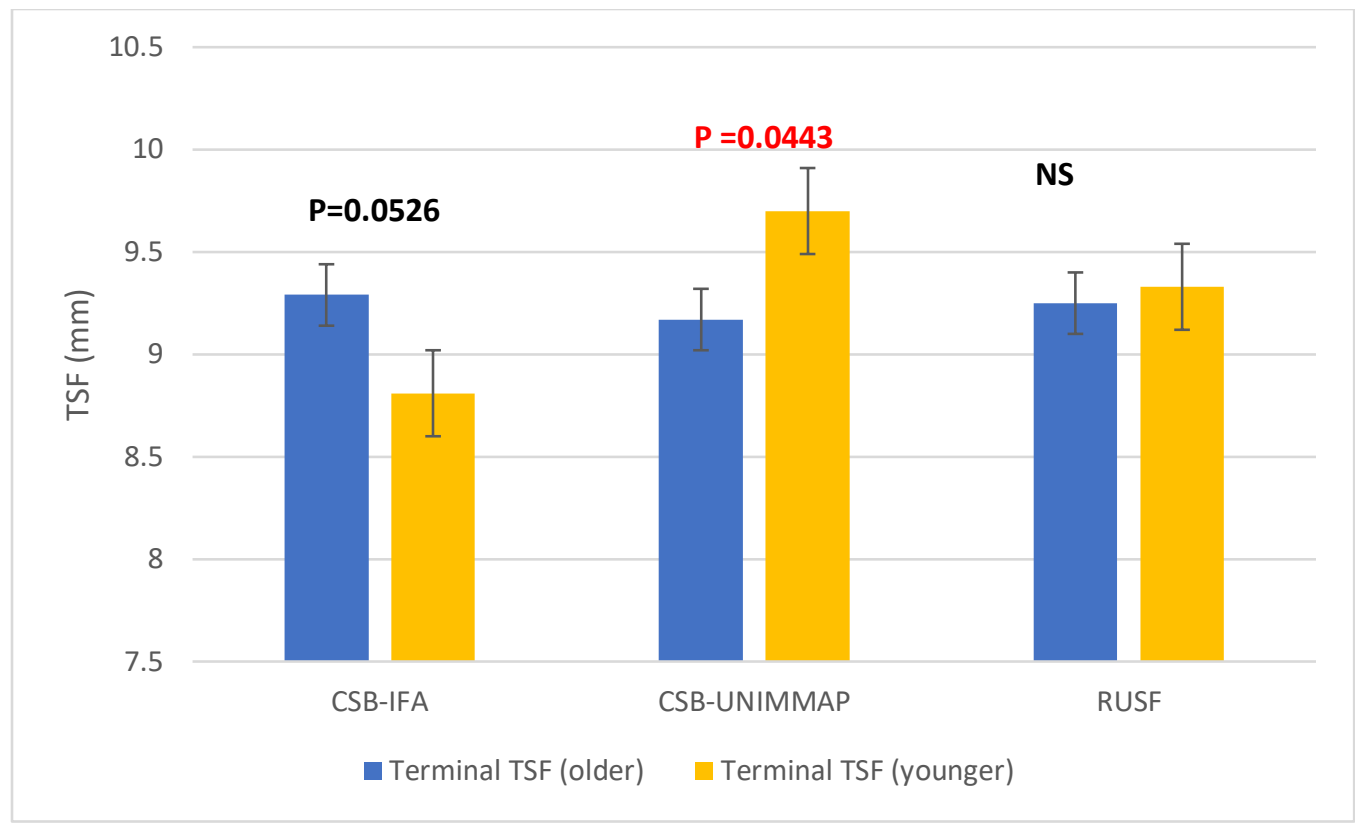

Figure 21. Terminal TSF in adolescents by age.

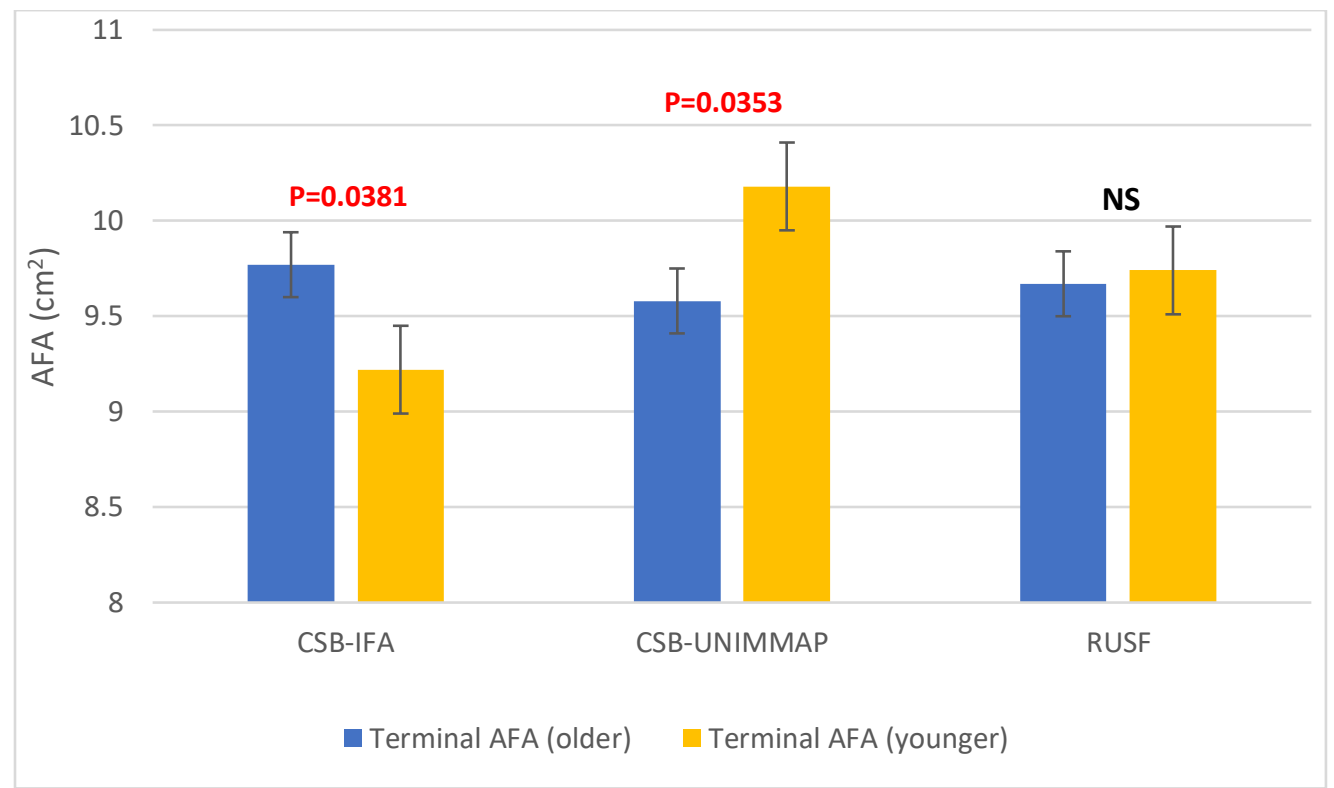

Figure 22. Terminal AFA in adolescents by age group.

Compared to the mean terminal AFA of younger adolescents, those in CSB-IFA had a $0.50 \mathrm{~mm}$ smaller terminal AFA, while those in CSB-UNIMMAP had a $0.47 \mathrm{~mm}$ larger terminal AFA, 95\% CI [-0.85, -0.14], [0.11, 0.82] $(\mathrm{P}=0.0061$ and 0.0105 , 
respectively). In pairwise comparison, the mean terminal AFA for young adolescents in CSB-IFA was $0.96 \mathrm{~cm}^{2}$ lower than those in CSB-UNIMMAP, 95\% CI [-1.70, -0.22] $(\mathrm{P}=$ 0.0066). Terminal AFA in RUSF was not significantly different from very young adolescents in CSB-IFA and CSB-UNIMMAP ( $\mathrm{P}=02038$ and 0.3452, respectively). When compared within interventions, terminal AFA varied between age groups in CSBIFA and CSB-UNIMMAP, but not RUSF, as seen in Figure 22. Compared to the overall mean, terminal AFA in very young adolescents was $0.28 \mathrm{~cm}^{2}$ lower than older adolescents in CSB-IFA, 95\% CI [0.02, 0.54], and $0.30 \mathrm{~cm}^{2}$ higher in CSB-UNIMMAP, 95\% CI [-0.58,-0.02] $(\mathrm{P}=0.0381$ and 0.0353 , respectively). Compared to the overall mean, terminal TSF in young adolescents was $0.24 \mathrm{~cm}^{2}$ lower in CSB-IFA, $95 \%$ CI [ 0.003, 0.48], although the difference was marginal $(\mathrm{P}=0.0526)$. In CSB-UNIMMAP, very young adolescents had a $0.27 \mathrm{~mm}$ larger terminal TSF compared to the overall mean, 95\% CI [-0.53, -0.007] $(\mathrm{P}=0.0443)$.

There was no difference in absolute change in MUAC, AMA, TSF, or AFA across or between intervention groups and age status. There was no difference in weekly change in MUAC, TSF, and AFA when comparing older and younger adolescents. Age status was a marginal predictor of weekly AMA change $(\mathrm{P}=0.0539)$. Compared to the overall mean weekly AMA change, very young adolescents had a $0.07 \mathrm{~cm}^{2}$ larger weekly increase that was consistent across intervention groups, 95\% CI [-0.001, 0.13].

\subsection{RELATIONSHIP WITH BIRTHWEIGHT}

Birthweight did not significantly differ across the three intervention groups, as seen in Table 13. However, in all groups, baseline MUAC, terminal MUAC, and MUAC measured at delivery also independently significantly predicted birthweight $(\mathrm{P}<0.0001$ 
for all). Each cm larger initial MUAC was associated with $0.08 \mathrm{~kg}$ greater birthweight, 95\% CI $[0.04,0.12]$, while each $\mathrm{cm}$ terminal MUAC was associated with $0.04 \mathrm{~kg}$ larger birthweight, 95\% CI $[0.01,0.06](\mathrm{P}=0.0021) . \beta$ values and associated standardized $\beta$ values are given in Table 14. Baseline AMA and AFA did not significantly predict birthweight. When separated into age groups, terminal MUAC, AMA, TSF, and AFA do not significantly predict birthweight.

Table 13. Mean birthweight for women in each intervention group. Values expressed as raw mean \pm SD.

\begin{tabular}{cccccc}
\hline & $\begin{array}{c}\text { CSB-IFA } \\
(\mathbf{N}=\mathbf{4 8 6})\end{array}$ & $\begin{array}{c}\text { CSB- } \\
\text { UNIMMAP } \\
(\mathbf{N = 4 8 0})\end{array}$ & $\begin{array}{c}\text { RUSF } \\
(\mathbf{N}=\mathbf{4 7 2})\end{array}$ & $\begin{array}{c}\text { Overall } \\
(\mathbf{N}=\mathbf{1 , 4 3 8})\end{array}$ & P-value \\
\hline $\begin{array}{c}\text { Birthweight, } \\
\text { kg }\end{array}$ & $2.73 \pm 0.41$ & $2.71 \pm 0.41$ & $2.74 \pm 0.43$ & $2.73 \pm 0.42$ & 0.5488 \\
\hline LBW, N(\%) & $142(29.3)$ & $127(26.5)$ & $125(26.5)$ & $394(37.8)$ & 0.5452 \\
\hline LBW defined as birthweight $<2.5 \mathrm{~kg}$. & & & & \\
\hline
\end{tabular}

LBW defined as birthweight $<2.5 \mathrm{~kg}$.

Table 14: $\beta$ and standardized $\beta$ for birthweight.

\begin{tabular}{lll}
\hline & $\boldsymbol{\beta}$ & Standardized $\boldsymbol{\beta}$ \\
\hline Initial MUAC, cm & 0.079 & 0.111 \\
\hline Terminal MUAC, cm & 0.039 & 0.084 \\
\hline MUAC at delivery, cm & 0.064 & 0.142 \\
\hline BMI at enrollment, kg/m $\mathbf{m}^{\mathbf{2}}$ & 0.022 & 0.080 \\
\hline Weight gain before delivery, kg & 0.024 & 0.159 \\
\hline Weeks on treatment & 0.004 & 0.056 \\
\hline Age at enrollment, years & 0.013 & 0.160 \\
\hline
\end{tabular}

Baseline BMI also significantly predicted birthweight, with each $\mathrm{kg} / \mathrm{m}^{2}$ higher BMI at enrollment associated with a $0.02 \mathrm{~kg}$ larger birthweight, 95\% CI [0.01, 0.04] $(\mathrm{P}=0.0026)$. Weight gain before delivery and number of weeks on treatment also independently significantly predicted birthweight $(\mathrm{P}<0.0001$ and $\mathrm{P}=0.0338$, respectively). Each $\mathrm{kg}$ of weight gain before delivery was associated with a $0.02 \mathrm{~kg}$ larger birthweight, 
$95 \%$ CI [0.02, 0.03], while each week on treatment resulted in a $0.004 \mathrm{~kg}$ larger birthweight, 95\% CI [0.0003, 0.007]. However, when both are included in the model, after accounting for weight gain before delivery, weeks on treatment are no longer significant. When weeks on treatment are accounted for first, weight gain before delivery is still statistically significant $(\mathrm{P}<0.0001)$, indicating the predictive power that gestational weight gain has on infant birthweight. A higher number of weeks on treatment is suggestive of greater supplemental energy and micronutrients compared to a mother treated for fewer weeks, assuming the mother alone is consuming all of her supplement. She is also able to obtain obstetric care during her visits to clinic, increasing the likelihood of higher birthweight with more visits. 


\subsection{RELATIONSHIP WITH BIRTH LENGTH}

There was no effect of MUAC, AMA, TSF, and AFA on birth length when analyzed as a whole group $(\mathrm{P}=0.5158,0.0632,0.1792$, and 0.1843 , respectively). However, when stratified according to seasonality assignment, anthropometric measurements had varying effects on birth length. Among births that occurred in the dry season, there was no effect of terminal MUAC, AMA, TSF, or AFA ( $\mathrm{P}=0.4880,0.1332$, 0.2141, and 0.2276, respectively). Among births that occurred during the rainy season, there was significant variation in birth length $(\mathrm{P}=0.0043)$. For every $\mathrm{cm}$ of terminal MUAC, birth length increased by $0.29 \mathrm{~cm}, 95 \% \mathrm{CI}[0.02,0.55](\mathrm{P}=0.0385)$. There was no effect of terminal AMA, TSF, or AFA ( $\mathrm{P}=0.1403,0.3348,0.3217$, respectively). 


\section{CHAPTER 5 \\ DISCUSSION}

In the current secondary analysis of data from a randomized controlled clinical trial, we found that treatment with the peanut- and dairy-protein-based RUSF resulted in larger increases in mid-upper arm circumference (MUAC) and arm muscle area (AMA) than treatment with a fortified corn-soy blended flour plus a prenatal multiple micronutrient supplement (CSB-UNIMMAP) or a fortified corn-soy blended flour with iron and folic acid supplement (CSB-IFA). We also found that the treatments had different effects on women's anthropometrics depending on age status.

At baseline, this population was young, with $48.1 \%$ of participants overall classified as adolescents (age $\leq 19$ years old) and the mean age being 21.55 years old. A criteria that changed after initial enrollment during the primary study were the minimum age. Initially, enrollment age was $\geq 18$ years, but was lowered to $\geq 16$ years. In the current analysis, this allowed for a larger adolescent sample size. Although the ages of the women appear mostly normally distributed, there are a few discrepancies. Ages 18, 20,30 , and 35 years were reported at a higher frequency than expected from a random sample. The higher frequency of age 18 could potentially be the result of women misreporting their ages to allow enrollment into the study under the previous inclusion criteria. The higher relative frequencies of ages 20,30 , and 35 could possibly be a result of women providing a rough estimate of their age, as age may not be closely monitored or tracked in this setting.

The study population was also short and underweight, with $23.4 \%$ of women having short stature (defined as height $<150 \mathrm{~cm}$ ) and $18.3 \%$ being underweight $(\mathrm{BMI}<$

$18.5 \mathrm{~kg} / \mathrm{m}^{2}$ ). The mean BMI at enrollment was $19.69 \mathrm{~kg} / \mathrm{m}^{2}$, which is classified as normal 
(BMI $18.5-24.9 \mathrm{~kg} / \mathrm{m}^{2}$ ). However, the IOM recommends $12.5-18 \mathrm{~kg}$ of total weight gain for women classified as underweight by pre-pregnancy BMI $\left(<18.5 \mathrm{~kg} / \mathrm{m}^{2}\right)$

(Rasmussen et al., 2009). The average weight at enrollment was $46.82 \mathrm{~kg}$; gaining 12.5 $\mathrm{kg}$ over the course of pregnancy would give women a mean BMI of approximately 25.0 $\mathrm{kg} / \mathrm{m}^{2}$. However, the median weight gain was $2.5 \mathrm{~kg}$ over the course of enrollment, and the mean antenatal weight was $49.5 \mathrm{~kg}$, indicating that the women in the study had inadequate weight gain relative to IOM recommendations. Although we were unable to measure pre-pregnancy BMI, it is likely to be very low after gestational weight gain has occurred prior to enrollment, indicative of malnutrition.

\subsection{MUAC}

On average, MUAC at the end of the intervention period was greater than initial MUAC for all intervention groups. This is congruent with expected anthropometric changes secondary to gestational weight gain. There is mixed evidence in the literature as to whether dietary interventions during malnourished pregnancies significantly increase MUAC. A study of rural Gambian women found that a nutritional supplement during pregnancy did not significantly increase gains in MUAC when compared to unsupplemented pregnant women (Prentice, Cole, Foord, Lamb, \& Whitehead, 1987). Underweight pregnant women in Argentina gained $2.4 \mathrm{~cm}$ in MUAC on average over the course of pregnancy (López et al., 2011).

At baseline, MUAC measurements were not significantly different between adolescent and mature women in the current study (22.27 vs $22.29 \mathrm{~cm}$, respectively). This differs from the findings of Kalanda, et al., who found that pregnant Malawian 
adolescents had significantly lower MUACs at baseline compared to mature women (24.1 $\mathrm{cm}$ and $25.3 \mathrm{~cm}$, respectively) (Kalanda et al., 2006). A study of pregnant Jamaican women observed that adolescents had significantly lower baseline MUACs than mature women (26.7 cm vs $29.7 \mathrm{~cm}$, respectively). However, the women in these studies had higher MUACs overall compared to those of the current study, in both adolescents and mature women. The current study's population may have had poorer nutritional status overall, reducing the variability in MUAC associated with age in more adequately nourished women.

Terminal MUAC was significantly lower in adolescents than in mature women across all groups. Initial MUAC did not differ by age groups, indicating adolescents overall accrued less mass over the course of enrollment compared to mature women. A previous investigation of pregnant Malawian mothers found significantly lower MUAC measurements in adolescents compared to mature women, congruent with the findings of the current study (Kalanda et al., 2006). Adolescents have increased nutrient needs for their own linear growth; in combination with the increased needs of pregnancy, the intervention supplement may have been inadequate to influence significant maternal growth relative to mature women. In a study comparing pregnant adolescents to nonpregnant adolescents in Bangladesh, pregnancy resulted in halted vertical growth and losses in MUAC compared to growth patterns of never-pregnant adolescents (Rah et al., 2008). Terminal MUAC was highest for mature women in RUSF (22.54 cm) when compared to mean terminal MUAC of mature women in CSB-IFA and CSB-UNIMMAP. Both mature women and adolescents in RUSF had significantly larger terminal MUAC measurements compared to baseline ( $\mathrm{P}<0.0001$ and 0.0230 , respectively), with 
no differences between initial and terminal measurements for adolescents in CSBUNIMMAP.

Absolute increases in MUAC on average were greatest for women in the RUSF group ( $\mathrm{P}=0.0181)$, even when controlling for weeks on treatment. Women in RUSF had an average increase of $0.21 \mathrm{~cm}$ in their MUAC measurements after controlling for time, while women in the CSB-IFA and CSB-UNIMMAP groups both had an average increase of $0.07 \mathrm{~cm}$.

Adolescents in RUSF had the largest increase in MUAC compared to adolescents in CSB-IFA and CSB-UNIMMAP, but this was not significantly different. Adolescents in CSB-UNIMMAP had no significant change between initial and terminal measurements. However, mature women in RUSF had significantly larger increases in MUAC compared to adolescents in RUSF $(\mathrm{P}=0.0033)$, and had the largest increase of all age and intervention groups. This is suggestive of increased efficacy of the RUSF in accruing maternal mass in women who are no longer undergoing vertical growth. The competition for nutrients is then theoretically limited only toward expansion of maternal and fetal tissues related to pregnancy, rather than pubescent growth. As previously mentioned, comparisons of changes in MUAC over the course of pregnancy have found consistently larger measurements in mature women when compared to adolescents. However, absolute increases in lean body mass were found to be larger compared to mature women in a study of pregnant Jamaican women (Thame et al., 2007). This is not congruent with the findings of the current study, although the women in the previously mentioned study were adequately nourished, and the study was observational rather than a randomized-controlled trial. 
The lack of increase in MUAC for adolescents in CSB-UNIMMAP and greater increases in women given RUSF is suggestive of a protective effect of RUSF for pregnant, moderately malnourished women of normal tissue accretion expected during pregnancy. There have been few studies assessing the changes in MUAC in moderately malnourished adolescents over the course of pregnancy, especially in response to nutritional interventions.

Maternal BMI and MUAC significantly predicted birth weight, and maternal MUAC at the end of enrollment significantly predicted birth length if birth occurred during the rainy season. This is consistent with the literature suggesting that overall adequate nutritional status prior to and during pregnancy results in larger infants, regardless of body composition. Overall maternal nutritional status before and during pregnancy is therefore an important contributor to positive birth outcomes, especially in times of low food availability.

\subsection{AMA}

For all intervention groups, terminal AMA was significantly larger than initial AMA ( $\mathrm{P}<0.0001$ for all). Women in the RUSF group experienced the largest increase in AMA $\left(1.16 \mathrm{~cm}^{2}, \mathrm{P}=0.0391\right)$, after controlling for time. When separated by age, all groups experienced a significant positive increase in AMA; however, mature women in RUSF had the greatest increase compared to all other groups $\left(1.46 \mathrm{~cm}^{2}, \mathrm{P}=0.0343\right)$.

A study of HIV-infected pregnant Malawian women (mean age $=25.9$ years old) measured baseline AMA to be $36.7 \mathrm{~cm}^{2}$, with a weekly change of $0.03 \mathrm{~cm}^{2}$ on average (Thomas et al., 2013). The current study population had a baseline AMA of $29.9 \mathrm{~cm}^{2}$, 
over $6 \mathrm{~cm}^{2}(22 \%)$ smaller than that of Thomas, et al. The current study population also experienced an overall weekly AMA change of $0.20 \mathrm{~cm}^{2} / w e e k$, regardless of age status. Although HIV-infection in the previous study could have contributed to losses in LBM, the authors indicate similarity to observations in HIV-uninfected groups. The larger increase in AMA in the current study could be attributed to the higher protein quality of RUSF relative to CSB-IFA and CSB-UNIMMAP. RUSF contains milk-based protein, which is of higher biological value and has been shown to be conducive to increasing tissue accretion.

Protein digestibility-corrected amino acid score (PDCAAS) is a method of evaluating protein quality. It calculates a value from 0-1.0 based off of a protein's limiting essential amino acid (EAA) and digestibility (Hoppe et al., 2008). Plant-derived proteins such as corn and soy, which have PDCAAS scores of 0.35 and 0.93 respectively, are inadequate in at least one EAA. When blended together, some of the limiting amino acids in corn are compensated by the addition of soy. However, soy and cereal grains are known to contain factors, such as phytates and tannins, that inhibit absorption of micronutrients and protein in the gut, potentially reducing its efficacy. Addition of milk protein to a blended supplemental product increases the digestibility and bioavailability of the overall protein content, reflected by a higher PDCAAS score (Hoppe et al., 2008). Therefore, corn-soy blend supplemental foods, such as that used for CSB-IFA and CSBUNIMMAP in the current study, potentially have lower protein quality and reduced absorption relative to RUSF. A preliminary analysis of dietary intake with the supplement found that women in the CSB-IFA and CSB-UNIMMAP groups consumed 49.9 and $48.1 \mathrm{~g}$ protein per day, respectively, and the RUSF group had a significantly 
higher protein intake (64.4 g per day). The RUSF group had the highest protein intake of the three intervention groups, which likely contributed to the larger relative increase in AMA over the course of enrollment.

The efficacy of dairy in treatment of malnutrition is currently being investigated. The current research focus in the literature is the contribution of dairy intake and supplementation on recovery from moderate and severe malnutrition in infants and children (Diop, Dossou, Ndour, Briend, \& Wade, 2003; Olsen et al., 2007). A randomized controlled trial comparing the efficacy of a product similar to the current study's RUSF food (ready-to-use therapeutic food, or RUTF) against F100 (a milk-based liquid food that was the WHO standard of care for severe malnutrition in children at the time of publication) found that severely malnourished Senegalese children given RUTF had greater weight gain and higher energy intakes compared to those given F100 (Diop et al., 2003). This is attributed to the RUTF's increased energy density and reduced risk of contamination compared to F100, although milk-based therapeutic foods in general have been found to have higher protein quality than similar blended foods like corn-soy blended flours (Hoppe et al., 2008).

Dairy intake has also been thought to improve the overall integrity of the gastrointestinal tract. This is important in this population because malnutrition and viral and parasitic infection can cause enteropathy, such as villous flattening and crypt hyperplasia (Schneider \& Viteri, 1972). This can exacerbate malnutrition and decrease the effectiveness of dietary interventions by reducing absorption throughout the gut.

Previous studies of dairy intake in pregnant women have been limited in number, and tend to focus on the effects of dairy intake on birthweight in normal pregnancies 
(Borazjani, Angali, \& Kulkarni, 2013; Olsen et al., 2007). However, increased maternal dairy intake has been correlated with increased infant birthweights, suggesting a contribution of dairy intake toward favorable birth outcomes. Because of the importance of accretion of lean mass for healthy pregnancy, and the role of high quality protein on anabolism of lean tissue, future research should also focus on dairy-based interventions for recovery from malnutrition in pregnancy. This will require further investigation into the unique needs of pregnancy with regards to malnutrition, and separate investigation into effects on maternal and fetal outcomes (Dirienzo, 2016). The current study provides further evidence of milk-based protein supplementation correlating with increases in lean body mass in moderately malnourished women over the course of pregnancy.

The findings of the current analysis differ somewhat from those found in an analysis of HIV-infected pregnant Malawian women enrolled in the BAN study. When typical Malawian dietary patterns were separated into plant-based, grain-based and animal-based diets and anthropometric measurements of women in each group measured, women consuming the animal-based diet pattern had smaller AMA than women in the grain-based group, despite having a higher intake of animal and total protein. The authors suggest that the increased physical activity of an agricultural lifestyle, most common among women who consumed the grain-based diet, were a stronger determinant of muscle mass than protein intake alone (Ramlal et al., 2015). We were unable to assess physical activity in the current study. However, the quantification and qualification of the effects of agricultural- and lifestyle-related physical activity on mother's energy expenditure and body composition would be beneficial in future studies. 


\subsection{TSF AND AFA}

Overall, all groups experienced losses in TSF and AFA over the course of intervention, with no difference between intervention groups. The loss in TSF was not significantly different between mature women and adolescents, but the difference between initial and terminal TSF was significant in both age groups. The loss in AFA was significantly larger in adolescents compared to mature women $\left(-0.57 \mathrm{~cm}^{2}\right.$ vs -0.34 $\mathrm{cm}^{2}$ ). During normal pregnancy, AFA increases during the first trimester and decreases in the third trimester due to mobilization of energy stores away from maternal fat to the fetus (Taggart et al., 1967; Thomas et al., 2013).

However, these observations are based off assessments of healthy pregnancies with adequate fat stores prior to conception. The literature is inconsistent regarding changes in fat mass in malnourished women and in women with lower socioeconomic status. In a study of 608 poor American women with low pre-pregnancy weight, losses in AFA resulted in birthweights significantly lower than that of normal weight and overweight women, for which AFA loss resulted in increased birthweight (M. L. Hediger et al., 1994). However, in a study of 1,669 Zimbabwean pregnancies, low AFA was associated with increased birthweight ((Friis et al., 2004). In the current population, the majority of women were enrolled after the first trimester, and had low pre-pregnancy weight status. Losses in already low fat stores may be indicative of worsening nutritional status rather than simply the result of physiological changes of pregnancy. However, losses in TSF and AFA did not differ across interventions, congruent with the similarity of mean birthweights across interventions. 
The literature shows that supplementation of approximately $900 \mathrm{kcal}$ per day may not be sufficient to match the energy deficit caused by high levels of physical activity associated with agricultural work and activities of daily living in this population. Previous studies have estimated energy expenditure in similar pregnant populations; estimations of basal metabolic rate in pregnant Nigerian women were 1404 kcal per day on average (Cole, Ibeziako, \& Bamgboye, 1976), while measurements of total energy expenditure (basal metabolic rate plus energy expenditure of physical activity) of pregnant Gambian women ranged from 2017 kcal per day to $2590 \mathrm{kcal}$ per day during periods of peak agricultural activity (Heini, Schutz, \& Jéquier, 1992; Singh et al., 1989). In a preliminary analysis of energy intake, women in the CSB-IFA group consumed $992 \mathrm{kcal}$ per day on average and $1618 \mathrm{kcal}$ per day with the supplement, women in CSB-UNIMMAP consumed $1483 \mathrm{kcal}$ per day including supplemental intake, and women in RUSF consumed 1912 kcal per day including their supplemental intake. It is estimated that on average, women in the CSB-IFA and CSB-UNIMMAP group consumed an additional $400 \mathrm{kcal}$ per day from their intervention supplement, while women in RUSF consumed approximately 600 additional kcal per day from their supplement. Despite receiving 893, 893, and 920 kcal per day from CSB-IFA, CSBUNIMMAP, and RUSF respectively, this may have not been sufficient to induce accrual of fat tissue during pregnancy. The previously mentioned analysis of adequately nourished HIV-infected pregnant Malawian women enrolled in the BAN study measured a mean energy intake of 1,378 kcal per day (Ramlal et al., 2015). This evidence for inadequate dietary intake in pregnant Malawian women supports the need for additional supplementation, particularly in adolescents. 


\subsection{BIRTHWEIGHT}

The response of birthweight to nutritional interventions has been varied. In underweight Chilean women, a milk-based fortified intervention food resulted in significantly higher birthweights when compared to those given powdered milk (3178 vs $3105 \mathrm{~g}$ ), although these birthweights were higher than those observed in the current study (Mardones-Santander et al., 1988). Maternal supplementation of small quantitiy lipidbased supplements during pregnancy and lactation concurrently with infant supplementation in Malawian mothers found increases in birthweight and other infant outcomes, although this supplementation was more intensive than that of the current study (Prado et al., 2016). Lipid-based supplements increased birthweight in Ghanian pregnant women as well (Adu-Afarwuah et al., 2015). However, other studies have found no increase in birthweight following supplementation, as seen in the current study (Adair \& Pollitt, 1985; Ashorn et al., 2015).

BMI and MUAC at enrollment and MUAC at the end of enrollment significantly predicted infant birthweight. This is consistent with the literature in that overall better maternal nutritional status results in larger infants. If maternal stores and size are sufficient prior to and during pregnancy, she can divert more nutrients and energy toward the developing fetus. However, the lack of variability in birthweight relative to the degree of increase in MUAC and AMA is not congruent with the literature that suggests accrual of lean tissue and recovery of maternal nutritional status results in better birth outcomes (Butte et al., 2003; Gernand, Christian, Paul, et al., 2012; Kulkarni et al., 2006; S. A. Lederman et al., 1999; Widen \& Gallagher, 2014). However, there is limited evidence that AFA can be a determinant of infant birthweight (M. L. Hediger et al., 1994). TSF 
and AFA both decreased to a similar degree across all groups over the course of intervention in the current study, following the pattern of similarity in birthweight across groups. Hediger, et al. suggests that undernourished women who lose more fat during pregnancy have lower birthweights than well-nourished women who also lose fat. This is suggestive that, in this malnourished population, losses in fat are associated with lower birthweight, contrary to findings in the literature related to more well-nourished women.

The effectiveness of nutritional supplementation in maternal and fetal outcomes may be affected by seasonality; Malawi is characterized by a wet and a dry season. Delivery during the wet season (January - May) is often associated with lower birthweight and gestational weight gain, due to decreased food availability during this time (Hartikainen et al., 2005). The current study did not assess the temporal effects of seasonality on changes in maternal outcomes or infant birthweight. However, deliveries during the wet season could have decreased GWG, resulting in less favorable mean changes in body composition.

\subsection{STRENGTHS AND LIMITATIONS}

A major strength of this study was the randomization. The comprehensive data collection and training of research team members collecting anthropometric measurements of Mamachiponde allowed for longitudinal analysis of changes in body composition during enrollment.

The study is limited in that no true control group was included. The national guidelines of Malawi prescribe supplemental food for moderately malnourished pregnant women. It is therefore unethical for women to not receive some supplemental food, and 
therefore, we cannot compare these results against that of untreated moderately malnourished pregnant women. Additionally, because the current analysis was performed on a study of moderately malnourished women, the results may not necessarily be generalizable to an adequately nourished or severely malnourished pregnant population.

Additionally, the current secondary analysis is limited in that it was performed retrospectively. Temporal and anthropometric data needed to be transformed to be able to answer the study's research questions. A temporal parameter (weeks from delivery) was created for the purpose of this analysis in order to allow for longitudinal analysis of anthropometric changes. This was done due to the inability to accurately assess gestational age by ultrasound. Ultrasound is not routine or accessible in Malawi clinics, particularly rural ones. This limits the ability to enroll women at the same gestational age, and assess longitudinal relationships of gestational age and anthropometric changes.

Similarly, more objective and accurate measurements of body composition, such as dual x-ray absorptiometry (DXA), bioelectric impedance analysis, and doubly labeled water, were unable to be used due to their contraindication during pregnancy and cost, limiting their access and feasibility of use in the current study. Therefore, anthropometric measurements were used to estimate maternal muscle mass and fat mass. Technician training is required to ensure accurate measurement of MUAC and TSF, which the current study employed. However, there is always a chance that inter-person variability was present, especially with multiple trained technicians administering anthropometric measurements over the course of the study.

If there were unlimited resources, it would have been interesting to accurately assess changes in body composition using more objective methods. Additionally, it 
would have been interesting to assess physical activity and energy expenditure

(mentioned above) to measure possible relationships with body composition, although that is outside the scope of the current study. 


\section{REFERENCES}

Abubakari, A., Kynast-Wolf, G., \& Jahn, A. (2015). Maternal determinants of birth weight in Northern Ghana. PLoS ONE, 10(8), 1-15. http://doi.org/10.1371/journal.pone.0135641

Adair, L. S., \& Pollitt, E. (1985). Outcome of maternal nutritional supplementation: a comprehensive review of the Bacon Chow study. The American Journal of Clinical Nutrition, 41(5), 948-978. Retrieved from http://ovidsp.ovid.com/ovidweb.cgi?T=JS\&PAGE=reference $\& D=\operatorname{med} 2 \& N E W S=N \& A N=3$ 993612

Adair, L. S., Pollitt, E., \& Mueller, W. H. (1984). The Bacon Chow study: effect of nutritional supplementation on maternal weight and skinfold thicknesses during pregnancy and lactation. British Journal of Nutrition, 214, 357-369.

Adu-Afarwuah, S., Lartey, A., Okronipa, H., Ashorn, P., Zeilani, M., Peerson, J. M., ... Dewey, K. G. (2015). Lipid-based nutrient supplement increases the birth size of infants of primiparous women in Ghana. American Journal of Clinical Nutrition, 101(4), 835-846. http://doi.org/10.3945/ajcn.114.091546

Andersson, R., \& Bergström, S. (1997). Maternal nutrition and socio-economic status as determinants of birthweight in chronically malnourished African women. Tropical Medicine and International Health, 2(11), 1080-1087.

Ashorn, P., Alho, L., Ashorn, U., Cheung, Y. B., Dewey, K. G., Gondwe, A., ... Vosti, S. A. (2015). Supplementation of Maternal Diets during Pregnancy and for 6 Months Postpartum and Infant Diets Thereafter with Small-Quantity Lipid-Based Nutrient Supplements Does Not Promote Child Growth by 18 Months of Age in Rural Malawi : A Randomized Controlled Tri, 1345-1353. http://doi.org/10.3945/jn.114.207225.1345

Barker, D. J. P. (1997). Maternal nutrition, fetal nutrition, and disease in later life. Nutrition, 13(9), 807-813. http://doi.org/10.1016/S0899-9007(97)00193-7

Black, R. E., Victora, C. G., Walker, S. P., Bhutta, Z. A., Christian, P., De Onis, M., ... Uauy, R. (2013). Maternal and child undernutrition and overweight in low-income and middleincome countries. The Lancet, 382(9890), 427-451. http://doi.org/10.1016/S01406736(13)60937-X

Blössner, M., \& de Onis, M. (2005). Malnutrition: quantifying the health impact at national and local levels. Geneva, World Health Organization (Vol. 12).

Borazjani, F., Angali, K. A., \& Kulkarni, S. S. (2013). Milk and protein intake by pregnant women affects growth of foetus. Journal of Health, Population and Nutrition, 31(4), 435445 .

Bosy-Westphal, A., Later, W., Hitze, B., Sato, T., Kossel, E., Glüer, C. C., ... Müller, M. J. (2008). Accuracy of bioelectrical impedance consumer devices for measurement of body composition in comparison to whole body magnetic resonance imaging and dual X-ray absorptiometry. Obesity Facts, 1, 319-324. http://doi.org/10.1159/000176061

Brabin, L., Verhoeff, F., \& Brabin, B. (2002). Maternal height, birthweight and cephalo pelvic disproportion in urban Nigeria and rural Malawi. Acta Obstetricia et Gynecologica Scandinavica, 81, 502-507.

Branca, F., Pastore, G., Demissie, T., \& Ferro-Luzzi, A. (1993). The nutritional impact of seasonality in children and adults of rural Ethiopia. European Journal of Clinical Nutrition, 47(12), 840-850.

Butte, N. F., Ellis, K. J., Wong, W. W., Hopkinson, J. M., \& O’Brian Smith, E. (2003).

Composition of gestational weight gain impacts maternal fat retention and infant birth weight. American Journal of Obstetrics and Gynecology, 189(5), 1423-1432. http://doi.org/10.1067/S0002-9378(03)00596-9

Carlin, A., \& Alfirevic, Z. (2008). Physiological changes of pregnancy and monitoring. Best 
Practice and Research: Clinical Obstetrics and Gynaecology, 22(5), 801-823. http://doi.org/10.1016/j.bpobgyn.2008.06.005

Chamberlain, G., \& Broughton-Pipkin, F. (1998). Clinical Physiology in Obstetrics 3E (3E ed.). Wiley.

Chen, X.-K., Wen, S. W., Fleming, N., Demissie, K., Rhoads, G. G., \& Walker, M. (2007). Teenage pregnancy and adverse birth outcomes: a large population based retrospective cohort study. International Journal of Epidemiology, 36(2), 368-73. http://doi.org/10.1093/ije/dyl284

Chu, S. Y., Callaghan, W. M., Bish, C. L., \& D’Angelo, D. (2009). Gestational weight gain by body mass index among US women delivering live births, 2004-2005: fueling future obesity. American Journal of Obstetrics and Gynecology, 200(3), 271.e1-271.e7. http://doi.org/10.1016/j.ajog.2008.09.879

Colbourn, T., Lewycka, S., Nambiar, B., Anwar, I., Phoya, A., \& Mhango, C. (2013). Maternal mortality in Malawi, 1977 - 2012. http://doi.org/10.1136/bmjopen-2013-004150

Cole, A. H., Ibeziako, P. A., \& Bamgboye, E. A. (1976). Basal metabolic rate and energy expenditure of pregnant Nigerian women. Journal of the American Dietetic Association, 69(1), 24-28.

Conde-Agudelo, A., Belizán, J. M., \& Lammers, C. (2005). Maternal-perinatal morbidity and mortality associated with adolescent pregnancy in Latin America: Cross-sectional study. American Journal of Obstetrics and Gynecology, 192(2), 342-349. http://doi.org/10.1016/j.ajog.2004.10.593

Contreras Campos, M. E., Rodríguez-Cervantes, N., Reza-López, S., Ávila-Esparza, M., ChávezCorral, D. V., \& Levario-Carrillo, M. (2012). Body composition and newborn birthweight in pregnancies of adolescent and mature women. Maternal and Child Nutrition, 11(2), 164 172. http://doi.org/10.1111/j.1740-8709.2012.00434.x

Diop, E. H. I., Dossou, N. I., Ndour, M. M., Briend, A., \& Wade, S. (2003). Comparison of the efficacy of solid ready-to-use food and a liquid, milk-based diet for the rehabilitation of severely malnourished children: a randomized trial. Am J Clin Nutr, 78, 302-307.

Dirienzo, D. (2016). Research Gaps in the Use of Dairy Ingredients in Food Aid Products. Food and Nutrition Bulletin, 37(Supplement 1), S51-S57. http://doi.org/10.1177/0379572116628351

Duggleby, S. L., \& Jackson, A. A. (2001). Relationship of maternal protein turnover and lean body mass during pregnancy and birth length. Clinical Science (London, England: 1979), 101(1), 65-72.

Espo, M., Kulmala, T., Maleta, K., Cullinan, T., Salin, M. L., \& Ashorn, P. (2002). Determinants of linear growth and predictors of severe stunting during infancy in rural Malawi. Acta Paediatrica, 91(12), 1364-1370. http://doi.org/10.1111/j.1651-2227.2002.tb02835.x

Fall, C. H. D., Sachdev, H. S., Osmond, C., Restrepo-mendez, M. C., Victora, C., Martorell, R., $\&$ Stein, A. D. (2015). Association between maternal age at childbirth and child and adult outcomes in the off spring: a prospective study in fi ve low-income and middle-income countries ( COHORTS collaboration ). The Lancet Global Health, 3(7), e366-e377. http://doi.org/10.1016/S2214-109X(15)00038-8

Fazio-Tirrozzo, G., Brabin, L., Brabin, B., Agbaje, O., Harper, G., \& Broadhead, R. (1998). A community based study of vitamin A and vitamin E status of adolescent girls living in the Shire valley, Southern Malawi. European Journal of Clinical Nutrition.

Fleming, N., Ng, N., Osborne, C., Biederman, S., Yasseen, A. S., Dy, J., .. Walker, M. (2013). Adolescent Pregnancy Outcomes in the Province of Ontario: A Cohort Study. Journal of Obstetrics and Gynaecology Canada, 35(3), 234-245. http://doi.org/10.1016/S17012163(15)30995-6

Forsum, E., Sadurskis, A., \& Wager, J. (1988). Resting metabolic rate and body composition of 
healthy Swedish women during pregnancy. American Journal of Clinical Nutrition, 47, 942-947.

Frederick, I. O., Williams, M. A., Sales, A. E., Martin, D. P., \& Killien, M. (2008). Prepregnancy body mass index, gestational weight gain, and other maternal characteristics in relation to infant birth weight. Maternal and Child Health Journal, 12(5), 557-567. http://doi.org/10.1007/s10995-007-0276-2

Friis, H., Gomo, E., Nyazema, N., Ndhlovu, P., Krarup, H., Kaestel, P., \& Michaelsen, K. F. (2004). Maternal body composition, HIV infection and other predictors of gestation length and birth size in Zimbabwe. Br J Nutr, 92(5), 833-840. http://doi.org/10.1079/BJN20041275

Frisancho, A. R. (1997). Reduction of birth weight among infants born to adolescents: Maternalfetal growth competition. Annals of the New York Academy of Sciences, 817(3 13), 272280. http://doi.org/10.1111/j.1749-6632.1997.tb48213.x

Frisancho, A. R., Matos, J., Leonard, W., \& Yaroch, L. (1985). Developmental and nutritional determinants of pregnancy outcome among teenagers. American Journal of Physical Anthropology, 66(3), 247-261. http://doi.org/10.1002/ajpa.1330660302

Gernand, A. D., Christian, P., Paul, R. R., Shaikh, S., Labrique, A. B., Schulze, K. J., ... Jr, K. P. W. (2012). Maternal Weight and Body Composition during Pregnancy Are Associated with Placental and Birth Weight in Rural Bangladesh, C(3), 1109-1115. http://doi.org/10.3945/jn.112.163634.>50th

Gernand, A. D., Christian, P., Schulze, K. J., Shaikh, S., Labrique, A. B., Shamim, A. A., \& Jr, K. P. W. (2012). Maternal Nutritional Status in Early Pregnancy Is Associated with Body Water and Plasma Volume Changes in a Pregnancy Cohort in Rural. The Journal of Nutrition, C(142), 1109-1115. http://doi.org/10.3945/jn.111.155978.nonpregnant

Geubbels, E. (2006). Epidemiology of Maternal Mortality in Malawi. Malawi Medical Journal, $18,206-225$.

Ghezzi, F., Franchi, M., Balestreri, D., Lischetti, B., Mele, M. C., Alberico, S., \& Bolis, P. (2001). Bioelectrical impedance analysis during pregnancy and neonatal birth weight. European Journal of Obstetrics, Gynecology, and Reproductive Biology, 98, 171-176. http://doi.org/10.1016/S0301-2115(01)00330-X

Hartikainen, H., Maleta, K., Kulmala, T., \& Ashorn, P. (2005). Seasonality of Gestational Weight Gain and Foetal Growth in Malawi. East African Medical Journal, 82(6), 294-299.

Hediger, L. M., Scholl, T. O., Ances, Isadore, G., Belsky, D. H., \& Salmon, R. W. (1990). Rate and amount of weight gain during adolescent pregnancy: associations with maternal weightfor-height and birth-weight. American Journal of Clinical Nutrition, 52, 793-9.

Hediger, M. L., Scholl, T. O., Schall, J. I., Healey, M. F., \& Fischer, R. L. (1994). Changes in maternal upper arm fat stores are predictors of variation in infant birth weight. The Journal of Nutrition, 124(1), 24-30.

Heini, A., Schutz, Y., \& Jéquier, E. (1992). Twenty-four-hour energy expenditure in pregnant and nonpregnant Gambian women, measured in a whole-body indirect calorimeter. American Journal of Clinical Nutrition, 55(6), 1078-1085.

Henriksson, P., Löf, M., \& Forsum, E. (2013). Assessment and prediction of thoracic gas volume in pregnant women: an evaluation in relation to body composition assessment using air displacement plethysmography. The British Journal of Nutrition, 109(1), 111-7. http://doi.org/10.1017/S0007114512000906

Holness, N. (2015). A global perspective on adolescent pregnancy. International Journal of Nursing Practice, 21(5), 677-681. http://doi.org/10.1111/ijn.12278

Hoppe, C., Andersen, G. S., Jacobsen, S., Mølgaard, C., Friis, H., Sangild, T., \& Michaelsen, K. F. (2008). The Use of Whey or Skimmed Milk Powder in Fortified Blended Foods for Vulnerable Groups: A Literature Review The Use of Whey or Skimmed Milk Powder in 
Fortified Blended Foods for Vulnerable Groups. J. Nutr, 138, 145-161.

Huston Presley, L., Wong, W. W., Roman, N. M., Amini, S. B., \& Catalano, P. M. (2000). Anthropometric estimation of maternal body composition in late gestation. Obstetrics and Gynecology, 96(1), 33-37. http://doi.org/10.1016/S0029-7844(00)00857-7

Hytten, F., \& Chamberlain, G. (1991). Clinical Physiology in Obstetrics. Blackwell Science Inc.

Hytten, F. E., Thomson, A. M., \& Taggart, N. (1966). Total body water in normal pregnancy. The Journal of Obstetrics and Gynaecology of the British Commonwealth, 73(4), 553-61.

Retrieved from http://www.ncbi.nlm.nih.gov/pubmed/5912619

Institute of Medicine. (1990). Nutrition During Pregnancy: Part I: Weight Gain, Part II: Nutrient Supplements (Vol. 480). Retrieved from http://www.nap.edu/catalog/1451.html

Jelliffe, E. F. (1968). Low birth-weight and malarial infection of the placenta. Bulletin of the World Health Organization.

Kalanda, B. F. (2007). Maternal anthropometry and weight gain as risk factors for poor pregnancy outcomes in a rural area of Southern Malawi. Malawi Medical Journal, 19(4), 149-153. http://doi.org/10.4314/mmj.v19i4.10945

Kalanda, B. F., Verhoeff, F. H., \& Brabin, B. J. (2006). Chronic malnutrition in pregnant adolescents in rural Malawi: an anthropometric study. Acta Obstetricia et Gynecologica Scandinavica, 85(1), 33-39. http://doi.org/10.1080/00016340500334869

Kashiwazaki, H., Dejima, Y., Orias-Rivera, J., \& Coward, W. (1995). Energy expenditure determined by the doubly labeled water method in Bolivian Aymara living in a high altitude agropastoral community. American Journal of Clinical Nutrition, 62(5), 901-910.

Keverenge-Ettyang, G. A., van Marken Lichtenbelt, W., Esamai, F., \& Saris, W. (2006). Maternal nutritional status in pastoral versus farming communities of West Pokot, Kenya: Differences in iron and vitamin A status and body composition. Food and Nutrition Bulletin, 27(3), $228-235$.

Kominiarek, M. A., \& Peaceman, A. M. (2017). Gestational weight gain. American Journal of Obstetrics and Gynecology, (May), 1-10. http://doi.org/10.1007/978-3-642-25023-1_8

Kosmiski, L. (2011). Energy expenditure in HIV infection. American Journal of Clinical Nutrition, 94, 1677-1682. http://doi.org/10.3945/ajcn.111.012625.1

Kotler, D. P. (2000). Body composition studies in HIV-infected individuals. Ann N Y Acad Sci, 904, 546-552. Retrieved from http://www.ncbi.nlm.nih.gov/entrez/query.fcgi?cmd=Retrieve $\& \mathrm{db}=$ PubMed\&dopt=Citation \&list_uids=10865803

Kotler, D. P. (2000). Nutritional Alterations Associated with HIV Infection. JAIDS: Journal of Acquired Immune Deficiency Syndromes, 25, S81-S87.

Kramer, M. S. (2003). The epidemiology of adverse pregnancy outcomes: an overview. The Journal of Nutrition, 133(5 Suppl 2), 1592S-1596S.

Kruger, H. S. (2005). Maternal anthropometry and pregnancy outcomes: a proposal for the monitoring of pregnancy weight gain in outpatient clinics in South Africa. Curationis, 28(4), 40-49. http://doi.org/10.4102/curationis.v28i4.1012

Kulkarni, B., Shatrugna, V., \& Balakrishna, N. (2006). Maternal lean body mass may be the major determinant of birth weight: A study from India. European Journal of Clinical Nutrition, 60(11), 1341-4. http://doi.org/10.1038/sj.ejcn.1602461

Kulmala, T., Vaahtera, M., Ndekha, M., Koivisto, A. M., Cullinan, T., Salin, M. L., \& Ashorn, P. (2001). Gestational health and predictors of newborn weight amongst pregnant women in rural Malawi. African Journal of Reproductive Health, 5(3), 99-108.

Lawrence, M., Coward, W. A., Lawrence, F., Cole, T. J., \& Whitehead, R. G. (1987). Fat gain during pregnancy in rural African women: the effect of season and dietary status. American Journal of Clinical Nutrition, 45, 1442-50.

Lechtig, A., Yarbrough, C., Delgado, H., Martorell, R., Klein, R. E., \& Béhar, M. (1975). Effect 
of moderate maternal malnutrition on the placenta. American Journal of Obstetrics and Gynecology, 123(2), 191-201. http://doi.org/10.1016/0002-9378(75)90526-8

Lederman, S. A., Paxton, A., Heymsfield, S. B., Wang, J., Thornton, J., \& Pierson, R. N. (1999). Maternal body fat and water during pregnancy : Do they raise infant birth weight? American Journal of Obstetrics and Gynecology, 235-240. http://doi.org/10.1016/S00029378(99)70181-X

Lederman, S., Paxton, A., Heymsfjeld, S. B., Wang, J., Thornton, J., \& Pierson, R. N. (1997). Body Fat and Water Changes During Pregnancy in Women With Different Body Weight and Weight Gain. Obstetrics and Gynecology, 90(4), 483-488.

Levario-Carrillo, M., Rodríguez, N., Tufiño-Olivares, E., Del Refugio Jiménez, M., DelgadoMonge, M. C., \& Reza-López, S. (2008). Body composition of women with newborns who are small for gestational age. Neonatology, 95(1), 15-22. http://doi.org/10.1159/000151751

López, L. B., Calvo, E. B., Poy, M. S., del Valle Balmaceda, Y., \& Cámera, K. (2011). Changes in skinfolds and mid-upper arm circumference during pregnancy in Argentine women. Maternal and Child Nutrition, 7(3), 253-262. http://doi.org/10.1111/j.17408709.2009.00237.x

Lukaski, H. C., Siders, W. a, Nielsen, E. J., \& Hall, C. B. (1994). Total body water in pregnancy: assessment by using bioelectrical impedance. The American Journal of Clinical Nutrition, $59,578-585$.

MacDorman, M. F., \& Gregory, E. (2015). Fetal and Perinatal Mortality: United States, 2013. National Vital Statistics Reports, 64(8), 1-24.

Maleta, K. (2006). Undernutrition. Malawi Medical Journal, 18(4), 191-207.

Mardones-Santander, F., Rosso, P., Stekel, A., Ahumada, E., Llaguno, S., Pizarro, F., ... Walter, T. (1988). Effect of a milk-based food supplement on maternal nutritional status and fetal growth in underweight Chilean women. American Society for Clinical Nutrition.

Mardones-santander, F., Salazar, G., Rosso, P., \& Villarroel, L. (1998). Maternal Body Composition Near Term and Birth Weight. Obstetrics and Gynecology, 91(6), 873-877.

Marshall, N. E., Murphy, E. J., King, J. C., Haas, E. K., Lim, J. Y., Wiedrick, J., ... Purnell, J. Q. (2016). Comparison of multiple methods to measure maternal fat mass in late gestation. The American Journal of Clinical Nutrition, (C). http://doi.org/10.3945/ajen.115.113464

Maso, M., Gong, E., Jacobson, M., Bross, D., \& Heald, F. (1988). Anthropometric Predictors of Low Birth Weight Outcome in Teenage Pregnancy. Journal of Adolescent Health Care, 9 , 188-193.

McCarthy, E. a, Strauss, B. J. G., Walker, S. P., \& Permezel, M. (2004). Determination of maternal body composition in pregnancy and its relevance to perinatal outcomes. Obstetrical \& Gynecological Survey, 59(10), 731-742-746. http://doi.org/10.1097/01.ogx.0000140039.10861.91

Mutimura, E., Anastos, K., Zheng Lin, Z., Cohen, M., Binagwaho, A., \& Kotler, D. P. (2010). Effect of HIV infection on body composition and fat distribution in Rwandan women. Journal of the International Association of Physicians in AIDS Care (Chicago, Ill. : 2002), 9(3), 173-8. http://doi.org/10.1177/1545109710366472

National Statistical Office of Malawi. (2011). Malawi 2010 Demographic and Health Survey. Retrieved from http://www.measuredhs.com.

Olsen, S. D., Halldorsson, T. I., Willett, W. C., Knudsen, V. K., Gillman, M. W., Mikkelsen, T. B., ... Consortium, T. N. (2007). Milk consumption during pregnancy is associated with increased infant size at birth: prospective cohort study. American Journal of Clinical Nutrition, 86(4), 1104-1110 7p. http://doi.org/86/4/1104 [pii]

Özaltin, E., Hill, K., \& Subramanian, S. V. (2010). Association of Maternal Stature with Offspring Mortality, Underweight, and Stunting in Low- to Middle-Income Countries. JAMA: The Journal of the American Medical Assocation, 303(15), 1507-1516. 
http://doi.org/10.1021/nl061786n.Core-Shell

Papathakis, P. C., Rollins, N. C., Brown, K. H., Bennish, M. L., \& Van Loan, M. D. (2005). Comparison of isotope dilution with bioimpedance spectroscopy and anthropometry for assessment of body composition in asymptomatic HIV-infected and HIV-uninfected breastfeeding mothers. The American Journal of Clinical Nutrition, 82(3), 538-546. http://doi.org/82/3/538 [pii]

Papathakis, P. C., Singh, L. N., \& Manary, M. J. (2016). How maternal malnutrition affects linear growth and development in the offspring. Molecular and Cellular Endocrinology, 1-8. http://doi.org/10.1016/j.mce.2016.01.024

Paxton, A., Lederman, S. A., Heymsfield, S. B., Wang, J., Thornton, J. C., \& Jr, R. N. P. (1998). Anthropometric equations for studying body fat in pregnant women. American Journal of Clinical Nutrition, 67, 104-110.

Pelletier, D., Arimond, M., Johnson, F. C., Liang, E., Low, J., Mvula, P., ... Simler, K. (1995). Maternal anthropometry predictors of intrauterine growth retardation and prematurity in the Malawi Maternal and Child Nutrition study. Bulletin of the World Health Organization, 73 Suppl, 80-81.

Pipe, N. G., Smith, T., Halliday, D., Edmonds, C. J., Williams, C., \& Coltart, T. M. (1979). Changes in fat, fat-free mass and body water in human normal pregnancy. Br J Obstet Gynaecol, 86(12), 929-940. Retrieved from

http://www.ncbi.nlm.nih.gov/entrez/query.fcgi?cmd=Retrieve $\& d b=P u b M e d \& d o p t=C i t a t i o n$ \&list_uids $=118770$

Prado, E. L., Maleta, K., Ashorn, U., Vosti, S. A., Sadalaki, J., \& Dewey, K. G. (2016). Effects of maternal and child lipid-based nutrient supplements on infant development: a randomized trial in Malawi. American Journal of Clinical Nutrition, 103, 784=93. http://doi.org/10.1016/j.earlhumdev.2016.05.011

Prentice, A. M., Cole, J., Foord, A., Lamb, H., \& Whitehead, R. (1987). Increased birthweight after prenatal dietary supplementation of rural African women. American Journal of Clinical Nutrition, 46(6), 912-925.

Rah, J. H., Christian, P., Shamim, A. A., Arju, U. T., Labrique, A. B., \& Rashid, M. (2008). Pregnancy and lactation hinder growth and nutritional status of adolescent girls in rural Bangladesh. Journal of Nutrition, 138(8), 1505-1511. Retrieved from http://jn.nutrition.org/cgi/content/abstract/138/8/1505?etoc

Rah, J. H., Christian, P., Shamim, A. A., Arju, U. T., Labrique, A. B., \& Rashid, M. (2009). Predictors of stunting and thinness in post-menarcheal adolescent girls in rural Bangladesh. Public Health Nutrition, 12(12), 2400-9. http://doi.org/10.1017/S1368980009005345

Ramlal, R. T., Tembo, M., King, C. C., Ellington, S., Soko, A., Chigwenembe, M., ... Adair, L. (2015). Dietary patterns and maternal anthropometry in HIV-Infected, pregnant Malawian women. Nutrients, 7(1), 584-594. http://doi.org/10.3390/nu7010584

Rasmussen, K. M., Yaktine, A. L., \& Institute of Medicine. (2009). Weight Gain During Pregnancy: Reexamining the Guidelines. Washington (DC): National Academies Press.

Rayco-Solon, P., Fulford, A., \& Prentice AM. (2005). Differential effects of seasonality on preterm birth and intrauterine growth restriction in rural Africans. American Journal of Clinical Nutrition, 81(1), 134-139.

Ricalde, A. E., Gustavo, V.-M., \& Cristina d'A, A. (1998). Mid-upper arm circumference in pregnant women and its relation to birth weight, 32(2), 523-30.

Robič, T., Benedik, E., Mis, N. F., Bratanič, B., Rogelj, I., \& Golja, P. (2014). Challenges in determining body fat in pregnant women. Annals of Nutrition and Metabolism, 63(4), 341349. http://doi.org/10.1159/000358339

Schaible, U. E., \& Kaufmann, S. H. E. (2007). Malnutrition and infection: Complex mechanisms and global impacts. PLoS Medicine, 4(5), 0806-0812. 
http://doi.org/10.1371/journal.pmed.0040115

Schneider, R. E., \& Viteri, F. E. (1972). Morphological aspects of the duodenojejunal mucosa in protein-calorie malnourished children and during recovery. American Journal of Clinical Nutrition, (25), 1092-1102.

Scholl, T., Hediger, M. L., Schall, J., Khoo, C.-S., \& Fischer, R. L. (1994). Maternal growth during pregnancy and the competition for nutrients. American Journal of Clinical Nutrition, $60,183-188$.

Scholl, T. O., Hediger, M. L., \& Ances, I. G. (1990). Maternal growth during pregnancy and decreased infant birth weight. American Journal of Clinical Nutrition, 51, 790-793.

Shirima, C. P., \& Kinabo, J. L. (2005). Nutritional status and birth outcomes of adolescent pregnant girls in Morogoro, Coast, and Dar es Salaam regions, Tanzania. Nutrition, 21(1), 32-38. http://doi.org/10.1016/j.nut.2004.09.006

Singh, J., Prentice, a M., Diaz, E., Coward, W. a, Ashford, J., Sawyer, M., \& Whitehead, R. G. (1989). Energy expenditure of Gambian women during peak agricultural activity measured by the doubly-labelled water method. The British Journal of Nutrition, 62, 315-329. http://doi.org/10.1079/BJN19890033

Sohlstrom, A., \& Forsum, E. (1995). Changes in adipose tissue volume and distribution during reproduction in Swedish women as assessed by magnetic resonance imaging. Am J Clin Nutr, 61(2), 287-295. Retrieved from http://www.ncbi.nlm.nih.gov/pubmed/7840065

Stevens-Simon, C., \& McAnarney, E. (1993). Skeletal Maturity and Growth of Adolescent Mothers: Relationship to Pregnancy Outcome. Journal of Adolescent Health, 14(6), 428432.

Streuling, I., Beyerlein, A., Rosenfeld, E., Schukat, B., \& Von Kries, R. (2011). Weight gain and dietary intake during pregnancy in industrialized countries - A systematic review of observational studies. Journal of Perinatal Medicine, 39(2), 123-129. http://doi.org/10.1515/JPM.2010.127

Subcommittee on Nutrition and Diarrheal Diseases Control, Subcommittee on Diet, Physical Activity, and Pregnancy Outcome, C. on I. N. P., \& Food and Nutrition Board. (1992). Nutrition Issues in Developing Countries: Part I: Diarrheal Diseases, Part II: Diet and Activity During Pregnancy and Lactation. Washington, D.C.: National Academies Press.

Taggart, N. R., Holliday, R. M., Billewicz, W. Z., Hytten, F. E., \& Thomson, a M. (1967). Changes in skinfolds during pregnancy. The British Journal of Nutrition, 21(2), 439-451. http://doi.org/10.1079/BJN19670045

Tang, A. M., Dong, K., Deitchler, M., Chung, M., Maalouf-Manasseh, Z., Tumilowicz, A., \& Wanke, C. (2013). Use of Cutoffs for Mid-Upper Arm Circumference ( MUAC ) as an Indicator or Predictor of Nutritional and Health- Related Outcomes in Adolescents and Adults : A Systematic Review. Food and Nutrition Technical Assictance, (November), 137.

Thame, M., Trotman, H., Osmond, C., Fletcher, H., \& Antoine, M. (2007). Body composition in pregnancies of adolescents and mature women and the relationship to birth anthropometry. European Journal of Clinical Nutrition, 61(1), 47-53. http://doi.org/10.1038/sj.ejcn.1602484

Thomas, R., Tembo, M., Soko, A., Chigwenembe, M., Ellington, S., Kayira, D., ... Team, B. S. (2012). Maternal mid-upper arm circumference is associated with birth weight among HIVinfected Malawians. Nutrition in Clinical Practice: Official Publication of the American Society for Parenteral and Enteral Nutrition, 27(3), 416-21. http://doi.org/10.1177/0884533611435991

Thomas, R., Tembo, M., Soko, A., Chigwenembe, M., Tohill, B., Kayira, D., ... Team, B. S. (2013). Patterns of body composition among HIV-infected, pregnant Malawians and the effects of famine season. Maternal Child Health Journal, 17(2), 1-15. 
http://doi.org/10.1007/s10995-012-0970-6.Patterns

Tomkins, A., \& Watson, F. (1989). Malnutrition and Infection - A review.

Toro-Ramos, T., Sichieri, R., \& Hoffman, D. J. (2016). Maternal fat mass at mid-pregnancy and birth weight in Brazilian women. Annals of Human Biology, 43(3), 212-218. http://doi.org/10.3109/03014460.2015.1032348

Triunfo, S., \& Lanzone, A. (2014). Impact of overweight and obesity on obstetric outcomes. Journal of Endocrinological Investigation, 37(4), 323-329. http://doi.org/10.1007/s40618014-0058-9

Triunfo, S., \& Lanzone, A. (2015). Impact of maternal under nutrition on obstetric outcomes. Journal of Endocrinological Investigation, 38, 31-38. http://doi.org/10.1007/s40618-0140058-9

United Nations Children's Fund and World Health Organization. (2004). Low Birthweight: Country, regional and global estimates. Unicef.

Vaahtera, M., Kulmala, T., Ndekha, M., Koivisto, A., Cullinan, T., Salin, M., \& Ashorn, P. (2000). Antenatal and perinatal predictors of infant mortality in rural Malawi, 200-204.

van Raaij, J., Peek, M. E. M., Vermaat-Miedema, S. H., Schonk, C. M., \& Hautvast, J. G. (1988). New equations for estimating body fat mass in pregnancy from body density or total body water. American Journal of Clinical Nutrition, (48), 24-29.

Ververs, M. tesse, Antierens, A., Sackl, A., Staderini, N., \& Captier, V. (2013). Which Anthropometric Indicators Identify a Pregnant Woman as Acutely Malnourished and Predict Adverse Birth Outcomes in the Humanitarian Context? PLoS Currents, (JUNE), 1-15. http://doi.org/10.1371/currents.dis.54a8b618c1bc031ea140e3f2934599c8

Villar, J., Cogswell, M., Kestler, E., Castillo, P., Menendez, R., \& Repke, J. (1992). Effect of fat and fat-free mass deposition during pregnancy on birth weight. American Journal of Obstetrics and Gynecology, 167(5), 1344-1352.

Weigel, M. M., Callec, A., Armijosayb3e, R. X., Vegac3d, I. P., Bayascvd, B. V, \& Montenegrocpd, C. E. (1996). The effect of chronic intestinal parasitic infection on maternal and perinatal outcome. International Journal of Gynecology \& Obstetrics, 52, 9-17.

WHO, \& MCA. (2015). Malawi African Region Maternal and Perinatal Health Profile Department of Maternal, Newborn, Child and Adolescent Health (MCA/WHO) Demographics and Information System Health status indicators -Maternal and Perinatal mortality.

Widen, E. M., \& Gallagher, D. (2014). Body composition changes in pregnancy: measurement, predictors and outcomes. European Journal of Clinical Nutrition, 68(6), 643-52. http://doi.org/10.1038/ejen.2014.40

Wilkinson, A. L., Pedersen, S. H., Urassa, M., Michael, D., Todd, J., Kinung'hi, S., ... McDermid, J. M. (2015). Associations between gestational anthropometry, maternal HIV, and fetal and early infancy growth in a prospective rural/semi-rural Tanzanian cohort, 201213. BMC Pregnancy and Childbirth, 15, 277. http://doi.org/10.1186/s12884-015-0718-6

Young, M. F., Nguyen, P. H., Addo, O. Y., Hao, W., Nguyen, H., Pham, H., ... Ramakrishnan, U. (2015). The relative influence of maternal nutritional status before and during pregnancy on birth outcomes in Vietnam. European Journal of Obstetrics Gynecology and Reproductive Biology, 194, 223-227. http://doi.org/10.1016/j.ejogrb.2015.09.018 